\title{
Decentralization and Overborrowing in a Fiscal Federation
}

\author{
Si Guo, Yun Pei, and Zoe Xie
}

\section{Working Paper 2018-9 \\ August 2018}

\begin{abstract}
We build an infinite horizon equilibrium model of fiscal federation, where anticipation of transfers from the central government creates incentives for local governments to overborrow. Absent commitment, the central government over-transfers, which distorts the central-local distribution of resources. Applying the model to fiscal decentralization, we find when decentralization widens local governments' fiscal gap, borrowings by both local and central governments rise. Quantitatively, fiscal decentralization accounts for from 19 percent to 40 percent of changes in general government debt in Spain during 1988-2006. A macroprudential tax on local borrowing that implements Pareto optimal allocation would reduce debt by 27 percent and raise welfare by 3.75 percent.
\end{abstract}

JEL classification: E61, E62, H74

Key words: fiscal federalism, time-consistent policy, decentralization, public debt

https://doi.org/10.29338/wp2018-09

The authors thank Luc Eyraud and Lusine Lusinyan for sharing their data set. This paper was previously titled "Fiscal Decentralization, Intergovernmental Transfer, and Overborrowing." This paper has benefited from discussions with Jinhui Bai, Toni Braun, Yongsung Chang, Lei Fang, Galina Hale, Juan Carlos Hatchondo, Jonathan Heathcote, Roozbeh Hosseini, Zhen Huo, Anastasios Karantounias, Karen Kopecky, Federico Mandelman, Fernando Martin, Toshihiko Mukoyama, and Juan Rubio-Ramirez. They also thank seminar and conference participants and discussants at the Atlanta Fed, Fed Research Scrum (San Francisco), Tsinghua Macro Workshop 2018, Econometric Society Summer Meetings (Davis), and the Society of Economic Dynamics (Mexico City). The views expressed here are the authors' and not necessarily those of the International Monetary Fund (IMF), its executive board, IMF management, the Federal Reserve Bank of Atlanta, or the Federal Reserve System. Any remaining errors are the authors' responsibility.

Please address questions regarding content to Si Guo, International Monetary Fund, 700 19th Street NW, Washington DC 20431, sguo@imf.org; Yun Pei, Department of Economics, University at Buffalo, 415 Fronczak Hall, Buffalo, NY 14260, yunpei@buffalo.edu; or Zoe Xie, Research Department, Federal Reserve Bank of Atlanta, 1000 Peachtree Street NE, Atlanta, GA 30309-4470, xiexx196@gmail.com.

Federal Reserve Bank of Atlanta working papers, including revised versions, are available on the Atlanta Fed's website at www.frbatlanta.org. Click "Publications" and then "Working Papers." To receive e-mail notifications about new papers, use frbatlanta.org/forms/subscribe. 


\section{INTRODUCTION}

Since the early 1980s, many countries went through fiscal (de)centralization reforms that changed the national(central)-subnational(local) shares of tax revenue and expenditure responsibility. However, the shifts of revenue often lag behind spending, resulting in widening vertical fiscal imbalances. Figure 1 illustrates the shifts in subnational revenue and spending in three OECD countries. ${ }^{1}$ The gap ( fiscal gap) between subnational governments' own revenue and spending is made up by transfers from the national government or debt issuance by subnational governments.

Figure 1: Subnational government's own revenue(blue) and spending(red): Portugal, Spain and UK
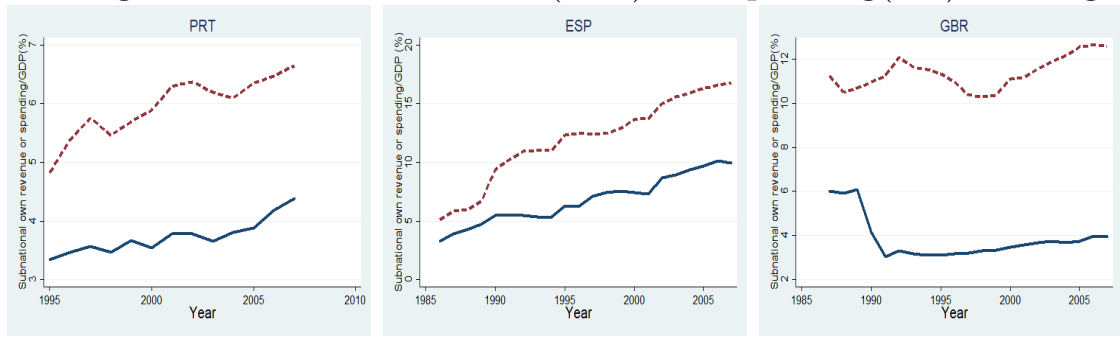

A rising vertical fiscal imbalance (fiscal gap) suggests an increasing reliance of local governments on transfers or debt to finance spending. A common view holds that a greater reliance on central government transfers softens local governments' budget constraints (see Wildasin 1997, Rodden et al. 2003). A softer local budget constraint can negatively impact aggregate fiscal performance (see Goodspeed 2016 for a review of this literature). Figure 2 illustrates as vertical fiscal imbalance rises, (a) local government's transfer income as a share of total revenue (reliance on transfer) increases, and (b) general government debt accumulation rises. Indeed, the empirical literature has documented a positive correlation between vertical fiscal imbalance and a country's aggregate fiscal performance (see for example, Eyraud and Lusinyan 2013, Aldasoro and Seiferling 2014).

There has been no attempt to understand the quantitative importance of soft budget constraint on public debt accumulation in a dynamic equilibrium setup. This paper aims to fill this gap. As an application of the framework we ask: How changes in local governments' share of revenue and spending responsibility in the context of fiscal decentralization affect aggregate public debt.

We build a dynamic equilibrium model where the central government makes distortionary transfers to help make up for local fiscal gap, but transfers create ex ante overborrowing incentives for local governments. This model generates the empirically established positive relationship between (1) a higher vertical fiscal imbalance as a result of fiscal decentralization, and (2) higher aggregate government debt levels. We argue that when revenue lags behind spending decentralization (widening vertical fiscal imbalance), local governments' increased reliance on inter-governmental transfers encourages local governments' borrowings and raises the debt levels of both central and local governments. We further explore ways to implement the social planner's allocation and to undo the effects of fiscal decentralization on aggregate debt. More broadly, we see our analysis help frame issues of

\footnotetext{
${ }^{1}$ In Portugal and Spain, faster decentralization of spending relative to revenue led to larger vertical fiscal imbalances.
} In the UK, centralization of tax revenue in the early 1990s was the driving force behind the sharp rise in VFI. 
Figure 2: Vertical fiscal imbalance(blue) vs subnational transfer revenue or debt accumulation(red): Portugal, Spain and UK

Panel (a): Vertical fiscal imbalance vs subnational transfer revenue
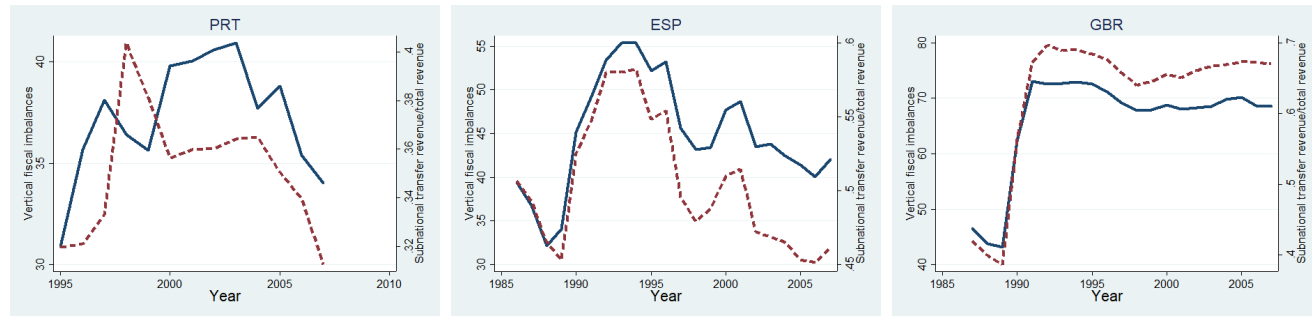

Panel (b): Vertical fiscal imbalance vs change in general government debt
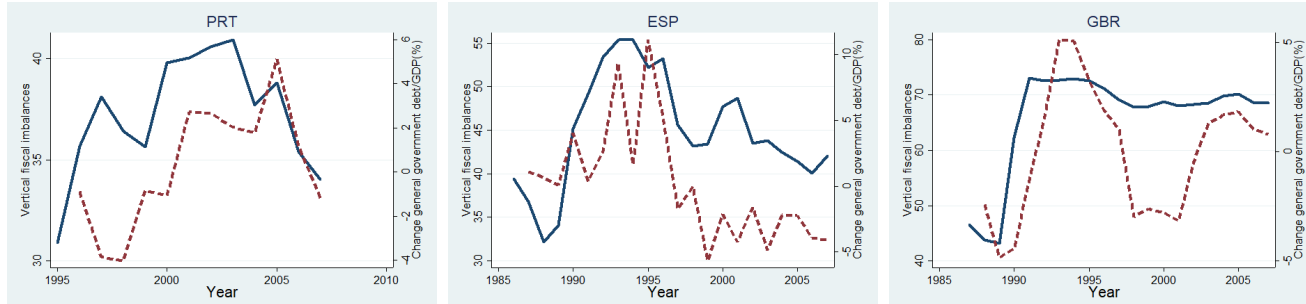

moral hazard created by transfers within a fiscal federation and the optimal design of such transfer policies.

We do so in an infinite horizon dynamic model with two levels of benevolent governments one central and many local governments. Each level of government makes its own spending and borrowing decisions. In addition, each period, the central government makes time-varying transfers to local governments to help make up for local fiscal gaps. We assume that the transfer depends on the fiscal condition of a local government, such that, other things equal, the central government makes bigger transfers when the local government's accumulated debt at the beginning of the period is higher. A higher transfer rate effectively lowers the cost of borrowing for the local government, and encourages local government's borrowing ex ante.

A transfer that depends on individual local government's fiscal condition (debt) is key to our mechanism. Without it, the two levels of governments collapse into one. In particular, the central government can use lump-sum transfers to relocate resources to and from local governments following decentralizations, so that the total debt level remains unchanged. We provide empirical evidence in support of this assumption. In Spain a region's transfer income is positively correlated with its debt accumulation, and controlling for region's characteristics Sorribas-Navarro (2011)'s regression analysis confirms this relationship.

Because of distortionary transfer, the central government's transfer decision has the classic time inconsistency problem: ex ante the central government has incentives to promise low future transfers to minimize the local government's overborrowing incentive (ex ante incentive); after the local governments' debt choices are made, however, the central government prefers higher transfers to 
maintain local spending and reduce future need to borrow (ex post incentive) ${ }^{2}$

We characterize a time-consistent equilibrium without central government commitment to future transfer and debt policies, and compare it with the Pareto optimal allocation. The Pareto optimal allocation can be derived from a social planner's problem: the central government chooses the amount of transfers to equalize the marginal utilities of central and local government spending each period.

In our equilibrium without commitment, the central government also wants to use transfers to equalize marginal utilities of spending. However, because the central government's transfers are distortionary, there is an additional consideration. More specifically, the transfers lower local government's cost of borrowing, and create a wedge between the private (local government's) and the public (central government's) cost of local government debt. As a result, compared to the local government, the central government wants a lower local government debt. To this end, the central government over-transfers (than needed to equalize marginal utilities) to reduce local government's need to borrow. Higher transfers today relax local budget constraint, and in response, local governments reduce borrowing today (debt to be repaid tomorrow). At the same time, because the higher transfers allocate more resources to local governments, they lead to an over-supply of local relative to central government spending.

In addition to relaxing local government's budget and reducing borrowing ex post, the higher transfer lowers local government's cost of borrowing and creates extra incentives for local governments to over-borrow. Absent commitment the central government treats this ex ante incentives as forgone, which is why in the equilibrium there is over-transfer. Interestingly, the (Ramsey) central government with commitment under-transfers. This is because the Ramsey central government takes into account the ex ante overborrowing incentives. In equilibrium the cost of overborrowing is high enough to offset the ex post benefit of relaxing local government budget constraint.

We then explore ways to implement the social planner's allocation. In particular, we consider an ex ante tax on local government borrowing, in the spirit of macroprudential policy. We show that the ex ante tax and ex post transfers together can implement the social planner's allocation. Further, the policies are time consistent. Intuitively, the additional tax offsets any overborrowing incentive of transfers, allowing the central government to use transfers to achieve the planner's central-local resource sharing scheme. This new equilibrium has lower aggregate debt levels than the single-instrument equilibrium. Furthermore, the aggregate debt is invariant to fiscal decentralization, because the central government optimally adjusts debt tax in tandem with transfer policy to offset any changes in local government's overborrowing incentive following a decentralization.

We apply the model to study the quantitative impact of fiscal decentralization on transfer and borrowing. We model fiscal decentralization as exogenous changes in the inter-governmental distribution of revenue (revenue decentralization) and spending responsibility (expenditure decentralization).

\footnotetext{
${ }^{2}$ Gordon and Guerron-Quintana (2018) also model overborrowing by local governments. In their model, local governments anticipate new migrants to bear some burden of future repayment but do not put preference weights on future migrants in current decision making. Their emphasis is on migration-induced regional overborrowing and default, and abstracts from a central fiscal authority. In contrast, we focus on the interaction between central and local fiscal authorities.
} 
A revenue decentralization increases local's share of total revenue, and lowers vertical fiscal imbalances. A smaller local fiscal gap means less reliance on transfers to supplement its budget. As the central government retains a smaller share of total revenue, it is less able to make transfers. Lower transfer reduces local government's overborrowing incentive and lowers local debt. Central debt also falls because of smaller total transfers. A spending decentralization increases local's share of total spending responsibility, and increases vertical fiscal imbalances. A larger local fiscal gap increases the central government's incentive to give transfers to supplement local government's budget. Higher transfers exacerbate ex ante overborrowing incentive and raise local government debt level. Central government debt also rises despite a lower share of central spending responsibilities. Putting things together, when increases in local revenue lag behind increases in spending responsibility, vertical fiscal imbalances become larger and general government debt increases, consistent with the empirical findings.

In a quantitative exercise, we calibrate the steady state equilibrium using data moments of Spain during two episodes of fiscal decentralizations: 1988-1996 and 1996-2006. ${ }^{3}$ We find that fiscal decentralization accounts for $40 \%$ of the overall debt increase during 1988-1996 and 19\% of the debt decrease during 1996-2006. Counterfactually, if the central government implements a macroprudential tax on local government borrowing, then general government debt will be $27 \%$ lower and welfare $3.75 \%$ higher.

To our knowledge, this paper is the first attempt to use a quantitative dynamic model to analyze the relationship between fiscal decentralization and aggregate fiscal performance. While there has been a large volume of literature using static or two-period models to study the common pool and soft budget constraint problems following Kornai (1986) and Velasco (2000), ${ }^{4}$ our dynamic infinite horizon model complements this literature in two dimensions. First, using an infinite horizon model allows us to match to data and quantify the effect of fiscal decentralization through counterfactual exercises. Second, in our infinite horizon model, the central government understands that its transfers today will not only affect local government's spending today, but also local government's debt due tomorrow (as well as the transfers choice tomorrow). In a typical static or two-period model, an implicit assumption is that the central government's policy does not affect local government debt

\footnotetext{
${ }^{3}$ We focus on the period pre-Euro crisis. Rules implemented post-Euro crisis more effectively (than rules implemented in the early 2000s) restricts borrowing and it is unclear whether soft budget constraint problem still exists in that environment.

4 Applied to the intergovernmental relation, the idea of soft budget constraint means that the central government 'softens' subnational governments' budgets by providing ex-post transfers or bailouts. Expecting additional resources from the central government, subnational governments have an incentive to engage in excessive spending and overborrowing. Various work considers different aspects of the soft budget problem. Wildasin (1997) applies the too-big-to-fail idea to study bailouts of subnational governments. Qian and Roland (1998) analyze bailouts of state-owned enterprises under the central government versus subnational governments. Inman (2003) studies optimality of hard budget constraint, while Besfamille and Lockwood (2008), and Sanguinetti and Tommasi (2004) compare hard and soft budget constraints. Akai and Sato (2011) analyze intergovernmental transfers when such transfers improve public investment spending. Boadway and Tremblay (2006) consider the optimal vertical fiscal gap that minimizes the efficiency cost of taxation in a fiscal federation. Breuille, Madies, and Taugourdeau (2006) incorporate capital taxation, and Breuille and Vigneault (2010) consider three layers of governments. Kothenburger (2007) assumes subnational government spending has spillover effects. For a comprehensive survey of the literature, see Kornai, Maskin, and Roland (2003), and Goodspeed (2016).
} 
choice in period two (end period), which is set to zero by construction. As a result, the central government chooses its policies (transfers, subsidy or tax), after local government makes its initial debt choice, to achieve some form of perfect resource sharing (e.g. equalization of marginal utilities between central and local governments or among local governments). In contrast, the additional consideration of future states and policies in our setup is the key reason that marginal utilities are not equalized in the dynamic equilibrium.

Our paper contributes to the theoretical literature on fiscal policies and debt accumulation when the central authority cannot commit. Cooper, Kempf, and Peled (2008) compare intergovernmental transfers when the central government can or cannot commit in a two-period model. In their setup, the central government uses transfers to smooth cross-region consumption and cross-region distortionary taxes in the second period, which give local governments incentives to accumulate debt in the first period. Chari and Kehoe (2007) and Beetsma and Uhlig (1999) argue for the desirability of debt constraints on member states if the monetary authority cannot commit. Dovis and Kirpalani (2017) study fiscal rules on local governments in a reputation model where the central government's commitment type is unknown. Cooper and Hubert (2004) study the interaction of fiscal and monetary policies in a monetary union when the monetary authorities can or cannot make commitment. Aguiar et al. (2015) jointly analyze the common monetary authority's monetary policy and member countries' fiscal policies when neither the monetary authority nor member countries can commit. We contribute to this literature by studying the quantitative effects of fiscal policy (fiscal decentralization in our case) on debt accumulation.

Because in reality both a country's central fiscal authority and local governments can accumulate debt, we find it relevant to relax the assumption of balanced central government's budget, which is used in most of the literature mentioned above. ${ }^{5}$ Modeling debt choices at two levels of governments generates interesting dynamic interactions between central and local governments. First, a higher local government debt gives the central government stronger incentives to make transfers which are financed by a higher central government debt. Second, a higher central government debt reduces its ability to make transfers by tightening its budget constraint; a lower transfer increases the local government's out-of-pocket debt interest payment, which in turn leads to a higher future local government debt. Third, when the local government expects a higher central government debt, in equilibrium it also anticipates lower transfers in the next period, which gives it incentives to choose a lower debt level.

Conceptually, the idea of moral hazard due to transfer or bailout applies more broadly to government bailing out firms or supranational union subsidizing member countries. Recent examples include the U.S. federal government bailing out AIG in the 2008 financial crisis and the European Union providing subsidies to Greece in the European debt crisis. Gourinchas, Martin, and Messer (2018) interpret EU bailouts of Greece and other Southern countries as transfers (low-interest EU

\footnotetext{
5 Among OECD countries, on average local government debt takes up $17 \%$ of general government debt between 1995 and 2007. Even though central government debt makes up majority of general government debt, local government debt is on average as volatile as central government debt. Table 12 reports means and standard deviations of local and central government debt levels for OECD countries.
} 
loans). In their setup, similar to the overborrowing incentive of local governments in our setup, the benefit to the Southern countries of borrowing more is the larger expected future transfers through bailout. In Bianchi (2016), bailouts relax firms' balance sheet constraints, but also induce moral hazard by encouraging firms to take more risk. In his setup, the planner can use an ex-ante debt tax similar to ours to offset the firms' risk-taking incentives and achieve the Pareto optimal allocation. Farhi and Tirole (2012) and Chari and Kehoe (2016) show that, when bailing out firms, some prudential policies can implement the commitment solution and improve welfare. Our paper highlights this theoretical result as well, but in the context of vertical inter-governmental transfers. More importantly, we do not impose balanced budget for the central government, so central government accumulates debt to finance transfer (bailout).

Finally, this paper is related to the literature on time-consistent public policy (see, for instance, Alesina and Tabellini 1990; Klein and Ríos-Rull 2003; Chari and Kehoe 2007; Battaglini and Coate 2008; Yared 2010; Martin 2011; Song, Storesletten, and Zilibotti 2012; Bachmann and Bai 2013; Karantounias 2017). Methodologically, this paper follows Klein, Krusell, and Ríos-Rull (2008) to characterize the Markov-perfect equilibrium government policy using the generalized Euler equation (GEE).

The rest of the paper proceeds as follows: Section 2 gives background on fiscal decentralization, focusing on the case of Spain. Section 3 presents the dynamic infinite-horizon model and characterizes the equilibrium and optimal policies. Section 4 calibrates the model to Spain and performs quantitative analysis, and Section 5 looks at transfer policy from a normative perspective. Finally, Section 6 discusses alternative specifications, and Section 7 concludes.

\section{Background on Fiscal Decentralization}

To provide some background on fiscal decentralization and also to focus the analysis, we start with the discussion of two questions about decentralization. We then take a closer look at Spain's decentralization pre-Euro crisis.

\subsection{Two questions about decentralization}

Why decentralize?

Countries undertake decentralization with the aim of better targeting the provision of goods and services to local needs. In some cases, decentralizations are driven by economic reasons when countries search for more efficient ways of delivering public services. The basic idea here follows from Oates (1972): local authorities have better knowledge about local tastes and needs, and can make financing, provision and delivery of public goods more efficient. In other cases, decentralizations are politically motivated when societies become disenchanted with centralized policies. In Spain, the strongly centralized system during the Franco regime motivated the creation of the autonomous communities (AC) in the Spanish Constitution of 1978 (Eyraud and Lusinyan 2013, IMF 2005).

In our analysis we are agnostic about the reasons to decentralize and consider the impact of decentralization on public debt. In a way our analysis speaks to the design of decentralization 
reforms given that a country has to decentralize.

Why does the devolution of revenue often lag behind spending?

Central governments are typically reluctant to give up taxing power. In fact, some degree of fiscal gap on the local level may be efficient, as Eyraud and Lusinyan (2013) argue, because central-local transfers allow the central government to buffer against external shock (e.g. war), to redistribute across regions in response to either ex ante (e.g. geographical and pre-existing economic conditions) or ex post (e.g. natural disaster that affects one region) differences. As a result, the decentralization of revenue is often slow and lags behind spending.

We focus our analysis on the spending and borrowing decisions and take revenue sharing between central and local governments as exogenously given.

\subsection{Spain}

Spain went through fiscal decentralization in the 1980s and 1990s by allowing regional governments to have more tax revenue and spending responsibilities. Since the creation of 17 financially autonomous regions (the Autonomous Communities or ACs) in 1978, the funding of these regions has been periodically reformed. From 1986 to 2001, the regional financing system was renegotiated about every 5 years. Changes in national versus regional spending responsibilities mainly come from shifts in the provision of health care and education at different points in time.

Since 1983 some tax revenues have been ceded to regional governments to increase regional revenue autonomy. But increases in regional revenue have lagged behind increases in regional spending. Figure 3 Panels a and b show that even though both regional revenue and spending as a share of total government revenue and spending increased during 1986-2007, the speed of increase was much faster in spending. For a consistent measure of changes in local fiscal gap, we follow the literature (see e.g. Eyraud and Lusinyan 2013) to define vertical fiscal imbalance (VFI) as the share of subnational own spending not financed through its own revenue.

$$
\mathrm{VFI}=\frac{\text { Subnational spending }- \text { Subnational revenue }}{\text { Subnational spending }} \times 100
$$

where subnational spending includes debt interest payment. The faster increase in spending led to rising vertical fiscal imbalances between mid-1980s and mid-1990s (Panel 3c).

Two major reforms that took place in 1997 and 2002 increased regional revenues by broadening regional tax bases. As a result of the reforms, increase in local revenue (as a share of total government revenue) was faster during 1996-2006 than 1988-1996. In Panel 3a the increase in regional revenue during the latter period is above the extrapolated trend from the earlier period (dashed red line). At the same time, the increase in local spending is on or slightly below trend post-1996 (Panel 3b). This leads to falling vertical fiscal imbalances during this latter period (Panel 3c).

To explore the effects of the reforms on debt, Panel 3d plots general government debt. The general government debt increased during 1988-1996, right before the 1997 reform, and fell afterwards until 2007. This pattern is consistent with the timing of reforms and with the cross-time empirical findings: 
Figure 3: Central and local government finances in Spain from 1986 to 2007.
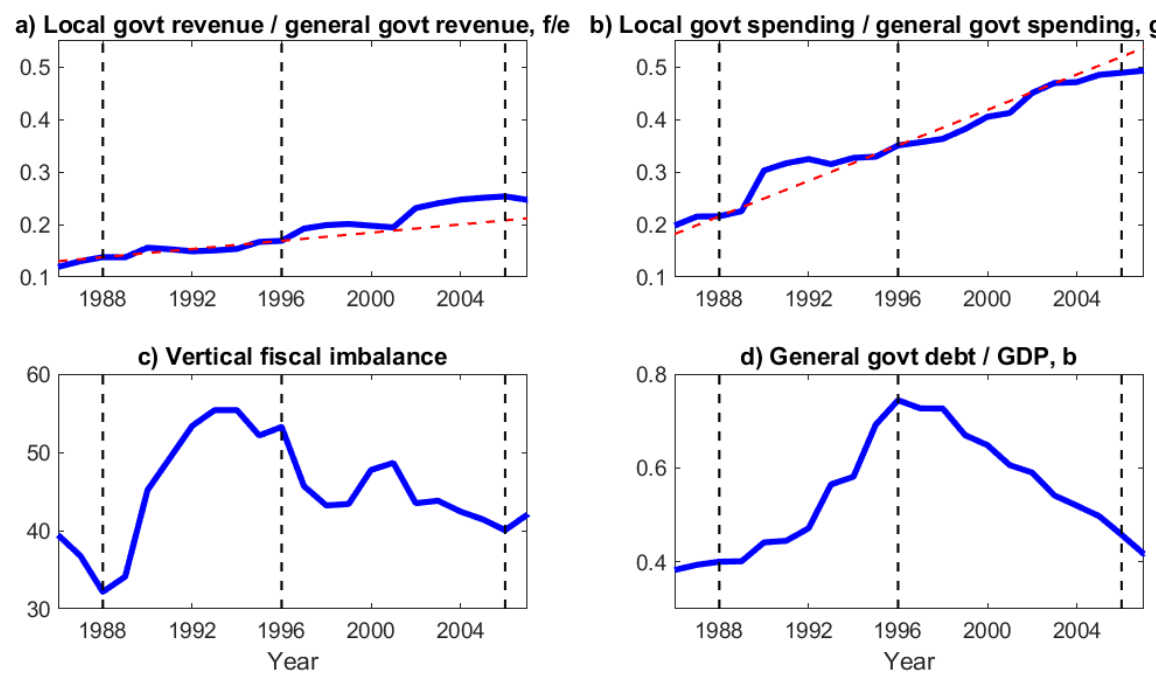

Note: Dotted vertical lines mark 1988, 1996, and 2006. Dashed red line extrapolates a linear trend from 1988 to 1996. periods of high vertical fiscal imbalance are associated with larger changes in debt levels. ${ }^{6}$

\section{MODEL}

We first set up the model environment, and characterize the social planner's allocation (Pareto optimal) as a benchmark. We then define, characterize and discuss results of a time-consistent Markov equilibrium, highlighting its inefficiencies and differences from both the social planner's allocation and a commitment (Ramsey) environment. Finally, we show that even without commitment, the social planner's allocation can be implemented using a policy instrument in the spirit of a macroprudential policy.

\subsection{Model environment}

We consider a small open economy. Time is discrete and infinite. There is a central government and a mass one of identical local regions. Each region has one local government and a mass one of identical households. Each period the representative household receives endowment income $y$, pays local tax $f$ and federal tax $e-f$, and consumes the residual. ${ }^{7}$

Preferences. There are infinitely many varieties of public goods, indexed by $\omega \in[0,1]$. The household cares about the consumption basket of central and local-provided goods, with period utility for this

\footnotetext{
6 The second period roughly coincided with housing boom in Spain. Increased property tax income likely also contributed to falling general government debt. We do not model the housing boom, but when calibrating local and central government revenue from the data, the quantitative exercise potentially captures any revenue effect of housing boom.

7 We do not explicitly model households' decisions, and instead take tax paying as exogenous. One can think of models where fiscal decentralization impacts households' incentives to pay taxes and hence the total tax revenue. Such considerations are outside the scope of this paper.
} 
consumption basket

$$
U\left(\left[\int_{0}^{1} q(\omega)^{\frac{\sigma-1}{\sigma}} d \omega\right]^{\frac{\sigma}{\sigma-1}}\right)
$$

where $q(\omega)$ is the quantity of good $\omega$. Suppose goods $\omega \in[0, \theta]$ are provided by the central government (e.g. national defense), and $\omega \in[\theta, 1]$ are purchased by the local government (e.g. local roads and fire stations). An increase in $1-\theta$ means more goods (or spending 'lines') are purchased by the local governments, for example, a decentralization of education and health care spending.

Under unitary elasticity of substitution between goods $(\sigma=1)$ and $\log$ utility, the utility becomes separable. ${ }^{8}$ Formally, the representative household living in region $i$ has the utility function

$$
\sum_{t=0}^{\infty} \beta^{t}[\underbrace{(1-\theta) u\left(g_{i, t}\right)+\theta v\left(c_{t}\right)}_{\text {utility from public consumption }}+\underbrace{w(y-e)}_{\text {utility from private consumption }}]
$$

where $c_{t}$ is the per capita central government spending and $g_{i, t}$ is the per capita public spending of local government $i$.

Both levels of governments are benevolent and utilitarian: they choose public consumption to maximize households' utilities subject to governments' budget constraints. We take household income $y$ and total government tax $e$ as exogenous, so the last part of the representative household's utility function $(w(y-e))$ drops out from the government's welfare maximization problem.

Interest rates. The governments have access to international bond markets. The interest rate schedules of central and local government bonds, $S(\cdot)$ and $R(\cdot)$, are exogenous functions of their respective levels of outstanding debt. In the baseline, we make the assumption that each local government's interest rate depends on the aggregate debt of all local governments, i.e. $R(B)$. As a robustness check, in Section 6.2 we investigate the alternative assumption where each region has its own interest rate schedule, and each local government internalizes the pecuniary cost of borrowing. Transfer. Each period, the central government makes transfers to local governments. In general, we can write the transfer received by region $i$ at time $t$ as a function of the region's debt $b_{i, t}$ and aggregate states $\left(B_{t}, d_{t}\right): T_{i, t}=T\left(b_{i, t} ; B_{t}, d_{t}\right)$. For tractability we adopt a specific affine structure

$$
T_{i, t}=\tau_{t} \cdot M\left(b_{i, t}\right) \quad \text { where } M\left(b_{i, t}\right)=\left[\left(1-\epsilon_{t}\right)+\epsilon_{t} b_{i, t} / f_{t}\right]
$$

where $\tau_{t}$ is chosen by the central government and is dependent on the aggregate states, i.e. $\tau_{t}=$ $\tau\left(B_{t}, d_{t}\right) ; b / f$ captures a region's fiscal strength and ability to make debt repayment; $\epsilon \in[0,1]$ has the interpretation of the progressivity of transfers across regions.

The choice of this function is motivated by three reasons. First, it nests different affine tax/transfer used in the literature. $\epsilon=1$ corresponds to the case of linear tax/subsidy widely used in the taxation literature (e.g. Lucas and Stokey 1983, Aiyagari et al. 2002, Werning 2007) and in the bailout literature (e.g. Bianchi 2016). $\epsilon=0$ means central government transfers are evenly distributed across regions and independent of a region's fiscal condition. ${ }^{9}$ A larger $\epsilon$ means the transfer scheme is more

\footnotetext{
8 Online Appendix A provides the details of the transformation.

${ }^{9}$ Online Appendix G provides more details on the theoretical implications of $\epsilon=0$.
} 
discriminative and depends more on region's fiscal conditions.

Second, in practice transfer schemes that in part depend on individual region's fiscal conditions (either explicitly or implicitly) are implemented in many countries. ${ }^{10}$ For Spain, as we will discuss in more details in the quantitative section (Section 4.1), transfers received by a region have both a general part that is non-discriminative on regions and a region-specific part that depends on the region's fiscal conditions at the time (everything else equal, a region's transfer income at any time is positively correlated with its lagged debt levels). Our transfer function captures this feature by allowing transfer income to consist of both parts.

Lastly, mathematically our transfer function is isomorphic to a wide class of affine structures. To the first-order approximation, $T_{i, t}=T\left(b_{i, t} ; B_{t}, d_{t}\right)$ can be written as $T_{i, t}=\hat{\tau}_{t} b_{i t}+\hat{\alpha}_{t} B_{t}+\hat{\beta}_{t} d_{t}+\hat{\gamma}_{t}$, or equivalently $T_{i, t}=\hat{\tau}_{t} b_{i t}+\Gamma_{t}$ where $\hat{\tau}_{t}$ and $\Gamma_{t}$ are functions of $\left(B_{t}, d_{t}\right)$. This can be transformed to (3) with $\hat{\tau}=\tau \epsilon / f$ and $\Gamma=\tau(1-\epsilon)$. The advantage of (3) is that $\epsilon$ has the economic interpretation of the proportion of transfers that depends on region's fiscal conditions.

Given the transfer function, ideally we would solve for $\{\epsilon, \tau\}$ jointly. But in order for the moral hazard mechanism that we highlight to work, we only need $\epsilon>0$ and do not require a model that endogenizes the choice of $\epsilon$. The model we present here takes $\epsilon$ as exogenous, both for tractability reasons and because in reality, the proportion of discriminative vs non-discriminative transfer (governed by $\epsilon$ ) is often decided a priori (e.g. Garcia-Milà and McGuire 2002). In the quantitative section, we calibrate $\epsilon$ to different periods in Spain. In addition, we present a simple two-period model in Online Appendix B with ex post heterogeneous regions where $\epsilon>0$ arises endogenously.

In the theoretical analysis of this section, we focus on the discriminative part of the transfer for simplicity (all results go through with the full transfer function (3))

$$
\hat{T}_{i, t}=\tau_{t} \cdot b_{i, t}
$$

and we return to the full transfer function for the quantitative exercises of later sections.

Timing. The state of the economy is summarized by the aggregate debt positions of the local and central government $(B, d)$. Figure 4 illustrates the time line within period $t$. Each period, the central government moves first (Stackelberg leader). It starts with outstanding debt $d$, and receives tax revenue $e-f$. It then decides its expenditure, which includes public consumption $c$ and transfer rate $\tau$ to local governments. The deficit is financed by new debt $d^{\prime}$ issued at interest rate $S\left(d^{\prime}\right)$. The representative local government wakes up with outstanding debt $b_{i}$. Its revenue consists of it own tax revenue $f$ and central government transfers. It chooses local public consumption $g_{i}$, and the deficit is financed by issuing new debt $b_{i}^{\prime}$ at an interest rate $R\left(B^{\prime}\right) .{ }^{11}$

\footnotetext{
10 Rodden (2003) describes the German experience where federal (central) government bailed out Bremen and Saarland, two states that were deeply in debt; in the U.S. municipal bonds are exempt from federal tax, which means the more debt a region (state, city, county) issues the more transfers it receives from the federal government; in China, central government subsidizes local debt by providing implicit guarantee on local debt or ordering state-owned banks to offer low interest rates; similarly in Argentina prior to 1991, provinces borrowed at low interest rates subsidized by the federal government through the banking sector (Webb 2003).

${ }^{11}$ Local government interest rate could alternatively depend on individual region's debt $b_{i}$. We discuss the choice of
} 


$\begin{array}{cccc}(B, d) & \text { Central government } & \text { Local governments } & \left(B^{\prime}, d^{\prime}\right) \\ \qquad & \text { transfer policy } \tau & \text { repays } b_{i}, \text { gets transfer } \tau M\left(b_{i}\right) & t+1 \\ & \text { repays } d, \text { borrows } d^{\prime}, \text { spends } c & \text { borrows } b_{i}^{\prime}, \text { spends } g_{i} & \end{array}$

Figure 4: Time line within period

In our model, all regions are identical, and in equilibrium all local governments choose the same level of debt. As such, the many small local governments collapse into one representative local government. In the rest of the paper we drop the subscript $i$.

\subsection{Pareto optimal allocation}

Before describing the government's problem, we first characterize the Pareto optimal allocation derived from a social planner's problem.

Definition 1. The social planner's problem consists of choosing a sequence of debt and spending $\left\{b_{t+1}, d_{t+1}, g_{t}, c_{t}\right\}_{t=0}^{\infty}$ that solves

$$
\max _{\left\{b_{t+1}, d_{t+1}, g_{t}, c_{t}\right\}_{t=0}^{\infty}} \sum_{t=0}^{\infty} \beta^{t}\left[(1-\theta) u\left(g_{t}\right)+\theta v\left(c_{t}\right)\right]
$$

subject to the following resource constraint for all time $t$

$$
g_{t}+c_{t}+b_{t}+d_{t}=\frac{b_{t+1}}{R\left(b_{t+1}\right)}+\frac{d_{t+1}}{S\left(d_{t+1}\right)}+e
$$

The solution to the social planner's problem is Pareto optimal.

Proposition 1. The social planner's solution (first-best) satisfies

$$
\begin{aligned}
\frac{u_{g, t}}{v_{c, t}} & =\frac{\theta}{1-\theta} \\
\beta \frac{u_{g, t+1}}{u_{g, t}} & =\frac{1}{R\left(b_{t+1}\right)}-\frac{b_{t+1} R_{b}\left(b_{t+1}\right)}{R\left(b_{t+1}\right)^{2}} \\
\beta \frac{v_{c, t+1}}{v_{c, t}} & =\frac{1}{S\left(d_{t+1}\right)}-\frac{d_{t+1} S_{d}\left(d_{t+1}\right)}{S\left(d_{t+1}\right)^{2}} .
\end{aligned}
$$

Equations (5)-(7) are the first-order conditions of the social planner's problem. Equation (5) indicates that central and local governments achieve perfect resource sharing. Further, under log utility, the equation becomes a condition for the central-local spending ratio, i.e. $c / g=\theta /(1-\theta)$.

local interest rate schedule when we introduce the local government's problem. 


\subsection{Distortion in local government's problem}

A representative local government takes central government's transfer rate $\tau$, debt $d^{\prime}$, and spending $c$ as given. It chooses spending $g$ and debt $b^{\prime}$ to maximize the welfare of its residents

$$
\begin{aligned}
W(b ; B)= & \max _{b^{\prime}, g}(1-\theta) u(g)+\theta v(c)+\beta W\left(b^{\prime} ; B^{\prime}\right) \\
\text { s.t. } & g+b \leq f+\frac{b^{\prime}}{R\left(B^{\prime}\right)}+\tau b
\end{aligned}
$$

where the interest rate schedule $R(\cdot)$ is a function of the aggregate local debt $B$ (instead of each region's public debt $b$ ). The representative local government's optimal choice of local public debt is characterized by its Euler equation,

$$
u_{g}=\beta R\left(B^{\prime}\right)(1-\underbrace{\tau^{\prime}}_{\text {transfer wedge }}) u_{g}^{\prime}
$$

where subscripts denote partial derivatives and primes indicate values of next period. The central government's transfer policy $\tau$ creates a wedge in the local government's inter-temporal decision. A larger $\tau$ reduces the marginal borrowing cost for the local government. ${ }^{12}$ Given central government's policy, there is symmetric equilibrium among the local governments in which $b=B$. In what follows, we use $b$ for the equilibrium (aggregate) level of local government debt.

\subsection{Equilibrium without commitment}

\subsubsection{Equilibrium definition}

Given the beginning-of-period state of the economy $(b, d)$, the central government chooses spending $c$, debt $d^{\prime}$ and transfer rate $\tau$ to maximize the welfare of its residents, subject to local governments' Euler equation.

In our setup, increasing the transfer rate at time $t$ has two effects on the local government. First, it relaxes its budget constraint at time $t$. Second, a higher transfer rate in expectation lowers local government's borrowing cost at $t-1$, giving it incentives to carry more debt into time $t$. As a result, the central government faces a trade-off between the ex post incentive of increasing local spending and the ex ante incentive of reducing local government moral hazard. This gives rise to the classic time-inconsistency problem: at time $t-1$, the central government may want to promise a relatively low $\tau_{t}$ to prevent local governments from overborrowing; at time $t$, however, the central government may prefer a higher $\tau_{t}$ to help finance local government consumption. Given this time-inconsistency problem, we consider the Markov equilibrium, in which the central government makes its policy decisions only based on current states, thus making the equilibrium time consistent.

\footnotetext{
12 Note that because each local government is infinitesimally small, it does not take into account the pecuniary cost of borrowing, i.e. how its own borrowing affects the interest rate and hence cost of borrowing. Therefore, there is no $R_{b}\left(B^{\prime}\right)$ term in the Euler equation. We investigate alternative assumptions of local government interest rate in robustness check Section 6.2.
} 
For convenience, we define the following functions of local and central government spending

$$
\begin{aligned}
G\left(b, b^{\prime}, \tau\right) & =f+\frac{b^{\prime}}{R\left(b^{\prime}\right)}-(1-\tau) b \\
C\left(b, d, d^{\prime}, \tau\right) & =e-f-\tau b+\frac{d^{\prime}}{S\left(d^{\prime}\right)}-d
\end{aligned}
$$

We follow Klein, Krusell, and Ríos-Rull (2008) to define the Markov equilibrium where choices are constrained to depend only on the value of the current period's states ( $b$ and $d$ ). In addition, we only consider equilibria where policy depends differentiably on these state variables.

Definition 2. A Markov-perfect equilibrium consists of the central government's value function $V$, policy rules $\phi$ and $p$, and the local government's policy rule $h$, such that for all aggregate states $(b, d), \tau=\phi(b, d), d^{\prime}=p(b, d)$ and $b^{\prime}=h(b, d)$ solve

$$
\max _{\tau, b^{\prime}, d^{\prime}} \quad(1-\theta) u\left(G\left(b, b^{\prime}, \tau\right)\right)+\theta v\left(C\left(b, d, d^{\prime}, \tau\right)\right)+\beta V\left(b^{\prime}, d^{\prime}\right)
$$

subject to the local government's optimality condition

$$
u_{g}\left(G\left(b, b^{\prime}, \tau\right)\right)=\beta R\left(b^{\prime}\right)\left(1-\phi\left(b^{\prime}, d^{\prime}\right)\right) u_{g}\left(G\left(b^{\prime}, h\left(b^{\prime}, d^{\prime}\right), \phi\left(b^{\prime}, d^{\prime}\right)\right)\right)
$$

and the central government's value function satisfies the functional equation

$$
V(b, d)=(1-\theta) u(G(b, h(b, d), \phi(b, d)))+\theta v(C(b, d, p(b, d), \phi(b, d)))+\beta V(h(b, d), p(b, d))
$$

This equilibrium is formulated as the central government choosing the transfer policy and debts at both central and local levels, subject to the local government's Euler equation. This is equivalent to letting the representative local government choose its own debt, taking the central government's policy rules as given.

The equilibrium captures the effect of expectation about future transfer policy $\left(\tau^{\prime}=\phi\left(b^{\prime}, d^{\prime}\right)\right)$ on the current local government's debt and spending decisions ( $b^{\prime}$ and $g$ ). It also allows the central government to take into account this expectation effect when making transfer decisions (terms $h\left(b^{\prime}, d^{\prime}\right)$ and $\phi\left(b^{\prime}, d^{\prime}\right)$ in Equation 11). In the equilibrium, both central and local governments' problems are solved with a rational expectation on future policy rules, and the central government's optimal policy rules today coincide with future policy rules. 


\subsubsection{Equilibrium characterization}

The equilibrium can be characterized by ${ }^{13}$

$$
\begin{aligned}
\{\tau\} & (1-\theta) u_{g} G_{\tau}+\theta v_{c} C_{\tau}=\lambda u_{g g} G_{\tau} \\
\left\{b^{\prime}\right\} \quad & (1-\theta) u_{g} G_{b^{\prime}}+\beta\left[(1-\theta) u_{g}^{\prime} G_{b}^{\prime}+\theta v_{c}^{\prime} C_{b}^{\prime}\right] \\
& =\lambda\left[u_{g g} G_{b^{\prime}}-\beta\left(1-\tau^{\prime}\right) R_{b}^{\prime} u_{g}^{\prime}-\beta R^{\prime}\left(1-\tau^{\prime}\right) u_{g g}^{\prime} G_{b}^{\prime}\right] \\
& +\lambda \Omega_{b^{\prime}}+\beta \lambda^{\prime} u_{g g}^{\prime} G_{b}^{\prime} \\
\left\{d^{\prime}\right\} \quad & \theta v_{c} C_{d^{\prime}}+\beta \theta v_{c}^{\prime} C_{d}^{\prime}=\lambda \Omega_{d^{\prime}}
\end{aligned}
$$

where

$$
\Omega_{x^{\prime}}=\beta R\left(b^{\prime}\right) \phi_{x}^{\prime} u_{g}^{\prime}-\beta R^{\prime}\left(1-\tau^{\prime}\right) u_{g g}^{\prime}\left[G_{\tau}^{\prime} \phi_{x}^{\prime}+G_{b^{\prime}}^{\prime} h_{x}^{\prime}\right], \quad x=\{b, d\}
$$

and $\lambda \geq 0$ is the Lagrange multiplier on the implementability constraint (11). $\Omega_{b^{\prime}}$ and $\Omega_{d^{\prime}}$ collect all the terms with derivatives of policy functions with respect to $b^{\prime}$ and $d^{\prime}$, respectively. These policy derivatives capture the effects of today's choices of $b^{\prime}$ and $d^{\prime}$ via effects on future policy choices on the right hand-side of the implementability constraint.

$\Omega_{b^{\prime}}$ has two terms. The first term captures the marginal effect of $b^{\prime}$ on the transfer wedge $\left(\phi\left(b^{\prime}, d^{\prime}\right)\right.$ in Equation 11) via the effect on future transfer policy $\phi^{\prime}$. In our quantitative work, this first term is positive, as transfer policy $\phi$ is increasing in local debt level $b$. The second term captures how changes in $b^{\prime}$ affect future local government spending $G^{\prime}$ via the effects on future transfer policy $\phi^{\prime}$ and local debt $h^{\prime}$. Similarly, $\Omega_{d^{\prime}}$ collects the effects of $d^{\prime}$ on the transfer wedge and future government spending.

From Equation (12) we have the following proposition.

Proposition 2. Under mild assumptions, the central-local ratio of marginal utility from spending in the Markov equilibrium steady state is higher than Pareto optimal, $v_{c} / u_{g}>(1-\theta) / \theta$. Further, with log utility the Markov equilibrium steady state central-local spending ratio is lower than Pareto optimal, $c / g<\theta /(1-\theta)$.

This result comes from Equation (12): it can be rewritten as $(1-\theta) u_{g}-\theta v_{c}=\lambda u_{g g}$ for $b \neq 0 ;{ }^{14}$ Lagrange multiplier $\lambda>0$ (see proof in Online Appendix E). Recall that in the social planner's allocation (Equation (5)), the $\theta$-weighted marginal utilities of central and local government consumption are equal. In the Markov equilibrium, however, central government's transfer creates distortion on local government's inter-temporal debt-spending decision, which is embodied in the local government's Euler equation. Because of this distortion, the Markov equilibrium cannot reach perfect resource sharing.

\footnotetext{
13 Slight abuse of notation (e.g. $u_{g g}$ for $u_{g g}(G)$ ) and derivatives of functions of local and central government spending (e.g. $G_{\tau}$ and $\left.C_{b^{\prime}}\right)$ are used to make the optimality conditions more compact. Online Appendix D.1 gives the expressions of the derivatives.

${ }^{14} G_{\tau}=b, C_{\tau}=-b$.
} 
Generalized Euler Equation (GEE) For a better understanding of the central government's decisionmaking, we combine the optimality conditions (12)-(14) to obtain two equilibrium conditions that jointly characterize the effects of changing transfer policy $\tau .{ }^{15}$ For expositional convenience, denote Equation (11) by $\eta\left(b, b^{\prime}, d^{\prime}, \tau\right)=0$, and use $\eta_{b}, \eta_{b^{\prime}}, \eta_{d^{\prime}}$ and $\eta_{\tau}$ to denote partial derivatives. ${ }^{16}$ Online Appendix D.1 includes a derivation of these conditions.

$$
\begin{aligned}
& 0=\underbrace{\left(u_{g} G_{\tau}+\frac{\theta}{1-\theta} v_{c} C_{\tau}\right)}_{\text {within-period shift in spending (-) }}+\overbrace{\left(-\frac{\eta_{\tau}}{\eta_{b^{\prime}}}\right)}^{d b^{\prime} / d \tau(-)} \underbrace{\left[u_{g} G_{b^{\prime}}+\beta\left(u_{g}^{\prime} G_{b}^{\prime}+\frac{\theta}{1-\theta} v_{c}^{\prime} C_{b}^{\prime}\right)\right]}_{\text {inter-temporal shift in spending via } b^{\prime}(-)} \\
& +\beta \overbrace{\left(-\frac{\eta_{\tau}}{\eta_{b^{\prime}}}\right)\left(-\frac{\eta_{b}^{\prime}}{\eta_{\tau}^{\prime}}\right)}^{d \tau^{\prime} / d \tau, b^{\prime \prime} \text { constant }(-)} \quad \underbrace{\left(u_{g}^{\prime} G_{\tau}^{\prime}+\frac{\theta}{1-\theta} v_{c}^{\prime} C_{\tau}^{\prime}\right)} \\
& \text { future within-period shift in spending (-) } \\
& 0=\underbrace{\left(u_{g} G_{\tau}+\frac{\theta}{1-\theta} v_{c} C_{\tau}\right)}_{\text {within-period shift in spending (-) }}+\overbrace{\left(-\frac{\eta_{\tau}}{\eta_{d^{\prime}}}\right)}^{d d^{\prime} / d \tau(-)} \underbrace{\left[\frac{\theta}{1-\theta} v_{c} C_{d^{\prime}}+\beta \frac{\theta}{1-\theta} v_{c}^{\prime} C_{d}^{\prime}\right]}_{\text {inter-temporal shift in spending via } d^{\prime}(-)}
\end{aligned}
$$

The Markov equilibrium can be characterized by conditions (11), (15) and (16).

Both conditions capture the marginal welfare effect of increasing the transfer rate $\tau$, each representing the effect through one state variable. Equation (15) captures the effect through changes in the local government's debt $b^{\prime}$ holding central government's debt choice $d^{\prime}$ constant, whereas Equation (16) sums up the effects through changing central debt $d^{\prime}$ and holding local debt constant. Notice that the second condition does not have the future resource sharing wedge. This is because the choice of central debt $d^{\prime}$ does not have an effect on next period local spending $G^{\prime}{ }^{17}$

A closer look at Equation (15) gives important insights. For easier exposition, we write the resource sharing wedges explicitly and collapse the current and future wedges into one in steady state, and Equation (15) becomes $^{18}$

$$
\overbrace{\text { within-period shift in spending }}^{\overbrace{\left[1+\beta\left(-\frac{\eta_{\tau}}{\eta_{b^{\prime}}}\right)\left(-\frac{\eta_{b}^{\prime}}{\eta_{\tau}^{\prime}}\right)\right]}^{(+)}\left(u_{g}-\frac{\theta}{1-\theta} v_{c}\right)} b+\underbrace{\overbrace{\left(-\frac{\eta_{\tau}}{\eta_{b^{\prime}}}\right)}^{(-)}\left[u_{g} G_{b^{\prime}}+\beta\left(u_{g}^{\prime} G_{b}^{\prime}+\frac{\theta}{1-\theta} v_{c}^{\prime} C_{b}^{\prime}\right)\right]}_{\text {inter-temporal shift in spending through } b^{\prime}}=0 .
$$

This steady state condition captures two marginal effects of increasing transfer rate on welfare. First, a higher transfer rate shifts within-period spending from central to local government; second,

\footnotetext{
15 The signs in parentheses in the GEEs are based on values in our quantitative exercise of Section 4.

${ }^{16}$ Explicitly, $\eta_{b}=u_{g g} G_{b}, \eta_{\tau}=u_{g g} G_{\tau}, \eta_{b^{\prime}}=\left[u_{g g} G_{b^{\prime}}-\beta\left(1-\tau^{\prime} M_{b}^{\prime}\right) R_{b}^{\prime} u_{g}^{\prime}-\beta R^{\prime}\left(1-\tau^{\prime} M_{b}^{\prime}\right) u_{g g}^{\prime} G_{b}^{\prime}\right]+\Omega_{b^{\prime}}, \eta_{d^{\prime}}=\Omega_{d^{\prime}}$. Using Implicit Function Theorem, ratios of $\eta$-derivatives have the interpretation of marginal effects holding other variables of the local government's Euler equation constant. For example, $-\eta_{\tau} / \eta_{b^{\prime}}$ gives the effect of changing $\tau$ on $b^{\prime}$ holding constant $b$ and $d^{\prime}$.

17 Mechanically, $d$ does not appear in Equation (11), and so $\eta_{d}$ is zero which means the $-\eta_{d}^{\prime} / \eta_{\tau}^{\prime}$ term is zero.

18 Where $G_{\tau}=-C_{\tau} \equiv b$.
} 
it changes $b^{\prime}$ (by $-\eta_{\tau} / \eta_{b^{\prime}}<0$ amount), which shifts spending inter-temporally.

In the social planner's allocation the second effect is zero, because the social planner sets $b^{\prime}$ such that the welfare effect of changing $b^{\prime}$ is zero. Thus, the social planner simply allocates spendings such that $u_{g}=\theta /(1-\theta) v_{c}$ as implied by setting the first effect alone.

In the Markov equilibrium, because the central government is constrained to use distortionary transfer policy (instead of assigning spending directly), the central and local governments have different marginal values of changing $b^{\prime}$. As a result the second effect is non-zero. To see this, we decompose the inter-temporal effect of a change of $b^{\prime}$ in (17) further into three components: the local government's Euler equation; an interest rate externality; and an effect on central government spending tomorrow through changing total transfers (Equation 18).

$$
u_{g} G_{b^{\prime}}+\beta\left(u_{g}^{\prime} G_{b}^{\prime}+\frac{\theta}{1-\theta} v_{c}^{\prime} C_{b}^{\prime}\right) \equiv \underbrace{\frac{1}{R^{\prime}} u_{g}-\beta u_{g}^{\prime}\left(1-\tau^{\prime}\right)}_{\text {local Euler equation }} \underbrace{-\frac{\theta}{1-\theta} \beta v_{c}^{\prime} \tau^{\prime}}_{\text {transfers tomorrow interest rate externality }} \underbrace{-\frac{b^{\prime} R_{b}^{\prime}}{R^{\prime 2}} u_{g}} .
$$

In the equilibrium, the local government's incentive is captured by setting the local Euler equation to zero. The central government, in contrast, internalizes two additional benefits of decreasing $b^{\prime}$ : it lowers the cost of interest rate externality; and it reduces the total transfers paid out tomorrow. Because of these two additional considerations, the welfare effect of decreasing $b^{\prime}$ is positive (or equivalents, the welfare effect of increasing $b^{\prime}$ is negative).

Because the marginal gain from reducing $b^{\prime}$ is positive for the central government, it wants a lower $b^{\prime}$ than the level determined by local government's inter-temporal condition. To do this, the central government uses higher transfers to relax local government's budget constraint and reduce the local government's need to borrow. In equilibrium, the transfer level is higher than implied by the within-period term of (17) alone. As a result, the marginal utility of local spending is too low relative to that of central spending, $u_{g}<\theta /(1-\theta) v_{c}$. In other words, compared with the social planner's allocation, the central government's over-transfer leads to over-supply of local government spending (Proposition 2).

There is, however, an additional ex ante effect of larger transfers. When the local government anticipates a larger transfer today, it borrows more the previous day. Because the central government in this time-consistent equilibrium considers ex ante incentives as forgone, it does not take into account this ex ante effect of larger transfers. In our quantitative exercise, the larger transfer, aimed to lower local debt, ends up raising local debt. In other words, over-transfer exacerbates over-borrowing.

\subsubsection{Effects of fiscal decentralization on equilibrium steady state}

We show the quantitative effects of fiscal decentralization in Section 4. Here, we give a qualitative interpretation of the effects on transfer rate based on the GEEs. A revenue decentralization (an increase in $f$ ) loosens local government's budget constraint and tightens central government's budget because of a one-to-one decrease in $e-f$. This means, all else equal, $u_{g}$ is smaller and $v_{c}$ is larger, and the within-period effects of transfers in Equations (15) and (16) are smaller. In other words, 
the (within-period) marginal benefit of shifting resource from central to local through transfers is smaller. So the central government lowers transfer rate $\tau$.

A spending decentralization (a higher $1-\theta$ ) affects both the within-period and inter-temporal effects of transfer in Equations (15) and (16). A higher $1-\theta$ raises the within-period effect by increasing the weight on $v_{c}$ (and $C_{\tau} \equiv-b$ ), and so the central government chooses a higher transfer rate. At the same time, spending decentralization also lowers the inter-temporal effect or transfer. A higher $1-\theta$ reduces the value of lower total transfers paid out tomorrow (Equation 18). This lowers the marginal benefit of reducing future local debt $b^{\prime}$. Since higher $\tau$ reduces $b^{\prime}$ (i.e. $-\eta_{\tau} / \eta_{b^{\prime}}<0$ in Equation 15), this effect gives the central government incentive to choose a lower transfer rate. In the quantitative section, we show the overall effect of a spending decentralization is to raise transfer rate; in other words, the within-period effect outweighs the inter-temporal effect.

\subsubsection{Comparison to equilibrium with commitment}

The central government in the Markov equilibrium over-transfers because its lack of commitment means it does not take into account the ex ante effect of transfers. As a comparison, we look at the equilibrium policy with commitment (Ramsey policy). Here we give a brief discussion of the main results. The full Ramsey problem set-up and equilibrium characterization can be found in Online Appendix C.

In the Ramsey problem, the central government chooses the entire sequence of policies and allocations at time zero, and at any time $t$, the central government sticks to the time- 0 plans. This captures its commitment to all future policies. Because of commitment to future policies, the Ramsey central government takes into account how time- $t$ policy affects local government incentives at time $t-1$. This is the key difference from the Markov equilibrium.

The main result is that the central-local ratio of marginal utility from spending in the Ramsey steady state is lower than the Pareto optimal, $v_{c} / u_{g}<(1-\theta) / \theta$. Recall that the central-local ratio of marginal utility from spending in the Markov steady state is higher than the Pareto optimal. Compared with the condition for the Markov equilibrium (Equation 12), the Ramsey government's choice of transfer rate takes into account not only its effects on central-local resource sharing and on local government's budget constraint and debt choice, but also the ex ante overborrowing effect on the local government. The Ramsey government takes into account the overborrowing effect because of its ability to commit to future policies. In equilibrium, the cost of overborrowing is greater than the ex post benefit of relaxed local government budget. As a result, the Ramsey central government under-transfers compared to the social planner's allocation, and the Ramsey steady state central-local spending ratio is higher than that in the social planner's allocation.

\subsection{Implement social planner's allocations}

We have shown that the central government over-transfers in the Markov equilibrium and undertransfers in the Ramsey equilibrium. As a next step, we discuss how to implement the social planner's allocations (Pareto optimal). The intuition is to construct a macroprudential policy such that it 
offsets the ex ante overborrowing incentives created by transfers, similar to Bianchi (2016).

We endow the central government with an additional instrument - ex ante tax on local government borrowing, and we show that ex ante debt tax $\left\{\hat{\tau}_{t}\right\}_{t=0}^{\infty}$ and ex-post transfer $\left\{\tau_{t}\right\}_{t=0}^{\infty}$ can implement the Pareto optimal allocation and is hence time consistent. ${ }^{19}$ Figure 5 illustrates the time line with the additional instrument.

\begin{tabular}{|c|c|c|c|c|c|}
\hline & Local governments $(t-1)$ & $(b, d)$ & Central government & Local governments & $\left(b^{\prime}, d^{\prime}\right)$ \\
\hline$t-1$ & borrows $b\left(1-\hat{\tau}^{-}\right)$ & $t$ & $\begin{array}{c}\text { transfer policy } \tau \\
\text { tax policy } \hat{\tau}\end{array}$ & $\begin{array}{c}\text { repays } b \text {, gets transfer } b \tau \\
\text { borrows } b^{\prime}(1-\hat{\tau}) \text {, spends } g\end{array}$ & $t+1$ \\
\hline
\end{tabular}

Figure 5: Time line with ex ante debt tax

With ex-ante debt tax the Ramsey problem (R2) becomes (writing in primal approach)

$$
\max _{\left\{b_{t+1}, d_{t+1}, g_{t}, \hat{\tau}_{t}\right\}_{t=0}^{\infty}} \sum_{t=0}^{\infty} \beta^{t}\left[(1-\theta) u\left(g_{t}\right)+\theta v\left(c_{t}\right)\right]
$$

subject to

$$
\begin{aligned}
\left(1-\hat{\tau}_{t}\right) u_{g}\left(g_{t}\right) & =\beta R\left(b_{t+1}\right)\left(1-\tau_{t+1}\right) u_{g}\left(g_{t+1}\right) \quad(I C) \\
c_{t} & =e_{t}+\frac{b_{t+1}}{R\left(b_{t+1}\right)}+\frac{d_{t+1}}{S\left(d_{t+1}\right)}-b_{t}-d_{t}-g_{t} \\
g_{t}+b_{t} & =\tau_{t} b_{t}+\left(1-\hat{\tau}_{t}\right) \frac{b_{t+1}}{R\left(b_{t+1}\right)}+f
\end{aligned}
$$

where the last constraint is the local government's budget constraint when ex-ante tax on debt is added.

Proposition 3. Suppose the government is also allowed to implement a debt tax $\hat{\tau}_{t}$ on local debt $b_{t+1}$ at $t$, then the equilibrium allocation of the Ramsey problem with ex ante debt tax (R2) is the same as the Pareto optimal allocation and hence it is time consistent.

We show it by proving that the Pareto optimal allocation satisfies the implementability condition (IC) and the local government's budget constraint with appropriately constructed $\left\{\tau_{t}^{R}, \hat{\tau}_{t}\right\}$ sequence. Given $b_{0}$ and $d_{0}$, denote the Pareto optimal allocation as $\left\{b_{t}^{*}, d_{t}^{*}, g_{t}^{*}, c_{t}^{*}\right\}$. Let

$$
\tau_{t}^{R}=\Omega\left(b_{t}^{*}, b_{t+1}^{*}, g_{t}^{*}, \hat{\tau}_{t}\right) \equiv \frac{g_{t}^{*}+b_{t}^{*}-\left(1-\hat{\tau}_{t}\right) b_{t+1}^{*} / R\left(b_{t+1}^{*}\right)-f}{b_{t}^{*}}
$$

Then the local government's budget constraint is satisfied. Construct $\left\{\hat{\tau}_{t}\right\}$ recursively such that

$$
1 /\left(1-\frac{b_{t+1}^{*} R_{b}\left(b_{t+1}^{*}\right)}{R\left(b_{t+1}^{*}\right)}\right)=\frac{1-\Omega\left(b_{t+1}^{*}, b_{t+2}^{*}, g_{t+1}^{*}, \hat{\tau}_{t+1}\right)}{1-\hat{\tau}_{t}}
$$

It is straightforward to verify that the social planner's first order condition with respect to $b_{t}$

19 In Online Appendix $\mathrm{F}$ we show how to implement the Pareto optimal allocation using an ex ante debt limit (instead of the ex ante tax discussed here). 
is essentially the same as the implementability condition (IC) of the problem (R2). Therefore, the Pareto optimal allocation $\left\{b_{t}^{*}, d_{t}^{*}, g_{t}^{*}, c_{t}^{*}\right\}$ together with the constructed policy sequence $\left\{\tau_{t}^{R}, \hat{\tau}_{t}\right\}$ also solves this new Ramsey problem. Because the Pareto optimal allocation is time-consistent, so is the allocation of this new Ramsey problem.

In general, if the only policy instrument is the ex-post transfer $\tau_{t}$, the Ramsey equilibrium allocation is not Pareto optimal. More importantly, it is not time consistent. As a result, the central government has incentive to deviate from the Ramsey optimal policy ex post. With the ex ante debt tax the central government can offset local government's ex ante overborrowing incentives. This allows the central government to use the ex-post transfer to achieve perfect resource sharing. In this case, the Ramsey policy is Pareto optimal and time consistent.

\section{Quantitative Analysis}

In this section we use a calibrated version of the model to study the quantitative impact of fiscal decentralization on government debt, spending and transfer. We first look at steady state and dynamic properties of the calibrated model. In particular, we highlight the dynamic inter-dependence between central and local debt. Using comparative statics we illustrate the qualitative effects of decentralization in equilibrium steady state. We then use counterfactual experiments to investigate the quantitative impact of fiscal decentralization on aggregate public debt. Finally, we examine the quantitative importance of dynamics in an infinite-horizon model.

We calibrate to data moments in Spain, and for two reasons. First, Spain went through several well-documented fiscal decentralizations, which make the country a good candidate for policy evaluations. Second, for the pre-2006 period that we look at, Spanish regional governments have little freedom in tax revenue collection, but more freedom to decide spending. This is consistent with our modeling choice where local governments choose spending taking pre-transfer revenue as exogenously given.

We look at the period between 1988 and 2006, and separate it into pre-1996 when both local fiscal gap (VFI) and general government debt were low, and post-1996 when both were high. For each period, we calibrate to the beginning and end years, and investigate to what extent the observable changes in revenues $f$ and $e$ and unobservable changes in spending responsibility $\theta$ drive the changes in government debt levels. All data used here come from the IMF Government Finance Statistics (GFS).

\subsection{Bring model to Spain}

In order to apply the model to Spain, we look at how closely the model captures Spain's institutional and empirical features. In particular, we focus on the transfer function and discuss how to adapt it to Spain.

Debt-dependent transfer. Our model assumes a transfer function that depends on each region's debt level. This is consistent with reality if, in reality, the central government assigns more grants to a region due to its stock of debt in the previous period. 
Using regional transfer income data from the Economic database of the Spanish Public Sector (BADESPE) and regional debt data from the central bank of Spain (Banco de España), we document a positive relationship between a region's (lagged) debt and the transfer it receives. The left panel of Figure 6 plots the (lagged) debt/GDP and gross transfer/GDP for each of the 15 regions in each year over 1994-2007. ${ }^{20}$ We use different shape/color markers for different time periods. For a clearer crossregion pattern, we take the average of a region's debt/GDP and gross transfer/GDP over 1994-2007, and plot the relationship in the right panel. Both plots show a clear positive correlation between a region's debt and its transfer income.

Figure 6: Relationship between Spain's regional debt and regional transfer income
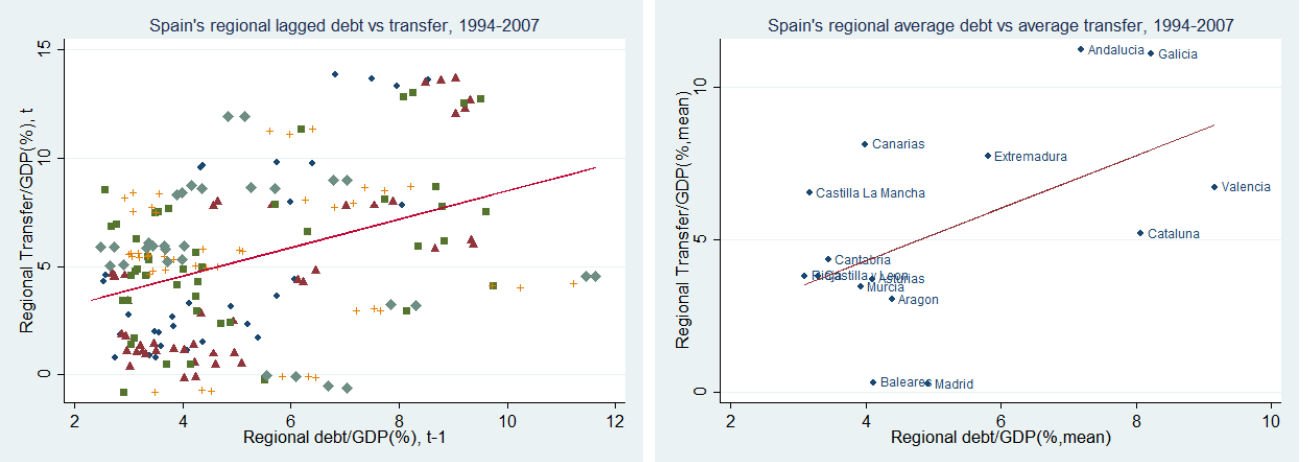

Note: Different shape/color markers in the left panel mark three-year time windows. Circle (०) for 1994-96; triangle $(\Delta)$ for 1997-99; square $(\square)$ for 2000-02; plus $(+)$ for 2003-05; diamond $(\diamond)$ for 2006-07.

Empirically, Sorribas-Navarro (2011) documents that during 1986-2006 in Spain, if a region increased its debt by $€ 100$ per capita, the grants from the central government would increase by $€ 1.3$ to $€ 9$ per capita. This result is robust after controlling for factors such as regional income, population, expenditure responsibilities and political alignment. This illustrates that the central government is indeed tempted to transfer more to regions that have larger debt outstanding.

A more general transfer function. Regional transfer income in Spain consists of two types of grants. Discriminative grants (e.g. transfers to investment projects) do not follow a set formula or clear rule for distribution. These grants can be used by the central government to allocate resources according to a region's economic and fiscal conditions. Non-discriminative grants (e.g. Health Care Grant, Guarantee Fund) are distributed based on a formula which is negotiated periodically.

Sorribas-Navarro (2011)'s empirical analysis suggests that while discriminative transfers respond to regional debt position at any time, (a priori) non-discriminative transfers only respond to debt when the regional financing system is renegotiated. This means not all transfers are debt-dependent all the time, which is consistent with the transfer function (3) copied below:

$$
T_{i, t}=\tau_{t} \cdot M\left(b_{i, t}\right), \quad \text { where } M\left(b_{i, t}\right)=\left[\left(1-\epsilon_{t}\right)+\epsilon_{t} b_{i, t} / f_{t}\right], \quad \epsilon \in[0,1]
$$

\footnotetext{
20 Because Navarra and the Basque country have very different fiscal systems from the other autonomous regions, we follow the literature and exclude them from this regional study. For the transfer measure we include all transfers from the central government to the autonomous region (CCAA).
} 
Table 1: Externally Calibrated Parameters

\begin{tabular}{llccc}
\hline \hline Parameter & Description & \multicolumn{3}{c}{ Value } \\
\hline$\beta$ & Time discount factor & 0.95 & \\
$\psi_{b}$ & Local interest elasticity & 0.03 & \\
$\psi_{d}$ & Central interest elasticity & & 0.03 & \\
& & 1988 & 1996 & 2006 \\
\cline { 3 - 5 }$e$ & Total government revenue/GDP & 0.3117 & 0.3684 & 0.3983 \\
$f$ & Local government revenue/GDP & 0.0430 & 0.0623 & 0.1011 \\
\hline Note: Trended GDP is used to calculate revenue-GDP ratios.
\end{tabular}

Table 2: Internally Calibrated Parameters

\begin{tabular}{llccc}
\hline \hline \multirow{2}{*}{ Parameter } & Target & \multicolumn{3}{c}{ Calibrated Values } \\
\cline { 3 - 5 } & & 1988 & 1996 & 2006 \\
\hline $\bar{B}$ & Local government debt/GDP & 0.01558 & 0.06699 & 0.002 \\
$\bar{D}$ & Central government debt/GDP & 0.53738 & 0.90842 & 0.38169 \\
$\theta$ & Central-local spending ratio & 0.855 & 0.69 & 0.59 \\
$\epsilon$ & Vertical fiscal imbalances & 0.002835 & 0.00174 & 0.00475 \\
\hline
\end{tabular}

Note: Trended GDP is used to calculate debt-GDP ratios from data.

We calibrate $\epsilon$ to different periods in Spain.

\subsection{Calibration}

We calibrate the parameters by matching the steady state model moments to their empirical counterparts in Spain for each of the target years.

We assume log utility for both central and local government spending. As a result, the parameter $\theta$ has the nice interpretation of the proportion of public goods responsible by the central government (see Online Appendix A). The annual time discount rate $\beta$ is set to be 0.95 .

We use exogenous interest rate schedules for both local and central debt, similar to Schmitt-Grohe and Uribe (2003)

$$
\begin{aligned}
R(b) & =1 / \beta+\psi_{b}(\exp (b-\bar{B})-1) \\
S(d) & =1 / \beta+\psi_{d}(\exp (d-\bar{D})-1)
\end{aligned}
$$

The elasticity parameters $\psi_{b}$ and $\psi_{d}$ are set according to the empirical literature on the sensitivity of local and central borrowing cost to debt. Grande, Masciantonio, and Tiseno (2013) estimate the demand elasticity of ten-year OECD public debt to be 3 basis points during 1995-2011. We use this value for $\psi_{d}$. There is no good data on interest rate elasticity of local debt, so in the benchmark we set $\psi_{b}$ to be equal $\psi_{d}$, and we do robustness checks on alternative values of $\psi_{b}$.

Total and local revenues $e$ and $f$ are taken from the GFS data and are expressed as percentages of national trend GDP. Table 1 summarizes the externally calibrated parameters.

This leaves four parameters to be calibrated internally: $\bar{B}$ and $\bar{D}$ for the interest rate schedules, 
Table 3: Targeted and Untargeted Moments

\begin{tabular}{|c|c|c|c|c|c|c|}
\hline \multirow[t]{2}{*}{ Moment } & \multicolumn{2}{|c|}{1988} & \multicolumn{2}{|c|}{1996} & \multicolumn{2}{|c|}{2006} \\
\hline & Data & Model & Data & Model & Data & Model \\
\hline \multicolumn{7}{|c|}{ Targeted Moments } \\
\hline Local government debt/GDP & 0.0620 & 0.0623 & 0.1295 & 0.1286 & 0.1218 & 0.1242 \\
\hline Central government debt/GDP & 0.3384 & 0.3600 & 0.6148 & 0.6090 & 0.3361 & 0.3404 \\
\hline Central-local spending ratio & 3.6317 & 3.8311 & 1.8282 & 1.7856 & 1.0424 & 1.1664 \\
\hline Vertical fiscal imbalance & 32.1774 & 32.4488 & 53.2391 & 50.9924 & 40.0494 & 43.7552 \\
\hline \multicolumn{7}{|c|}{ Untargeted Moments } \\
\hline Local spending/GDP & 0.0597 & 0.0605 & 0.1248 & 0.1205 & 0.1656 & 0.1731 \\
\hline Central spending/GDP & 0.2168 & 0.2316 & 0.2306 & 0.2151 & 0.1727 & 0.2019 \\
\hline Local interest payment/GDP & 0.0037 & 0.0032 & 0.0085 & 0.0067 & 0.0030 & 0.0066 \\
\hline Central interest payment/GDP & 0.0265 & 0.0164 & 0.0426 & 0.0262 & 0.0139 & 0.0166 \\
\hline
\end{tabular}

Note: Trended GDP is used as denominator for ratios. Vertical fiscal imbalance is calculated as $100 \times[1-f /(g+b-b / R(b))]$.

the spending responsibility $\theta$, and the degree of progressivity in transfer $\epsilon$. We jointly calibrate these parameters using steady-state moments targeting four data moments: (1) local debt to GDP ratio, (2) central debt to GDP ratio, (3) central-local spending ratio, and (4) vertical fiscal imbalance. Intuitively, local and central debt to GDP ratios identify $\bar{B}$ and $\bar{D}$ respectively. Central-local spending ratio identifies $\theta$, and vertical fiscal imbalance identifies $\epsilon$ as they are related to intergovernmental transfers. We allow these four parameters to change over time and calibrate them for each target year. Table 2 reports these internally calibrated parameters.

Table 3 presents the targeted and untargeted moments. We match the targeted moments reasonably well. In particular, the calibrated model captures three properties in the data: debts rose in 1988-1996 and fell in 1996-2006; central-local spending ratio fell in both time windows; vertical fiscal imbalances increased during the first period and decreased in the second. For the untargeted moments, the model also does fairly well in matching government spending, and debt interest payments.

\subsection{Markov policy functions: inter-dependence of local and central debt}

In this section we show the Markov equilibrium policy functions and highlight the inter-dependence between local and central government debts. Figure 8 plots $b^{\prime}, d^{\prime}$ and $\tau$ as functions of $(b, d)$ in Markov equilibrium. Panel A plots functions in 3-D, and Panel B plots in 2-D holding one of the states at its steady state value.

Next period's local (central) debt increases in current-period local (central) debt (Panel B plots 1 and 5). This is standard in any model with inter-temporal borrowing: as current-period debt gets larger, the local (central) government needs to borrow more for next period in order to balance budget.

More interestingly, next period's local (central) debt is also increasing in current-period central (local) debt (Panel B plots 2 and 4). This dynamic interdependence of local and central debt is missing 
from standard models with only debt of one level of government. Intuitively, a higher current-period local debt $b$ gives the central government more incentive to increase transfer rate in order to maintain local spending level ex post and lower local government's debt position in the future (hence transfer rate $\tau$ increases in local debt $b$ in Panel $\mathrm{B}$ plot 3 ). In order to finance the now higher transfer, the central government has to increase next-period debt $d^{\prime}$.

Figure 7: Illustration of dynamic interdependence of local and central debt

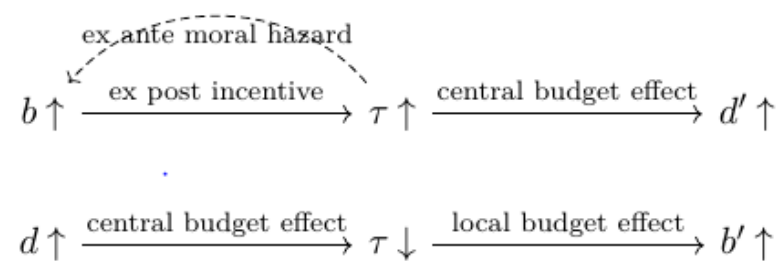

Similarly, as current-period central debt $d$ gets larger, the central government can only afford a lower transfer, hence the transfer rate $\tau$ falls as central debt $d$ increases in Panel B plot 6 . A lower transfer rate in the current period increases out-of-pocket debt interest payment for local government, and to balance its own budget local government has to increase next-period debt $b^{\prime}$.

Figure 7 summarizes the dynamic interdependence. Note that higher expected transfer $\tau$ raises $b$ through increasing the ex ante overborrowing incentive of the local government (dotted line in Figure 7). But the central government following time-consistent policy takes $b$ as given when choosing $d^{\prime}$, and so it does not take this ex ante moral hazard effect into account.

In addition to the dynamic inter-dependence illustrated here, the model also captures a withinperiod relationship between local and central debt. Online Appendix H illustrates this mechanism. Intuitively, local borrowing at time $t, b_{t+1}$, depends negatively on the same-period central borrowing $d_{t+1}$. When $d_{t+1}$ is higher, local government expects lower transfer at time $t+1$ - recall $\tau$ decreases in beginning-of-period $d$ as explained above. The expectation of lower $\tau_{t+1}$ reduces the local government's overborrowing incentive at time $t$, and so $b_{t+1}$ is lower.

\subsection{Inspecting qualitative effects of fiscal decentralization}

We now use the model calibrated to data in 1996 to study the effect of fiscal decentralization. In particular, we allow the parameter(s) governing fiscal decentralization ( $f$ and $\theta$ ) to vary while holding all other parameters at their 1996 values. ${ }^{21}$ We show that a revenue decentralization, modeled as an increase in local revenue $f$, reduces general government debt, while a spending decentralization, captured by a rise in local government's share of spending responsibility $1-\theta$, raises general government debt.

Revenue decentralization Figure 9 upper panel investigates the effects of a revenue decentralization by changing local revenue $f$, holding total revenue $e$ unchanged. The black line plots the effects on the equilibrium steady state debts, spendings, transfer rate, and vertical fiscal imbalance. A higher local revenue $f$ corresponds to a revenue decentralization.

\footnotetext{
21 The patterns are similar if the year 1988 or 2006 is used for this quantitative exercise.
} 
Figure 8: Markov policy functions

\section{A. 3-D Plots}
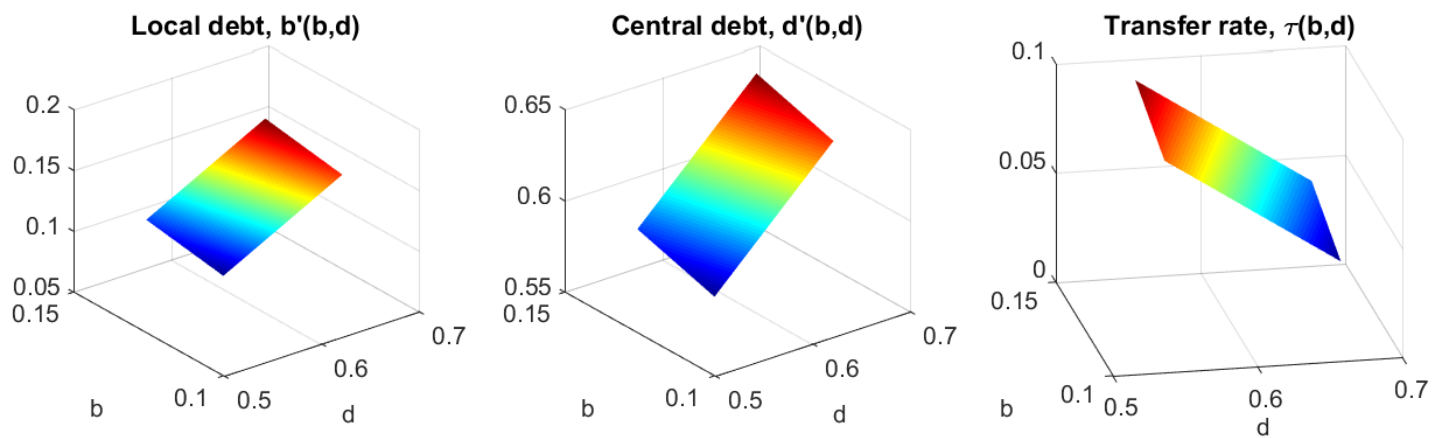

Note: All parameters are at calibrated 1996 values. Policy functions plotted over two states: local government debt (b) and central government debt $(d)$

\section{B. 2-D Plots}
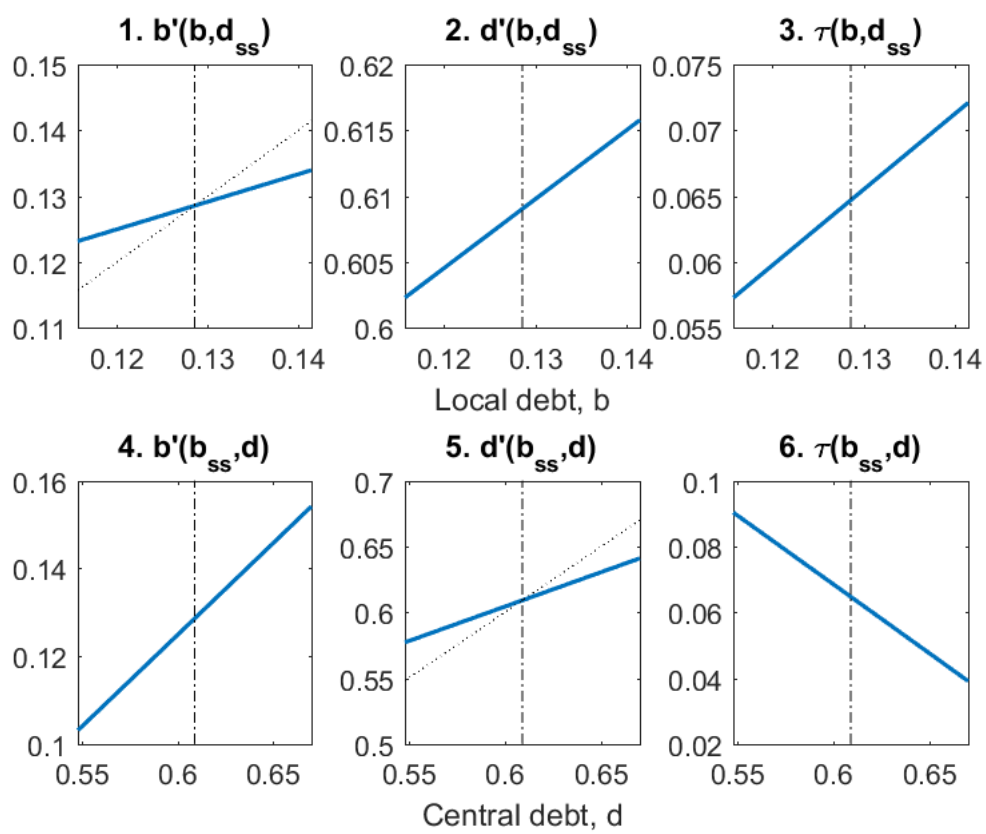

Note: All parameters are at calibrated 1996 values. Policy functions plotted over one state at a time while holding the other state at steady state value. Upper panel: over local government debt $(b)$ holding central government debt at steady state $\left(d=d_{s s}\right)$. Bottom panel: over central government debt $(d)$ holding local government debt at steady state $\left(b=b_{s s}\right)$. Dotted lines are 45-degree line. Dashed vertical lines mark steady state value of the varying state variable. 
Figure 9: Effects of fiscal decentralization on Markov equilibrium steady state

Effect of a change in local revenue $f$ on Markov steady state
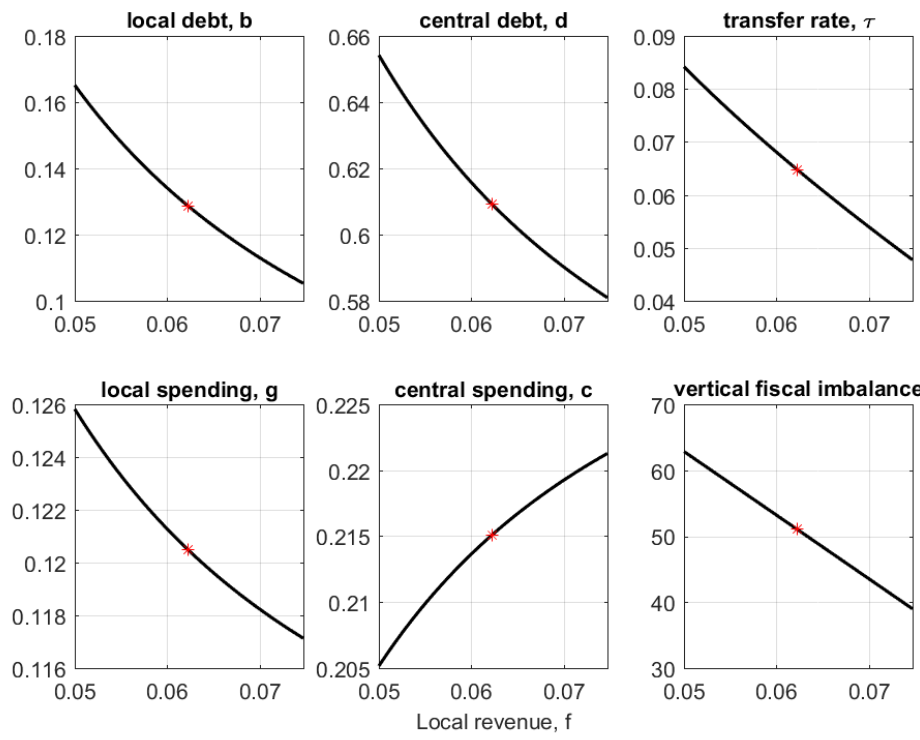

Note: All parameters except for local revenue $f$ are held at calibrated 1996 values. Black line plots steady states for different $f$ values. Red star marks the 1996 steady state. A higher local revenue $f$ corresponds to a revenue decentralization.

Effect of a change in spending responsibility $\theta$ on Markov steady state
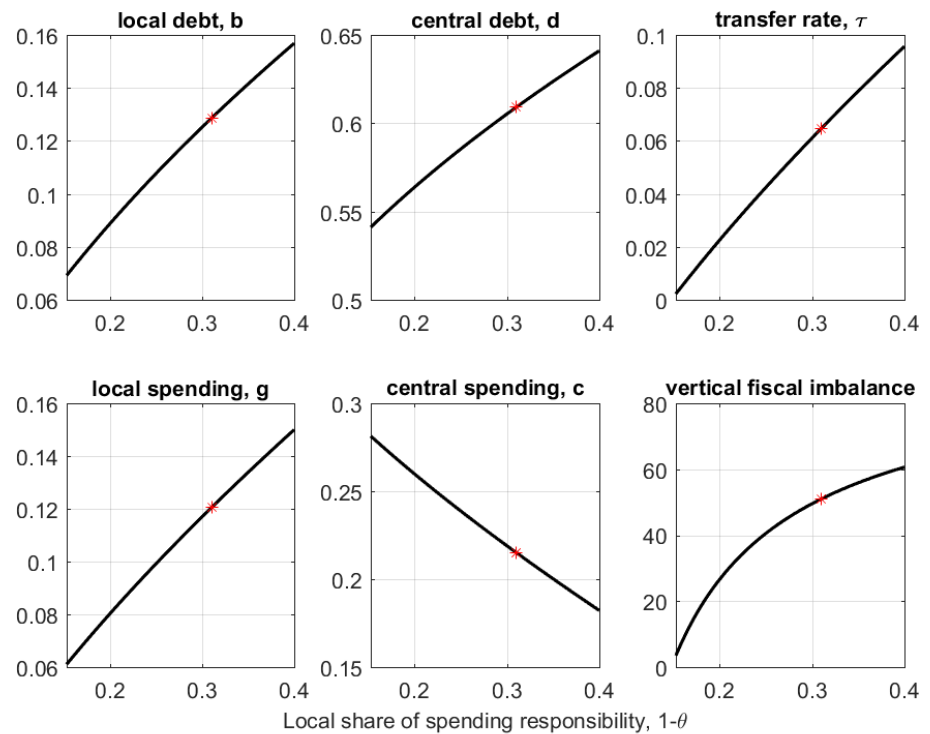

Note: All parameters except for spending responsibility $\theta$ are held at calibrated 1996 values. Black line plots steady states for different $\theta$ values. Red star marks the 1996 steady state. A higher local share of spending responsibility $1-\theta$ corresponds to a spending decentralization. 
A higher local revenue improves local government's fiscal independence (smaller fiscal gap) and reduces the need for transfers. At the same time, because total revenue does not change, higher local revenue means lower central revenue $(e-f)$, which reduces central government's ability to make transfers. As a result, transfer rate falls. The lower transfer rate raises the after-transfer cost of borrowing for the local government and reduces the ex-ante borrowing incentive and moral hazard. ${ }^{22}$

Smaller moral hazard in the local government's debt problem also improves central government's fiscal position. As the central government reduces transfer rate, holding local debt unchanged, then lower total transfer should exactly offset the reduction in central government's revenue, leaving central debt unchanged. However, because lower transfer rate also reduces ex ante overborrowing incentives of the local government, the lower local debt level in turn reduces total transfer even more than the reduction in central government's revenue. This relaxes central government's budget and reduces its need to carry debt.

Interestingly, a revenue decentralization lowers local spending $g$ (and raises central spending $c$ ), even though it raises the local share of revenue. Intuitively, a higher $f$ reduces local government's dependence on transfer, and lowers moral hazard. With smaller moral hazard, the equilibrium moves closer to the Pareto optimal allocation, which has a higher central-local spending ratio (Proposition 2). ${ }^{23}$

Spending decentralization To generate a spending decentralization in the model, we allow the spending responsibility parameter $\theta$ to change. Figure 9 lower panel plots the corresponding changes in the equilibrium steady state. A larger local share of spending responsibility $1-\theta$ corresponds to a spending decentralization.

A larger local share of spending responsibility $1-\theta$ widens the fiscal gap of the local government, and vertical fiscal imbalance becomes larger. A larger fiscal gap raises the central government's incentive to make transfers to ensure the local government has enough resources to meet the increased spending responsibility. However, the higher transfer rate makes local government debt less costly ex ante and increases the local government's incentive to overborrow.

The larger overborrowing incentive not only increases local debt but also central debt. With a higher transfer rate, holding local debt unchanged, the higher total transfer should be offset by local central government's spending responsibility, leaving central debt unchanged. However, because of increased overborrowing by local government, the increase in total transfer more than offsets lower spending, and as a result central government increases borrowing.

As a larger local share of spending responsibility raises transfers, the local government has more total resources, part of which goes to financing a higher level of local spending (due to higher spending

\footnotetext{
${ }^{22}$ A secondary effect of a change in $f$ operates through the transfer function $M(b) . b / f$ in the transfer function captures a local government's solvency or financial strength and hence its ability to make debt repayment. The modified local government's Euler equation (Equation 8) with $M(b)$ is $u_{g}=\beta R\left(b^{\prime}\right)\left(1-\tau^{\prime} \epsilon / f\right) u_{g}^{\prime}$. Since $f$ appears multiplicatively with transfer rate, larger $f$ reduces the distortion created by a given transfer, and thus makes local debt more costly and moral hazard smaller. This secondary effect works in the same direction as the primary effect highlighted in the main text, and without this secondary effect, the effects of revenue decentralization still hold.

23 The Pareto optimal spending ratio depends only on $\theta$ (Equation 5), so a revenue decentralization (change in $f$ ) does not change the Pareto optimal spending ratio.
} 
responsibility $1-\theta$ ), and the rest is used for larger debt interest payments. Spending by central government falls because of lower share of spending responsibility and tighter budget constraints as a result of higher transfers.

The comparative static exercise here should not be interpreted as an argument against spending decentralization. The point we are making is that spending decentralization should go hand-inhand with revenue decentralization. The model also ignores the potential efficiency gain of spending decentralization due to local government's better knowledge about local needs.

Figure 10: Debt-neutral revenue-spending decentralization

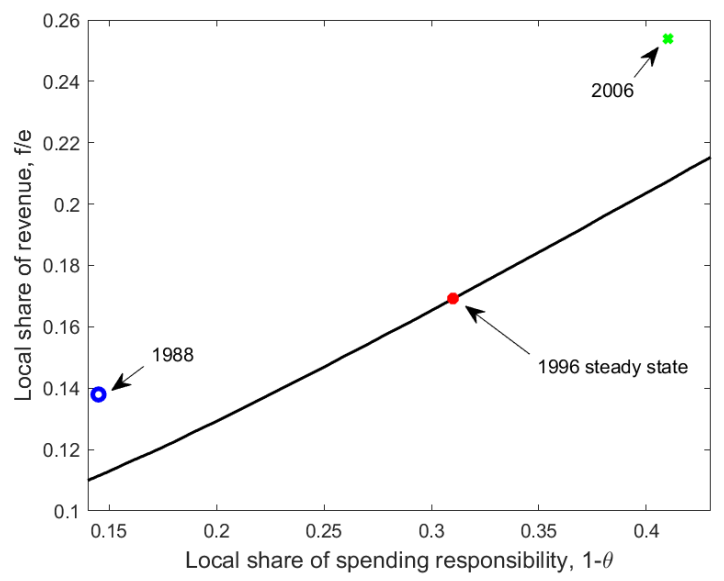

Note: All parameters except for spending responsibility $\theta$ and local revenue $f$ are held at calibrated 1996 values. Solid black line plots steady states with the same general government debt level as 1996. Red dot marks the 1996 steady state. Blue circle and green cross mark the 1988 and 2006 economies, respectively. A higher local share of spending responsibility $(1-\theta)$ corresponds to a spending decentralization. A higher local revenue $(f)$ holding total revenue $(e)$ unchanged corresponds to a revenue decentralization.

Balanced fiscal decentralization Spending decentralization alone raises debt levels, so how much revenue decentralization is needed to make a spending decentralization debt-neutral? Figure 10 plots the relationship between balanced revenue and spending decentralizations such that general government debt level is the same as in 1996 (red dot). ${ }^{24}$ The upward sloping line indicates a spending decentralization requires a proportionate increase in the share of local government revenue for the reform to be debt neutral or balanced.

Economies above (below) the line have lower (higher) levels of general government debt than 1996, because they have higher (lower) levels of local revenue for given levels of local spending share to keep general government debt level unchanged. For example, both 1988 and 2006 economies are above the line, and both have lower debt levels than 1996. During 1988-1996 the revenue decentralization lags behind spending decentralization, so debt levels increased in 1996 compared to 1988. Similarly,

\footnotetext{
24 Starting from the 1996 economy (red dot), a spending decentralization is represented by an increase in $1-\theta$ (move to the right on the horizontal axis), and a revenue decentralization is captured by a rise in $f$ holding total revenue $e$ unchanged (move upward along the vertical axis).
} 
Table 4: Counterfactual Experiment

Effects of fiscal decentralization on debt levels

\begin{tabular}{lccc}
\hline \hline \multirow{2}{*}{ Moment } & \multicolumn{3}{c}{ 1988-1996 } \\
\cline { 2 - 4 } & Model 1988 & Model 1996 & Counterfactual 1996 \\
\hline Local government debt & 0.0623 & 0.1286 & 0.1254 \\
Central government debt & 0.3600 & 0.6090 & 0.4230 \\
General government debt & 0.4222 & 0.7376 & $0.5484(\mathbf{4 0 \%})$ \\
\hline & \multicolumn{3}{c}{ 1996-2006 } \\
\cline { 2 - 4 } & Model 1996 & Model 2006 & Counterfactual 2006 \\
\hline Local government debt & 0.1286 & 0.1242 & 0.1058 \\
Central government debt & 0.6090 & 0.3404 & 0.5796 \\
General government debt & 0.7376 & 0.4646 & $0.6854(\mathbf{1 9 \%})$ \\
\hline
\end{tabular}

Note: General government debt is the sum of local and central government debt. Counterfactual uses revenue $(e$ and $f$ ) and spending responsibility $(\theta)$ from end year and all other parameters kept at the beginning year. Number in parentheses calculate the percent change in general government debt between two years that is explained by the counterfactual.

during 1996-2006, revenue decentralization caught up with spending, so debt levels fell. In the next section, we investigate the quantitative importance of shifts in local revenue and spending shares on differences in debt levels during these two periods.

\subsection{Counterfactual experiments: Quantitative effects of fiscal decentralization}

In this section we perform counterfactual experiments to see how much of the changes in debt levels in Spain can be attributed to changes in local revenue and spending responsibility. We allow parameters $f, e$ and $\theta$ to change while keeping all other parameters constant. The counterfactual levels of debt tell us how well the changes in revenue and spending responsibility account for movements in general government debt levels during 1988-1996 and 1996-2006. ${ }^{25}$

Table 4 summarizes results from the counterfactual experiments. The upper panel presents results of the 1988-1996 period, and the lower panel reports results of the 1996-2006 period. The first two columns contain calibrated model moments identical to those in Table 3. The third column reports results from the counterfactual experiments, and the number in parentheses calculates the percentage change in debt levels explained by the counterfactual movements in revenue ( $e$ and $f)$ and spending responsibility $(\theta)$.

Overall, shifts in revenue and spending responsibility explain $40 \%$ of the changes in general government debt from 1988 to 1996 and $19 \%$ of those from 1996 to $2006 .^{26}$ The experiment overattributes changes in overall debt to changes in local debt, generating $95 \%$ of changes in local debt and only $25 \%$ of changes in central debt during 1988-1996. This is because the model mechanism relies on the effect of changing transfer rate on local debt decisions. In reality, changes in central

\footnotetext{
25 Online Appendix K reports additional counterfactual moments in spending, transfer and fiscal gap.

26 One reason that decentralization in the model has a smaller explanatory power during the second period was because of a law implemented in 2002 (the General Law of Budgetary Stability) which made it harder for Spain's regional governments to borrow. The goal was to strengthen Spain's commitment to the European Union by incorporating EU regulation requirements. This objective is outside the scope of this paper.
} 
debt are more likely driven by factors not included in the model.

\subsection{Infinite-horizon versus two-period models}

Online Appendix I includes a two-period model to illustrate the overborrowing mechanism. One key difference between a two-period model and the infinite-horizon dynamic model here is how the consideration of future policies affects current policy choices. In the typical two-period model of Appendix I, the local government borrows in the first period, and the central government makes transfers in the second period. There is no borrowing in the second period. Thus, unlike our infinite-horizon model, the central government does not consider the effect of transfer on future local government borrowing (because it is set to zero).

Is this difference quantitatively important? Unfortunately a direct comparison between a twoperiod model and the steady state of our baseline model would be difficult, because a two-period model may not have a comparable steady state by assumption. Instead, we compare the steady state of our equilibrium with a modified equilibrium where the central government takes the local government's borrowing as exogenously given. This way the central government does not think its transfer today can affect future local government borrowing, mimicking setup of the two-period model. In this modified equilibrium, the local government's problem is unchanged from before and is characterized by its Euler equation (8). The central government solves a modified problem:

$$
\begin{array}{ll}
\max _{d^{\prime}, c, \tau} & (1-\theta) u(g)+\theta v(c)+\beta V\left(b^{\prime}, d^{\prime}\right) \\
\text { s.t. } & c \leq e-f-\tau M(b)+\frac{d^{\prime}}{S\left(d^{\prime}\right)}-d \\
& g \leq f+\tau M(b)+\frac{b^{\prime}}{R\left(b^{\prime}\right)}-b \\
& b^{\prime}=\hat{h}(b, d)
\end{array}
$$

where $b^{\prime}=\hat{h}(b, d)$ is the local government's policy function that satisfies Equation (8).

Compared with the infinite-horizon Markov equilibrium of Section 3.4, the modified central government's problem does not include the local government's Euler equation as an implementability condition. Instead, the central government takes the local government's policy function $b^{\prime}=\hat{h}(\cdot)$ as exogenously given. In other words, even though the local government's borrowing choice $b^{\prime}$ is made in expectation of the future transfer policy, the central government does not internalize this effect. ${ }^{27}$

From the central government's problem above we can derive its policy rules $d^{\prime}=\hat{p}(b, d)$ and $\tau=\hat{\phi}(b, d)$, which are characterized by

$$
\begin{aligned}
\frac{u_{g}}{v_{c}} & =\frac{\theta}{1-\theta} \\
\beta \frac{v_{c}^{\prime}}{v_{c}} & =\frac{1}{S\left(d^{\prime}\right)}-\frac{d^{\prime} S_{d}\left(d^{\prime}\right)}{S\left(d^{\prime}\right)^{2}} .
\end{aligned}
$$

\footnotetext{
27 In a typical two-period model, by assumption local governments have zero debt outstanding by the end of the second period, which is equivalent to setting $h(b)=0$ in our modified problem. In this sense, our modified equilibrium is a generalization of the typical two-period model.
} 
Table 5: Steady State Comparison in 1996

Markov equilibrium vs. Modified equilibrium

\begin{tabular}{lcc}
\hline \hline Moment & $\begin{array}{c}\text { Infinite-horizon model } \\
\text { (Markov equilibrium) }\end{array}$ & $\begin{array}{c}\text { Two-period model } \\
\text { (Modified equilibrium) }\end{array}$ \\
\hline Local government debt, $b$ & 0.1286 & 0.1145 \\
Central government debt, $d$ & 0.6090 & 0.4998 \\
Transfer rate, $\tau(\%)$ & 6.47 & 4.96 \\
\hline
\end{tabular}

Note: Calibrated 1996 parameter values are used. The central government in the modified equilibrium takes local government policy as given, similar to a typical two-period model.

The equilibrium is then characterized by Equations (8), (20) and (21).

We calculate the steady state of this modified equilibrium, using the calibrated parameter values of 1996, and compare it to the infinite-horizon Markov equilibrium in Table 5. Notice that the steady state levels of public debt and transfer rate are substantially lower in the modified equilibrium than in the Markov equilibrium. This is because in the Markov equilibrium, central government policy is forward-looking. In particular, the central government takes into account the effect of a higher current transfer rate $(\tau)$ on future local government debt $\left(b^{\prime}\right)$ and transfer rate $\left(\tau^{\prime}\right)$, while the central government in the modified equilibrium takes both as exogenously given. Because a higher current transfer rate relaxes local government's budget constraint and reduces the need to carry debt (recall $d b^{\prime} / d \tau<0$ from Section 3.4), the Markov equilibrium transfer rate is higher. ${ }^{28}$

\section{Optimal Transfer Policy: A Normative Perspective}

In this section we ask the normative question of how to make transfer policy better. We first present steady state results comparing (a) Markov, (b) Ramsey and (c) Pareto optimal allocations implemented using a macroprudential debt tax. This comparison provides an immediate illustration of the theoretical discussions in Section 3. We then discuss the effects of fiscal decentralization in (b) and (c) economies: Fiscal decentralization has weaker effects on debt in Ramsey economy and no effects when debt tax is used to achieve Pareto optimal. Finally, we look at the transition paths from the Markov to the Ramsey and Pareto economies.

\subsection{Steady state comparisons}

Table 6 compares the Markov economy in 1996, the economy under the Ramsey policy, and the Pareto optimal economy. Because the Ramsey central government has commitment to future policies, the central government internalizes the moral hazard cost of a high transfer rate. As a result, the Ramsey transfer rate at steady state is much smaller, and debt levels are also lower compared to the Markov economy. Pareto optimal allocation (second last column of Table 6) has the lowest local debt level,

\footnotetext{
28 It may seem counterintuitive that a forward-looking Markov policy that tries to reduce local debt ends up with higher debt levels than the static policy in the modified equilibrium. This is because the Markov policy is only forwardlooking and not backward-looking - it ignores the moral hazard effect of a higher transfer rate on the local debt level of the previous period. The Ramsey policy is both forward- and backward-looking and has lower transfer and debt levels.
} 
Table 6: Steady State Comparison

Markov vs. Ramsey vs. Pareto Optimal Economy in 1996

\begin{tabular}{lcccc}
\hline \hline Moment & Markov & Ramsey & Pareto Optimal & $\begin{array}{c}\text { Ramsey with } \\
\text { debt tax }\end{array}$ \\
\hline Local government debt, $b$ & 0.1286 & 0.1091 & 0.0338 & 0.0338 \\
Central government debt, $d$ & 0.6090 & 0.4998 & 0.4998 & 0.4998 \\
Transfer rate, $\tau(\%)$ & 6.47 & 4.39 & - & $\mathbf{4 . 6 8}$ \\
Central-local spending ratio, $c / g$ & 1.7856 & 2.4019 & 2.2258 & 2.2258 \\
Local government spending, $g$ & 0.1205 & 0.1007 & 0.1074 & 0.1074 \\
Central government spending, $c$ & 0.2151 & 0.2418 & 0.2390 & 0.2390 \\
Central-local transfer & 0.0648 & 0.0439 & 0.0467 & 0.0467 \\
Consumption equivalent welfare change & -3.75 & -1.21 & - & - \\
relative to P.O(\%) & - & - & - & $\mathbf{0 . 2 2}$ \\
Ex-ante debt tax rate, $\hat{\tau}(\%)$ & & & - & -
\end{tabular}

Note: Calibrated 1996 parameters are used. Consumption equivalent welfare change calculates the percentage change in both central and local spending to be equivalent to the Pareto optimal economy.

because there is no distortion of local government's borrowing incentive.

Both the Markov and Ramsey central governments are constrained to use transfer policy for resource sharing between local and central governments, but neither can achieve perfect resource sharing. Compared to the Pareto optimal, the central-local spending ratio is lower in the Markov equilibrium and higher under the Ramsey policy, consistent with Propositions 2 and 4.

As we demonstrate in Section 3.4.4, using an ex-ante debt tax together with ex-post transfers, a Ramsey government can reach Pareto optimal. The last column reports the allocations of the Ramsey economy with ex-ante debt tax. Using the formula in Proposition 3, we find that with a $0.22 \%$ ex-ante tax on local government debt, the Ramsey allocation in 1996 is Pareto optimal, which has $27 \%$ lower general government debt than the Markov equilibrium. Notice that the transfer rate $\tau$ in the Ramsey economy with ex-ante debt tax is slightly higher than the economy without (4.68\% vs. $4.39 \%$ ). This is because without ex-ante debt tax, the Ramsey government chooses a lower transfer rate out of concerns about the moral hazard effect of ex-post transfer. With the ex-ante debt taxes, the moral hazard effect is perfectly offset, allowing the central government to use ex-post transfers to achieve perfect resource sharing.

For both the Markov and Ramsey economies, we calculate the consumption equivalent welfare change, which is the percentage change in both central and local spending for the economy to be equivalent to the Pareto optimal economy. Not surprisingly, the Ramsey policy leads to higher welfare compared to the Markov equilibrium policy. Spending has to increase by $3.75 \%$ in the Markov economy to achieve the same welfare as that under the Pareto optimal allocation, but it only needs to increase by $1.21 \%$ in the Ramsey economy. ${ }^{29}$

\footnotetext{
29 Spending has to increase by $2.51 \%$ in the Markov economy to reach the same welfare as the Ramsey economy.
} 


\subsection{Fiscal decentralization in Ramsey allocations with and without ex-ante debt tax}

Figure 11 depicts the effects of a revenue (upper panels) and spending (lower panels) decentralization under the Ramsey policy. Similar to the Markov economy (Figure 9): A revenue decentralization leads to a lower transfer rate, a lower local government debt and a smaller vertical fiscal imbalance; a spending decentralization leads to a higher transfer rate, a higher local government debt, a higher local and a lower central government spending, and a larger vertical fiscal imbalance.

Ramsey without ex-ante debt tax. Two differences from the Markov economy are worth highlighting. First, a revenue decentralization (upper panels) reduces central government spending relative to local government spending, opposite of the effects in the Markov equilibrium. This is because an increase in the local share of revenue lowers local government's transfer dependence, reduces moral hazard from transfer, and moves allocations closer to Pareto optimal, which has lower central-local spending ratio than the Ramsey economy (Proposition 4). Second, consistent with Proposition 5, a fiscal decentralization does not affect central government debt, ${ }^{30}$ whereas an increase in local revenue lowers and an increase in local spending responsibility raises central government debt substantially in the Markov equilibrium.

Ramsey with ex-ante debt tax. Next, we look at the effects of fiscal decentralization in the equilibrium with ex ante debt tax in Figure 12. Recall that with the macroprudential debt tax, allocations achieve Pareto optimal (Proposition 3). Two properties are worth highlighting. First, notice that both local and central government debt levels are invariant to changes in local share of revenue or spending responsibility. This is achieved by the ex-ante debt tax, which always moves in tandem with transfer rate to offset the moral hazard effect of ex-post transfers. This invariance feature is a nice property, as it allows the central government to implement fiscal decentralization without changes to general government debt levels. Second, governmental spendings ( $g$ and $c$ ) are invariant to changes in local revenue (upper panels), as an increase in local revenue is entirely offset by a lower transfer and thus leaving local resources unchanged. ${ }^{31}$

\subsection{Transitions}

In addition to steady state, we look at transition paths from the Markov equilibrium economy. Figure 13 plots the transition paths in two scenario. In the first scenario (blue line), we assume the Markov government acquires commitment devices to implement the Ramsey policy. In the second scenario (orange), we allow the Markov government to use prudential debt tax in addition to ex-post transfer. In the latter case, we do not need to impose commitment, because the allocation is time-consistent.

Over the long-run, economies converge to their respective steady states, which are reported in

\footnotetext{
${ }^{30}$ Intuitively, because the Ramsey government takes into account the ex ante effect of transfer on local borrowing, the central government adjusts transfers in response to changing local fiscal gap just enough to offset the change in central resources, thus leaving central government debt level unchanged.

31 Because there is no moral hazard in this economy, any changes in vertical fiscal imbalance here simply reflect a change in local government revenue-spending ratio. More specifically. the last panel of Figure 12 shows a declining vertical fiscal imbalance as the share of local government spending responsibility increases. This is because while local revenue $f$ does not change, local spending $g$ increases as $1-\theta$ rises; and local debt $b$ does not vary so the interest component also does not change.
} 
Figure 11: Effects of fiscal decentralization on Ramsey steady state Effect of a change in local revenue $f$ on Ramsey steady state
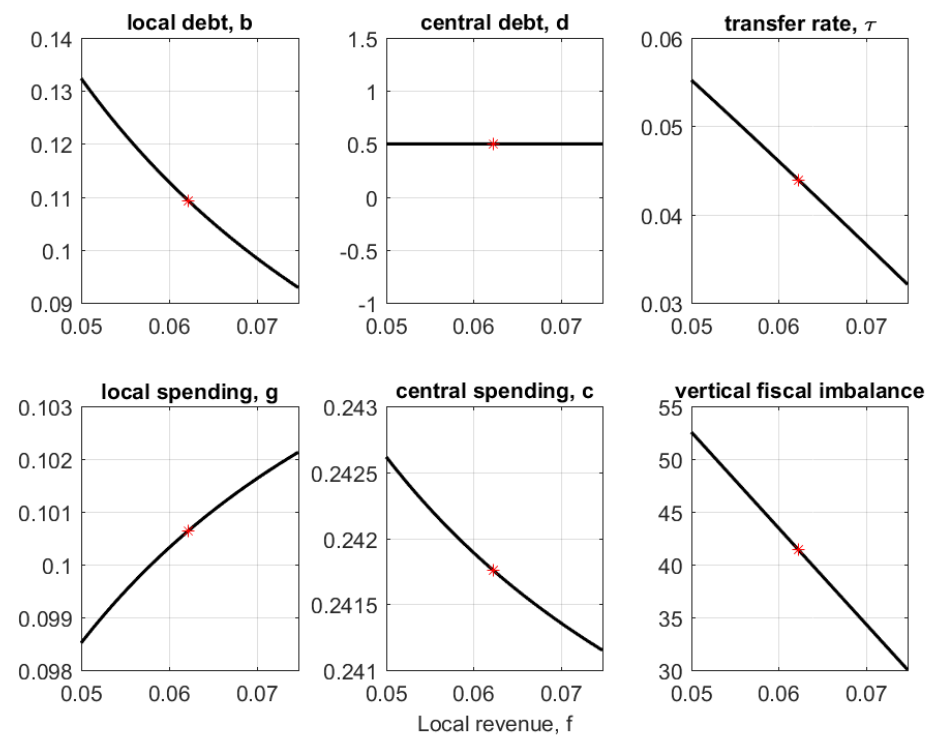

Note: All parameters except for local revenue $f$ are held at calibrated 1996 values. Solid black line plots steady states for different $f$ values. Red star marks the 1996 steady state. A higher local revenue $f$ corresponds to a revenue decentralization.

Effect of a change in spending responsibility $\theta$ on Ramsey steady state
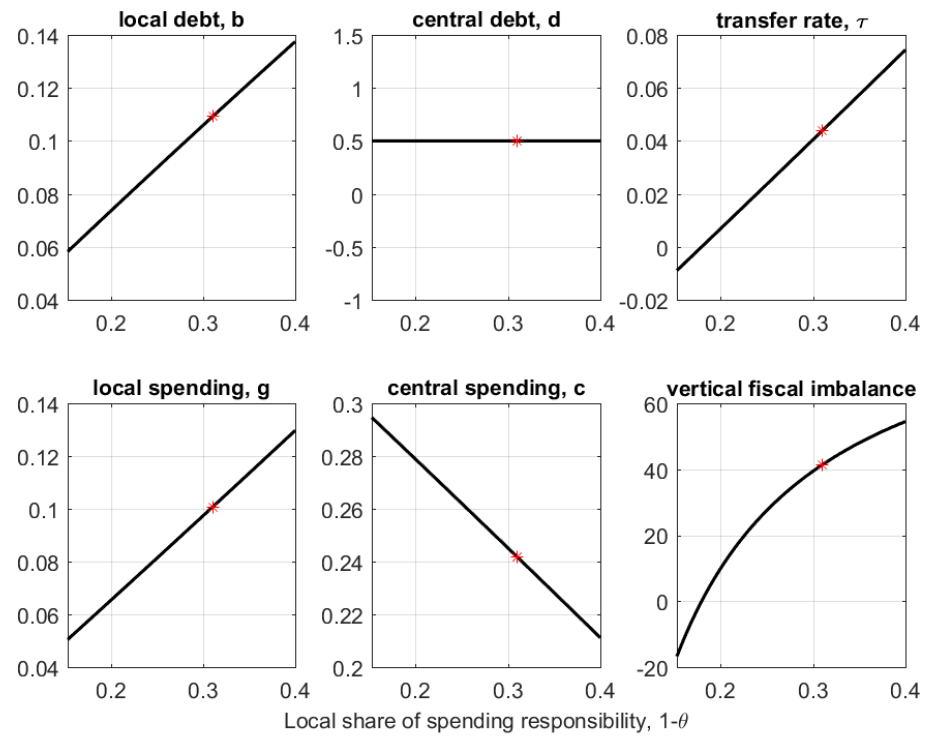

Note: All parameters except for spending responsibility $\theta$ are held at calibrated 1996 values. Black line plots steady states for different $\theta$ values. Red star marks the 1996 steady state. A higher local share of spending responsibility $1-\theta$ corresponds to a spending decentralization. 
Figure 12: Effects of fiscal decentralization on equilibrium steady state with ex ante debt tax Effect of a change in local revenue $f$ on equilibrium steady state with ex ante debt tax
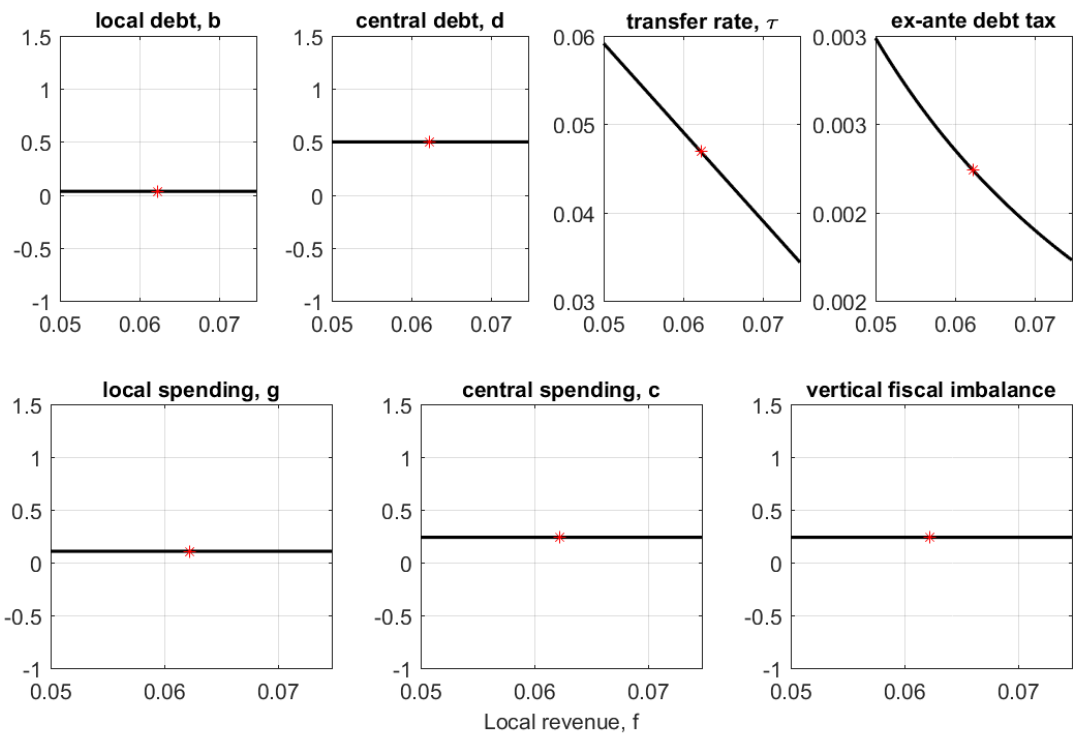

Note: All parameters except for local revenue $f$ are held at calibrated 1996 values. Solid black line plots steady states for different $f$ values. Red star marks the 1996 steady state. A higher local revenue $f$ corresponds to a revenue decentralization.

Effect of a change in spending responsibility $\theta$ on equilibrium steady state with ex ante debt tax
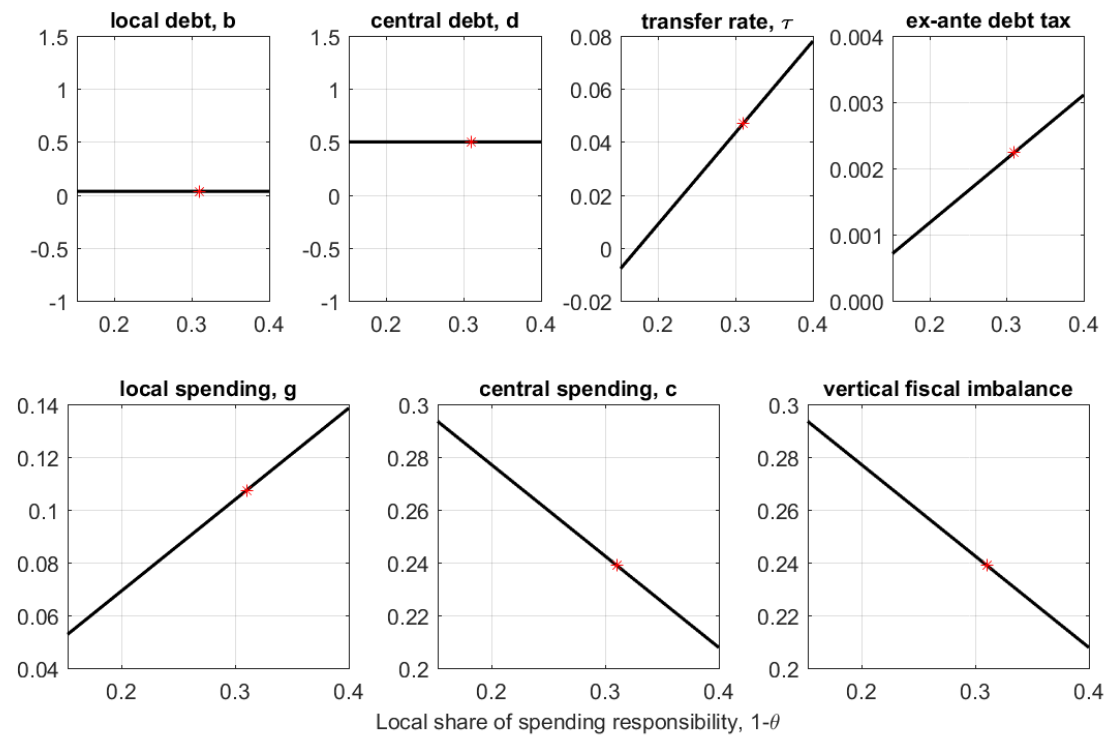

Note: All parameters except for spending responsibility $\theta$ are held at calibrated 1996 values. Black line plots steady states for different $\theta$ values. Red star marks the 1996 steady state. A higher local share of spending responsibility $1-\theta$ corresponds to a spending decentralization. 
Figure 13: Transitions from Markov equilibrium

to Ramsey economy and to equilibrium with ex ante debt tax
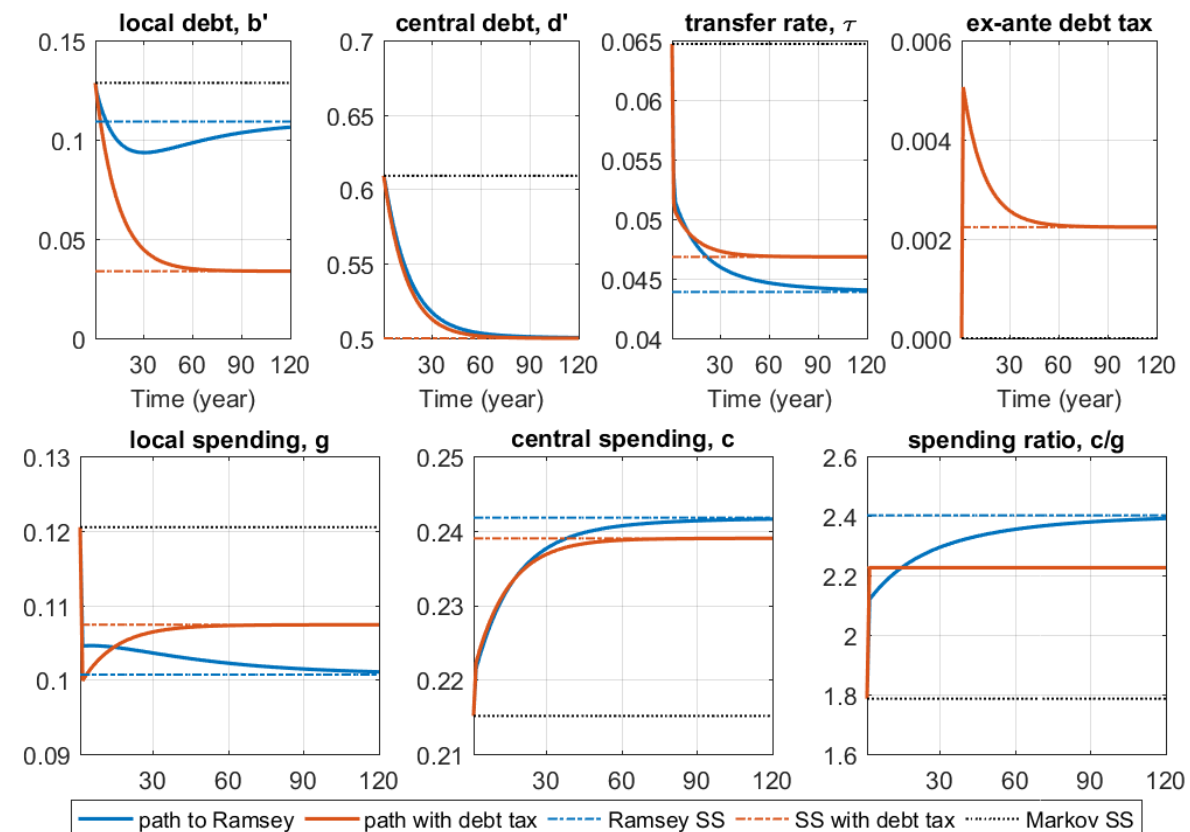

Note: All parameters are held constant at calibrated 1996 values. Dotted black line marks the steady state Markov economy in 1996. Solid blue line plots the transition path to the Ramsey economy, with dashed blue line marking the steady state Ramsey economy. Solid orange line plots the transition path to the equilibrium with ex ante debt tax, and dashed orange line marks the steady state of this economy.

Table 6. The two transition paths are broadly similar. In the first period, as the central government internalizes the moral hazard effect of transfers, transfer rates are reduced substantially. Lower transfer rates reduce the local government's overborrowing incentives, so local debt levels fall. Smaller total transfers reduce the central government's need to borrow, and as a result, central government debt also decreases. Lower central-local transfers reduce local spending and raise central spending, and as a result, central-local spending ratio rises.

The ex-ante debt tax allows the central government to offset the overborrowing incentives of transfers, so that transfers can be used to achieve perfect resource sharing. This effect shows up on the transition path (orange line): With the ex-ante debt tax, central-local spending ratio reaches steady state right away, whereas without debt tax it takes a long time. This ex-ante debt tax starts at a high level in the first period to undo the initial high overborrowing incentives. Because of the high tax level, the initial local government spending in the second scenario is lower than its steady state level. Over time as the overborrowing incentive gradually falls, so does the ex-ante debt tax, and local spending slowly rises to the steady state level.

It should be noted that we assume all structural parameters of the economy remain unchanged during the transitions. Although some underlying parameters in the economy, for example, elasticity of the interest rate schedule, will most likely change over decades, the assumption is necessary to 
Table 7: Alternative Values of Local Debt Interest Elasticity

\begin{tabular}{lcccccccc}
\hline \hline & \multicolumn{2}{c}{1988} & & \multicolumn{2}{c}{1996} & & \multicolumn{2}{c}{2006} \\
\cline { 2 - 3 }$\psi_{b}=$ & 0.03 & 0.05 & & 0.03 & 0.05 & & 0.03 & 0.05 \\
\hline Local government debt & 0.0623 & 0.0294 & & 0.1286 & 0.1041 & & 0.1242 & 0.0726 \\
Central government debt & 0.3600 & 0.3282 & & 0.6090 & 0.6220 & & 0.3404 & 0.3222 \\
Central/Local debt & $\mathbf{5 . 7 8}$ & $\mathbf{1 1 . 1 8}$ & & $\mathbf{4 . 7 4}$ & $\mathbf{5 . 9 8}$ & & $\mathbf{2 . 7 4}$ & $\mathbf{4 . 4 4}$ \\
\hline
\end{tabular}

Note: All other parameters are the same as in Table 2.

isolate the effect of adopting a different set of policies.

\section{Robustness}

\subsection{Alternative local debt interest elasticity}

In this section we perform robustness check on the elasticity of local government debt interest rates with respect to its debt position, $\psi_{b}$. In the benchmark we set it equal to the elasticity of central government debt interest rate schedule $\left(\psi_{b}=\psi_{d}\right)$. It is reasonable to think that local government may face a more elastic interest schedule. For example, local governments may have greater expected default risk and so a rising local debt level may prompt a larger increase in interest rates than a rising central government debt.

As an alternative specification we increase the elasticity for local debt interest rate to 0.05. First, we show the direct effect of having a more elastic local debt interest rate schedule. Table 7 compares the equilibrium steady state debt levels in the benchmark calibration $\left(\psi_{b}=0.03\right)$ to the equilibrium with higher $\psi_{b}$. We keep all other parameters unchanged to isolate the direct effect of a higher elasticity. The most obvious effect is debt shifting from local debt to central debt as reflected by the larger central-local debt ratio when $\psi_{b}$ increases. As local debt interest rate becomes more sensitive to debt increases, the local borrowing cost externality is also higher. Realizing this, the central government in equilibrium chooses a lower local debt.

Next, we use the higher local debt interest rate elasticity to re-calibrate the model and conduct counterfactual exercises similar to Section 4.5. Table 8 summarizes the results. The results are very similar to the benchmark. Fiscal decentralization explains $30 \%$ and $15 \%$ of general government debt level changes during 1988-1996 and 1996-2006, respectively. In Online Appendix L, we also plot the effects of a change in either local revenue $f$ or spending responsibility $\theta$ on debt, spending, transfer, and vertical fiscal imbalance in the Markov equilibrium under high local debt interest elasticity. Qualitatively, the effects are the same as the benchmark calibration.

\subsection{Alternative assumption on local interest rate schedule}

In the benchmark model, we assume local government debt interest rate is a function of aggregate local government debt, and each infinitesimal local government takes the interest rate as given. The underlying assumption is that foreign investors make their lending decisions based on the country's 
Table 8: Counterfactual Experiments Using Higher Local Debt Interest Elasticity

\begin{tabular}{|c|c|c|c|c|c|}
\hline \multirow[t]{2}{*}{ Parameter } & \multicolumn{3}{|c|}{ Calibrated Values } & & \\
\hline & 1988 & 1996 & 2006 & & \\
\hline $\bar{B}$ & 0.028 & 0.09 & 0.019 & & \\
\hline $\bar{D}$ & 0.5 & 0.86 & 0.28 & & \\
\hline$\theta$ & 0.86 & 0.7 & 0.595 & & \\
\hline$\epsilon$ & 0.00323 & 0.00178 & 0.00629 & & \\
\hline \multirow[t]{2}{*}{ Moment } & \multicolumn{3}{|c|}{ Calibrated Model } & \multicolumn{2}{|c|}{ Counterfactuals } \\
\hline & 1988 & 1996 & 2006 & $1988-1996$ & 1996-2006 \\
\hline Local government debt & 0.0622 & 0.1284 & 0.1214 & 0.1012 & 0.1146 \\
\hline Central government debt & 0.3620 & 0.6129 & 0.3382 & 0.4177 & 0.5859 \\
\hline General government debt & 0.4242 & 0.7413 & 0.4596 & $0.5188(\mathbf{3 0 \%})$ & $0.7006(\mathbf{1 5 \%})$ \\
\hline
\end{tabular}

Note: General government debt is the sum of local and central government debt. Using $\psi_{b}=0.05$ and recalibrating for each year. Counterfactual uses revenue $(e$ and $f)$ and spending responsibility $(\theta)$ from end year and all other parameters kept at beginning year. Numbers in parentheses calculate the percent change in general government debt between two years that is explained by the counterfactual.

macro indicators rather than each region's individual fiscal condition. ${ }^{32}$ As such, local governments do not internalize the impact of their borrowing on interest rates. The central government, in contrast, internalizes the pecuniary externality of debt on interest rates: an additional unit of local (central) borrowing raises the interest rate of local (central) government debt.

In this section, we consider an alternative local government interest rate schedule, where the borrowing rate depends on each region's accumulated debt. In this case, there is symmetry between central and local governments, in that both internalize the pecuniary costs of local borrowing. ${ }^{33}$

Social planner's problem is the same as defined and characterized in Section 3.2.

Local government's problem is different, because each local government internalizes the pecuniary (through interest rate) cost of higher borrowing:

$$
\begin{aligned}
W(b)= & \max _{b^{\prime}, g}(1-\theta) u(g)+\theta v(c)+\beta W\left(b^{\prime}\right) \\
\text { s.t. } & g+b \leq f+\frac{b^{\prime}}{R\left(b^{\prime}\right)}+\tau b
\end{aligned}
$$

where the interest rate schedule $R(\cdot)$ is a function of the region's public debt $b$ (instead of aggregate local debt $B$ ). The representative local government's optimal choice of local public debt is characterized by its Euler equation,

$$
u_{g} \underbrace{\left[1-\frac{b^{\prime} R_{b}^{\prime}}{R\left(b^{\prime}\right)}\right]}_{\text {pecuniary cost }}=\beta R\left(b^{\prime}\right)\left(1-\tau^{\prime}\right) u_{g}^{\prime}
$$

When $\tau^{\prime}=0$, the local government's Euler equation is identical to social planner's optimality con-

\footnotetext{
32 This is analogous to the scenario of aggregate collateral constraint in Uribe (2006), where individuals do not internalize the aggregate borrowing constraint.

33 In Online Appendix J we consider the case where neither local nor central governments internalize the pecuniary costs. In that case, there is also symmetry between central and local and we show the results still hold.
} 
dition with respect to $b^{\prime}$ (Equation 6). In other words, the only source of distortion here is from transfer; whereas with the baseline interest rate schedule $R(B)$, pecuniary cost externality creates an additional incentive for local governments to overborrow.

Central government's problem in Markov equilibrium is also different. More specifically, the derivative of local government's Euler equation with respect to $b^{\prime}$ is

$$
\begin{aligned}
\eta_{b^{\prime}}= & u_{g g} G_{b^{\prime}}\left[1-\frac{b^{\prime} R_{b}^{\prime}}{R\left(b^{\prime}\right)}\right]-u_{g}\left[\frac{R_{b}^{\prime}+b^{\prime} R_{b b}^{\prime}}{R\left(b^{\prime}\right)}-\frac{b^{\prime} R_{b}^{\prime 2}}{R\left(b^{\prime}\right)^{2}}\right]+\ldots \\
& -\beta R_{b}\left(b^{\prime}\right)\left(1-\phi^{\prime}\right) u_{g}^{\prime}+\beta R\left(b^{\prime}\right) \phi_{b}^{\prime} u_{g}^{\prime}-\beta R\left(b^{\prime}\right)\left(1-\phi^{\prime}\right) u_{g g}^{\prime}\left[G_{b}^{\prime}+G_{\tau}^{\prime} \phi_{b}^{\prime}+G_{b^{\prime}}^{\prime} h_{b}^{\prime}\right]
\end{aligned}
$$

where the highlighted parts are absent from the baseline model with $R(B)$. These terms are present here because the local government internalizes the pecuniary cost of borrowing, and the central government takes into account this fact when choosing policies.

The GEEs are still the same as before, except for this $\eta_{b^{\prime}}$ term whenever it shows up. Similar to the baseline, here the inter-temporal term through $b^{\prime}$ can again be written as

$$
u_{g} G_{b^{\prime}}+\beta\left(u_{g}^{\prime} G_{b}^{\prime}+\frac{\theta}{1-\theta} v_{c}^{\prime} C_{b}^{\prime}\right) \equiv \underbrace{\left[\frac{1}{R^{\prime}}-\frac{b^{\prime} R_{b}^{\prime}}{R^{\prime 2}}\right] u_{g}-\beta u_{g}^{\prime}\left(1-\tau^{\prime}\right)}_{\text {local Euler equation }} \underbrace{-\frac{\theta}{1-\theta} \beta v_{c}^{\prime} \tau^{\prime}}_{\text {transfers tomorrow }}
$$

Because the pecuniary term shows up inside the local government's Euler equation, the only extra cost for the central government now is its internalized cost of future transfers.

The Ex-ante tax on local government borrowing that restores optimality (Section 3.5) will be characterized by

$$
1=\frac{1-\Omega\left(b_{t+1}^{*}, b_{t+2}^{*}, g_{t+1}^{*}, \hat{\tau}_{t+1}\right)}{1-\hat{\tau}_{t}}
$$

where

$$
\tau_{t}^{R}=\Omega\left(b_{t}^{*}, b_{t+1}^{*}, g_{t}^{*}, \hat{\tau}_{t}\right) \equiv \frac{g_{t}^{*}+b_{t}^{*}-\left(1-\hat{\tau}_{t}\right) b_{t+1}^{*} / R\left(b_{t+1}^{*}\right)-f}{b_{t}^{*}}
$$

Notice there is no $b^{\prime} R_{b}^{\prime} / R^{\prime}$ term on the left hand-size of (24) since there is no overborrowing associated with pecuniary cost externality here. In other words, $\hat{\tau}$ only needs to offset overborrowing associated with distortionary transfers.

We recalibrate the model and show that (1) the model still generates sizable overborrowing and over-spending by local government, and (2) fiscal decentralization still changes debt level and the effects are quantitatively similar to the baseline. The quantitative results, summarized in Table 9, are similar to benchmark results of Section 4.5. Fiscal decentralization explains $26 \%$ and $34 \%$ of general government debt changes during the 1988-1996 and 1996-2006 periods, respectively. Online Appendix L includes plots of the effects of a revenue decentralization (change in $f$ ) and a spending decentralization (change in $\theta$ ) in this setup. The last column of Table 9 reports the debt levels of the social planner's allocation (Pareto optimal) in 1996 under this alternative assumption. Comparing between the social planner's allocation and Markov equilibrium shows that there is still overborrowing even when local government also internalizes pecuniary cost of borrowing. Furthermore, in this 
case the local government also over-spends: the central/local spending ratio is 1.80 in the Markov equilibrium compared with 2.47 in the social planner's allocation.

Table 9: Counterfactual Experiments Under Alternative Interest Rate Assumption: Local government interest rate depends on its own debt (instead of aggregate local government debt)

\begin{tabular}{|c|c|c|c|c|c|c|}
\hline \multirow[t]{2}{*}{ Parameter } & \multicolumn{3}{|c|}{ Calibrated Values } & & & \\
\hline & 1988 & 1996 & 2006 & & & \\
\hline $\bar{B}$ & 0.023 & 0.015 & 0.001 & & & \\
\hline $\bar{D}$ & 0.489 & 0.8 & 0.369 & & & \\
\hline$\theta$ & 0.828 & 0.692951 & 0.560 & & & \\
\hline$\epsilon$ & 0.0059 & 0.0074 & 0.0093 & & & \\
\hline \multirow[t]{2}{*}{ Moment } & \multicolumn{3}{|c|}{ Calibrated Model } & \multicolumn{2}{|c|}{ Counterfactuals } & Social planner \\
\hline & 1988 & 1996 & 2006 & $1988-1996$ & $1996-2006$ & 1996 \\
\hline Local government debt & 0.0618 & 0.1297 & 0.1215 & 0.1084 & 0.0983 & 0.0074 \\
\hline Central government debt & 0.3394 & 0.6123 & 0.3381 & 0.3822 & 0.5480 & 0.4357 \\
\hline General government debt & 0.4012 & 0.7420 & 0.4596 & $0.4907(26 \%)$ & $0.6463(34 \%)$ & 0.4421 \\
\hline
\end{tabular}

Note: General government debt is the sum of local and central government debt. Using $R(b)$ for local government interest rate schedule and recalibrating each year. Counterfactual uses revenue $(e$ and $f)$ and spending responsibility $(\theta)$ from end year and all other parameters kept at beginning year. Numbers in parentheses calculate the percent change in general government debt between two years that is explained by counterfactual.

\section{CONCLUSiON}

This paper develops an infinite horizon model to quantitatively study the relationship between fiscal decentralization and government borrowing when the central government faces a soft budget constraint problem. When revenue decentralization lags behind spending decentralization, local government faces a widening fiscal gap. Without commitment to future policies, the central government has a stronger incentive to make transfers to local governments to help make up for the widening fiscal gap. If transfers are at least partially dependent on local government debt, then higher transfers create larger ex ante incentives for local governments to overborrow, and local government debt rises. At the same time, higher transfers tighten central government's budget and increases its need to borrow. As a result, central government debt level also increases. Calibrating the model to two episodes of fiscal decentralization in Spain during 1988 to 2006, we find that decentralizations account for $19 \%$ to $40 \%$ of the general government debt changes.

We show that without commitment to future policies, the central government over-transfers, which leads to over-spending by local governments compared to Pareto optimal. With commitment, the Ramsey optimal policy internalizes the ex ante overborrowing incentive, which lowers central government's transfer incentive, but leads to under-spending by local governments. For policy makers, achieving Pareto optimal is desirable: Pareto optimal debt level is $27 \%$ lower and welfare is $3.75 \%$ higher in 1996 than the equilibrium without commitment. We show that the central government can use a macroprudential tax on local government borrowing in addition to transfers to implement Pareto optimal. The policies are time consistent and hence implementable by policy makers with- 
out commitment. Furthermore, using the prudential debt tax to offset overborrowing incentives, the central government can avoid deterioration in fiscal performance during fiscal decentralization reforms.

The results in this paper should not be understood as criticisms against fiscal decentralization, nor do we argue that decentralization necessarily worsens aggregate fiscal performance. In fact, we demonstrate how to construct debt-neutral or balanced fiscal decentralization, whereby local government's increased spending responsibilities are matched with increasing revenue streams so that the reform does not lead to widening local fiscal gap.

\section{REFERENCES}

Aguiar, M., M. Amador, E. Farhi, and G. Gopinath (2015): "Coordination and Crisis in Monetary Unions," Quarterly Journal of Economics, 130, 1727-1779.

Aiyagari, S. R., A. Marcet, T. J. Sargent, and J. Seppälä (2002): "Optimal Taxation without State Contingent Debt," Journal of Political Economy, 110, 1220-1254.

Akai, N. And M. SAto (2011): "A Simple Dynamic Decentralized Leadership Model with Private Savings and Local Borrowing Regulation," Journal of Urban Economics, 70, 15-24.

Aldasoro, I. And M. Seiferling (2014): "Vertical Fiscal Imbalances and the Accumulation of Government Debt," IMF Working Paper.

Alesina, A. And G. Tabellini (1990): "A Positive Theory of Fiscal Deficits and Government Debt," Review of Economic Studies, 57, 403-414.

Bachmann, B. And J. Bai (2013): "Public Consumption Over the Business Cycle," Quantitative Economics, $4,417-451$.

Battaglini, M. And S. Coate (2008): "A Dynamic Theory of Public Spending, Taxation, and Debt," American Economic Review, 98, 201-236.

Beetsma, R. And H. Uhlig (1999): "An Analysis of the Stability and Growth Pact," The Economic Journal, $109,546-571$.

Besfamille, M. And B. Lockwood (2008): "Bailouts in Federations: Is a Hard Budget Constraint Always Best?" International Economic Review, 49, 577-593.

Bianchi, J. (2016): "Efficient Bailouts," American Economic Review, 106, 3607-3659.

Boadway, R. And J.-F. Tremblay (2006): "A Theory of Fiscal Imbalance," Public Finance Analysis, 62, $1-27$.

Breullle, M.-L., T. Madies, and E. Taugourdeau (2006): "Does Tax Competition Soften Regional Budget Constraint?" Economics Letters, 90, 230-236.

Breuille, M.-L. And M. Vigneault (2010): "Overlapping Soft Budget Constraints," Journal of Urban Economics, 67, 259-269.

Chari, V. V. And P. J. Kehoe (2007): "On the Need for Fiscal Constraints in a Monetary Union," Journal of Monetary Economics, 54, 2399-2408.

(2016): "Bailouts, Time Inconsistency, and Optimal Regulation: A Macroecnomic View," American Economic Review, 106, 2458-2493. 
Cooper, R. And K. Hubert (2004): "Overturning Mundell: Fiscal Policy in a Monetary Union," Review of Economic Studies, 71, 371-396.

Cooper, R., H. Kempf, And D. Peled (2008): “Is It Is or Is It Ain’t My Obligation? Regional Debt in a Fiscal Federation," International Economic Review, 49, 1469-1504.

Dovis, A. And R. Kirpalani (2017): "Fiscal Rules, Bailous, and Reputation in Federal Governments," Working Paper.

Eyraud, L. And L. Lusinyan (2013): "Vertical Fiscal Imbalances and Fiscal Performance in Advanced Economies," Journal of Monetary Economics, 60, 571-587.

Farhi, E. And J. Tirole (2012): "Collective Moral Hazard, Maturity Mismatch, and Systemic Bailouts," American Economic Review, 102, 60-93.

Garcia-MilÀ, T. And T. J. McGuire (2002): "Fiscal Decentralization in Spain: An Asymmetric Transition to Democracy," Working paper.

Goodspeed, T. J. (2016): "Bailouts and Soft Budget Constraitns in Decentralized Government: A Synthesis and Surbey of an Alternative View of Intergovernmental Grant Policy," Working Paper.

Gordon, G. And P. Guerron-Quintana (2018): "On Regional Borrowing, Default, and Migration," Working paper.

Gourinchas, P. O., P. Martin, and T. Messer (2018): "The Economics of Sovereign Debt, Bailouts and the Eurozone Crisis," Working Paper.

Grande, G., S. Masciantonio, and A. Tiseno (2013): "The Elasticity of Demand for Sovereign Debt. Evidence from OECD Countries (1995-2011)," Working Paper.

IMF (2005): "Fiscal Discipline at Lower Levels of Government: The Case of Spain," International Monetary Fund Country Report no. 05/57. Washington.

Inman, R. P. (2003): "Transfers and Bailouts: Enforcing Local Fiscal Discipline with Lessons from U.S. Federalism," in Fisal Decentralization and the Challenge of Hard Budget Constraints, ed. by J. A. Rodden, G. S. Eskeland, and J. Litvack, Cambridge: The MIT Press, 35-84.

Judd, K. (2004): "Existence, Uniqueness, and Computational Theory for Time Consistent Equilibria: A Hyperbolic Discounting Example," Working paper.

Karantounias, A. G. (2017): "Optimal Time-Consistent Taxation with Default," Atlanta Fed Working Paper 2017-12.

Klein, P., P. Krusell, and J.-V. Ríos-Rull (2008): "Time-Consistent Public Policy," Review of Economic Studies, 75, 789-808.

Klein, P. And J.-V. Ríos-Rull (2003): "Time-Consistent Optimal Fiscal Policy," International Economic Review, 44, 1217-1246.

Kornai, J. (1986): "The Soft Budget Constraint," International Review of Social Sciences, 39, 3-30.

Kornai, J., E. Maskin, And G. Roland (2003): "Understanding the Soft Budget Constraint," Journal of Economic Literature, 41, 1095-1136.

Kothenburger, M. (2007): "Ex-post Redistribution in a Federation: Implications for Corrective Policy," Journal of Public Economics, 81, 481-496.

Lucas, R. E. And N. L. Stokey (1983): "Optimal Fiscal and Monetary Policy in an Economy Without Capital," Journal of Monetary Economics, 12, 55-93. 
Martin, F. M. (2011): "On the Joint Determination of Fiscal and Monetary Policy," Journal of Monetary Economics, 58, 132-145.

OAtes, W. E. (1972): Fiscal Federalism, New York: Harcourt Brace Jovanovich.

QIAn, Y. And G. Roland (1998): "Federalism and Soft Budget Constraint," American Economic Review, $88,1143-1162$.

Rodden, J. (2003): "Soft Budget Constraints and German Federalism," in Fisal Decentralization and the Challenge of Hard Budget Constraints, ed. by J. A. Rodden, G. S. Eskeland, and J. Litvack, Cambridge: The MIT Press, 35-84.

Rodden, J. A., G. S. Eskeland, And J. Litvack (2003): Fiscal Decentralization and the Challenge of Hard Budget Constraints, Cambridge: MIT Press.

Sanguinetti, P. And M. Tommasi (2004): "Intergovernmental Transfers and Fiscal Behavior Insurance Versus Aggregate Discipline," Journal of International Economics, 62, 149-170.

Schmitt-Grohe, S. And M. Uribe (2003): "Closing Small Open Economy Models," Journal of International Economics, 61, 163-185.

Song, Z., K. Storesletten, and F. Zilibotti (2012): "Rotten Parents and Disciplined Children: A Politico-Economic Theory of Public Expenditure and Debt," Econometrica, 80, 2785-2803.

Sorribas-Navarro, P. (2011): "Bailouts in a Fiscal Federal System: Evidence from Spain," European Journal of Political Economy, 27, 154-170.

Uribe, M. (2006): "Individual versus Aggregate Collateral Constraints and the Overborrowing Syndrome," NBER working paper No. 12260.

Velasco, A. (2000): "Debts and Deficits with Fragmented Fiscal Policymaking," Journal of Public Economics, 76, 105-125.

WebB, S. B. (2003): "Argentina: Hardening the Provincial Budget Constraint," in Fisal Decentralization and the Challenge of Hard Budget Constraints, ed. by J. A. Rodden, G. S. Eskeland, and J. Litvack, Cambridge: The MIT Press, 35-84.

Werning, I. (2007): "Optimal Fiscal Policy with Redistribution," Quarterly Journal of Economics, 122, 925-967.

WiLdAsin, D. E. (1997): "Externalities and Bailouts: Hard and Soft Budget Constraints in Intergovernmental Fiscal Relations," Working Paper.

Yared, P. (2010): "Taxes and Debt," Review of Economic Studies, 77, 806-840. 


\section{Online Appendix for "Decentralization and Overborrowing in a Fiscal Union"}

Si Guo, Yun Pei, and Zoe Xie ${ }^{34}$

34 GUO: International Monetary Fund (sguo@imf.org). PEI: University at Buffalo, SUNY (yunpei@buffalo.edu). XIE: Federal Reserve Bank of Atlanta (xiexx196@gmail.com). The views expressed in this paper are those of the authors and do not necessarily represent the views of the IMF, its Executive Board, IMF management, the Federal Reserve System or the Federal Reserve Banks. 


\section{A Transformation of $\theta$}

Assume there are infinitely many varieties of public goods, each indexed by $\omega \in[0,1]$. Goods $\omega \in[0, \bar{w}]$ are purchased by the local government. Goods $\omega \in[\bar{w}, 1]$ are purchased by the central government.

The household cares about the consumption basket: its period utility for this public consumption is $U(C)$ where the basket $C=\left[\int_{0}^{1} q(\omega)^{\frac{\sigma-1}{\sigma}} d \omega\right]^{\frac{\sigma}{\sigma-1}}$ and $U(C)=\frac{C^{1-\gamma}}{1-\gamma}$. Here $\sigma>0$ is the elasticity of substitution and $\gamma>0$ is the household's risk aversion.

Denote $g$ and $c$ as the local and central governments' total expense on consumption respectively, we have

$$
\begin{aligned}
C & =\left[\int_{0}^{1} q(\omega)^{\frac{\sigma-1}{\sigma}} d \omega\right]^{\frac{\sigma}{\sigma-1}} \\
& =\left[\int_{0}^{\bar{w}} q(\omega)^{\frac{\sigma-1}{\sigma}} d \omega+\int_{\bar{w}}^{1} q(\omega)^{\frac{\sigma-1}{\sigma}} d \omega\right]^{\frac{\sigma}{\sigma-1}} \\
& =\left[\int_{0}^{\bar{w}}\left(\frac{g}{\bar{w}}\right)^{\frac{\sigma-1}{\sigma}} d \omega+\int_{\bar{w}}^{1}\left(\frac{c}{1-\bar{w}}\right)^{\frac{\sigma-1}{\sigma}} d \omega\right]^{\frac{\sigma}{\sigma-1}} \\
& =\left[\bar{w}\left(\frac{g}{\bar{w}}\right)^{\frac{\sigma-1}{\sigma}}+(1-\bar{w})\left(\frac{c}{1-\bar{w}}\right)^{\frac{\sigma-1}{\sigma}}\right]^{\frac{\sigma}{\sigma-1}} \\
& =\left[\bar{w}^{\frac{1}{\sigma}} g^{\frac{\sigma-1}{\sigma}}+(1-\bar{w})^{\frac{1}{\sigma}} c^{\frac{\sigma-1}{\sigma}}\right]^{\frac{\sigma}{\sigma-1}}
\end{aligned}
$$

Therefore,

$$
U(C)=\frac{\left[(1-\theta) g^{1-\frac{1}{\sigma}}+\theta c^{1-\frac{1}{\sigma}}\right]^{\frac{\sigma(1-\gamma)}{\sigma-1}}}{1-\gamma}
$$

where $1-\theta=\frac{\bar{w}^{1 / \sigma}}{\bar{w}^{1 / \sigma}+(1-\bar{w})^{1 / \sigma}}$.

In the special case when $\sigma=1$, we have

$$
U(C)=\frac{\left[g^{1-\theta} c^{\theta}\right]^{1-\gamma}}{1-\gamma}
$$

If we further assume $\gamma=1$, then

$$
U(C)=(1-\theta) \log (g)+\theta \log (c)
$$

which is what we have in the model when risk aversion is 1 for both $u(\cdot)$ and $v(\cdot)$ functions. Moreover, the change of local and central spending responsibilities (captured by $\bar{w}$ ) is equivalent to the change of $\theta$. 


\section{B Simple Model With Endogenous $\epsilon$ in Transfer Function ${ }^{35}$}

The overborrowing mechanism works as long as total transfer depends on individual region's fiscal condition, captured by the accumulated debt $b_{i, t}$.

Here we present a simple model where $\epsilon>0$ arises endogenously. Intuitively, we think of $\epsilon$ as an a priori choice of all local governments. Mapping into Spain we can think of $\epsilon$ as the outcome of periodic (e.g. every five years) negotiations among all local governments. In this setup, there are two types of local governments, each of measure one. The two types are ex ante identical but may receive different shocks (ex post heterogeneous). The presence of shocks motivates local governments to demand $\epsilon>0$ as partial insurance against bad shocks.

Timing is as follows

- Period -1: Local governments choose $\epsilon$.

- Period 0: Idiosyncratic shock $\delta \in\{\bar{\delta},-\bar{\delta}\}, \bar{\delta}>0$ realizes on local government's budget with probability $p$ for good shock. Given shock realizations, local government chooses borrowing $b^{i}$ and spending $g_{0}^{i}$ (superscript for local government type, and subscript for time).

- Period 1: Central government chooses $\tau$ given the a priori determined $\epsilon$, and subject to the transfer function $T^{i}=\tau\left(1-\epsilon+\epsilon b^{i} / f\right)$ and local government spending $g_{1}^{i}$.

Local government wants $\epsilon>0$ so that if $\delta$ shock is bad, it gets more transfer.

\section{Period 1 Central government:}

$$
\begin{array}{cl}
\max _{\tau} & (1-\theta)\left[u\left(g^{1}\right)+u\left(g^{2}\right)\right]+\theta v(c) \\
\text { subject to } & g^{i}=f-b^{i}+\tau M\left(b^{i}, \epsilon\right) \\
& c=e-2 f-\tau\left[M\left(b^{1}, \epsilon\right)+M\left(b^{2}, \epsilon\right)\right]
\end{array}
$$

Choice of $\tau$ given realizations of $\delta$

$$
\{\tau\}:(1-\theta)\left[\frac{1}{g^{1}} M\left(b^{1}, \epsilon\right)+\frac{1}{g^{2}} M\left(b^{2}, \epsilon\right)\right]=\frac{\theta}{c}\left[M\left(b^{1}, \epsilon\right)+M\left(b^{2}, \epsilon\right)\right]
$$

Period 0 Local government $i$ ( $i$ is omitted):

$$
\begin{array}{rl}
\max _{b} & u\left(g_{0}\right)+u\left(g_{1}\right) \\
\text { subject to } & g_{0}=\delta+b \\
& g_{1}=f-b+\tau M(b, \epsilon)
\end{array}
$$

Choice of $b$ given realizations of $\delta$

$$
\{b\}: g_{1}=g_{0}\left(1-\frac{\epsilon \tau}{f}\right) \Rightarrow b=\frac{1}{2}\left[f-\delta+\frac{\tau}{1-\epsilon \tau / f}\right]
$$

Period -1 Local government $i$ ( $i$ is omitted): $\epsilon$ depends on anticipated $\tau$ which depends on realizations of both

\footnotetext{
35 We would like to thank Yongsung Chang and Karen Kopecky for helpful discussions on this section.
} 
own $\delta$ and the other type's $\delta$. But prior to shock realizations, each type makes the same choice for $\epsilon$

$$
\begin{aligned}
\max _{\epsilon} & \mathbb{E}_{\delta, \delta^{o}}\left\{u\left(g_{0}\right)+u\left(g_{1}\right)\right\} \\
\text { subject to } & g_{0}=\delta+b \\
& g_{1}=f-b+\tau M(b, \epsilon)
\end{aligned}
$$

Here $\epsilon$ affects conditional choices of $b$ and $\tau$, so the optimal $\epsilon$ depends on the derivatives of $b$ and $\tau$ with respect to $\epsilon$.

Equilibrium In equilibrium, realizations of own $\delta$ and the other type's $\delta$ both matter for choice of $b$ and $g$, so there are four possible values of $b$ (and $g$ ). But the central government only cares about how many types had good/bad shocks, so there are only three possible values for $\tau$.

We solve the equilibrium numerically. We construct a dense grid on $\epsilon$. For each $\epsilon$, solve (25) and (26) for $\{b, \tau\}$ under four possible realizations of shocks - (good, good), (good, bad), (bad,good), (bad, bad). Then solve problem (27) by finding the $\left(\epsilon,\left\{b_{i j}(\epsilon), \tau_{i j}(\epsilon)\right\}_{i=\{g, b\}, j=\{g, b\}}\right)$ that maximize local government value at period -1 .

Setting parameters: $e=0.6 ; f=0.15 ; \theta=0.5 ; p=0.5 ; \bar{\delta}=0.01$.

\begin{tabular}{lcccccc}
\hline \hline$\left(\delta, \delta^{\text {other }}\right)$ & $\epsilon$ & $b$ & $g_{0}$ & $\tau$ & $c$ & $g_{1}$ \\
\hline$(\bar{\delta}, \bar{\delta})$ & 0.5006 & 0.1450 & 0.1550 & 0.1000 & 0.1033 & 0.1033 \\
$(\bar{\delta},-\bar{\delta})$ & 0.5006 & 0.1451 & 0.1551 & 0.1001 & 0.0998 & 0.1033 \\
$(-\bar{\delta}, \bar{\delta})$ & 0.5006 & 0.1551 & 0.1451 & 0.1001 & 0.0998 & 0.0967 \\
$(-\bar{\delta},-\bar{\delta})$ & 0.5006 & 0.1550 & 0.1450 & 0.1000 & 0.0966 & 0.0966 \\
\hline
\end{tabular}

When shock realizations are symmetric (no ex post heterogeneity), $c / g=\theta /(1-\theta)$ as in the two-period model with exogenous $\epsilon$ (Appendix I). When shocks are asymmetric, resource distribution is distorted because the central government chooses larger $\tau$ to redistribute more to local governments that received bad shocks.

If shock is bigger: $\bar{\delta}=0.1$, then larger $\epsilon$ is chosen for insurance.

\begin{tabular}{lcccccc}
\hline \hline$\left(\delta, \delta^{\text {other }}\right)$ & $\epsilon$ & $b$ & $g_{0}$ & $\tau$ & $c$ & $g_{1}$ \\
\hline$(\bar{\delta}, \bar{\delta})$ & 0.5469 & 0.1058 & 0.2058 & 0.1016 & 0.1295 & 0.1295 \\
$(\bar{\delta},-\bar{\delta})$ & 0.5469 & 0.1092 & 0.2092 & 0.1044 & 0.0843 & 0.1296 \\
$(-\bar{\delta}, \bar{\delta})$ & 0.5469 & 0.2092 & 0.1092 & 0.1044 & 0.0843 & 0.0677 \\
$(-\bar{\delta},-\bar{\delta})$ & 0.5469 & 0.2020 & 0.1020 & 0.0986 & 0.0653 & 0.0653 \\
\hline
\end{tabular}




\section{Ramsey Problem}

This section presents the set-up and equilibrium characterization of the Ramsey problem. The main results are summarized in Section 3.4.4.

The central government can choose the entire sequence $\left\{b_{t+1}, d_{t+1}, \tau_{t}\right\}_{t=0}^{\infty}$ at time zero and it has commitment to all its future policies. The Ramsey problem is defined as

Definition 3. Given initial measures of debt positions $\left(b_{0}, d_{0}\right)$, the optimal policy of a central government with commitment consists of a sequence of debt and transfer policies $\left\{b_{t+1}, d_{t+1}, \tau_{t}\right\}_{t=0}^{\infty}$ that solves

$$
\max _{\left\{b_{t+1}, d_{t+1}, \tau_{t}\right\}_{t=0}^{\infty}} \sum_{t=0}^{\infty} \beta^{t}\left[(1-\theta) u\left(G\left(b_{t}, b_{t+1}, \tau_{t}\right)\right)+\theta v\left(C\left(b_{t}, d_{t}, d_{t+1}, \tau_{t}\right)\right)\right]
$$

subject to the implementability condition: for all time $t$

$$
u_{g}\left(G\left(b_{t}, b_{t+1}, \tau_{t}\right)\right)=\beta R_{t+1}\left(1-\tau_{t+1}\right) u_{g}\left(G\left(b_{t+1}, b_{t+2}, \tau_{t+1}\right)\right)
$$

Define the Lagrange multiplier of the constraint above as $\beta^{t} \gamma_{t}$. Writing it recursively, the first order conditions are ${ }^{36}$

$$
\begin{aligned}
\{\tau\} & (1-\theta) u_{g} G_{\tau}+\theta v_{c} C_{\tau}=\gamma u_{g g} G_{\tau}+\gamma^{-} R\left[u_{g}-(1-\tau) u_{g g} G_{\tau}\right] \\
\left\{b^{\prime}\right\} & (1-\theta) u_{g} G_{b^{\prime}}+\beta\left[(1-\theta) u_{g}^{\prime} G_{b}^{\prime}+\theta v_{c}^{\prime} C_{b}^{\prime}\right] \\
& =\gamma\left[u_{g g} G_{b^{\prime}}-\beta R_{b}^{\prime}\left(1-\tau^{\prime}\right) u_{g}^{\prime}-\beta R^{\prime}\left(1-\tau^{\prime}\right) u_{g g}^{\prime} G_{b}^{\prime}\right] \\
& -\gamma^{-} R(1-\tau) u_{g g} G_{b^{\prime}}+\beta \gamma^{\prime} u_{g g}^{\prime} G_{b}^{\prime} \\
\left\{d^{\prime}\right\} & \theta v_{c} C_{d^{\prime}}+\beta \theta v_{c}^{\prime} C_{d}^{\prime}=0
\end{aligned}
$$

The distinctions between the Markov and Ramsey equilibria can be seen, for example, from the comparison of Equations (13) and (29). Both are central government's first-order condition with respect to the local government debt choice $b^{\prime}$, and characterize the effect of a marginal increase in $b^{\prime}$. Because the Ramsey government has commitment, it considers how an increase in $b^{\prime}$ affects commitment in the previous period. This commitment is captured by the $\gamma^{-}$term in (29), where $\gamma^{-}$is the shadow value of loosening the local government's optimality condition in the previous period. In contrast, in the Markov equilibrium, the central government optimizes taking periods past as given, and does not consider how today's choice influences choices in the previous period. Instead of carrying terms with $\lambda^{-}$, Equation (13) has an additional term $\Omega_{b^{\prime}}$ with policy derivatives, which reflects that the central government considers how today's policy choices affect future choices through expectations in a Markov equilibrium.

This distinction gives rise to the potential time-inconsistency problem of the Ramsey allocation. At time zero, when the central government chooses transfer plan $\left\{\tau_{t}^{*}\right\}_{t=0}^{\infty}$, it understands that the time- $t$ choice $\tau_{t}^{*}$ affects the local government's debt choice $b_{t}$ made by the local government at time $t-1$. However, when time $t$ comes and after observing the local government's debt choice $b_{t}$, the central government may find it sub-optimal to stick to $\tau_{t}^{*}$, because the effect of $\tau_{t}^{*}$ on $b_{t}$ is already foregone. In other words, the ex-ante optimal plan (before observing $b_{t}$ ) may differ from the ex-post optimal plan (after observing $b_{t}$ ).

\footnotetext{
${ }^{36}$ Prime indicates future values, and "-" indicates variables of the previous period. Writing conditions recursively is more compact and makes for easier comparison with the Markov equilibrium conditions. Online Appendix D.2 gives the expressions for the auxiliary functions.
} 
From the optimality conditions (28)-(30) we have the following propositions.

Proposition 4. The central-local ratio of marginal utility from spending in the Ramsey steady state is lower than Pareto optimal, $v_{c} / u_{g}<(1-\theta) / \theta$. Further, with log utility the Ramsey steady state central-local spending ratio is higher than Pareto optimal, $c / g>\theta /(1-\theta)$.

To see this result notice that the left hand-side of Equation (28) simplifies to $b\left[(1-\theta) u_{g}-\theta v_{c}\right]$. At steady state, the right hand-side of Equation (28) becomes $\gamma R u_{g}+\gamma[1-R(1-\tau)] u_{g g} b$. This expression is strictly positive: the first part is positive; the second part is strictly positive because $R(1-\tau)$ is greater than 1 from the steady state optimality condition of the local government and $u_{g g}$ is negative.

Compared with the condition for the Markov equilibrium (Equation 12), the Ramsey government's choice of transfer rate takes into account not only the effects on local-central resource sharing and local government's budget constraint and debt choice, but also the ex ante overborrowing incentive of local governments (the term with $\gamma^{-}$in Equation 28). This additional term arises from the Ramsey government's ability to commit to future policy. Because of this term, the additional value of raising transfer rate beyond perfect resource sharing $(c / g=\theta /(1-\theta))$ is negative, and so the Ramsey steady state spending ratio is higher than the first-best.

Proposition 5. Under the Ramsey policy, the steady state central government debt is the same as the Pareto optimal allocation and is invariant to changes in local revenue or spending responsibility.

Comparing the last conditions for the Ramsey (Equation 30) and social planner's solutions (Equation 7), ${ }^{37}$ at steady state both conditions are identical and can be simplified to depend only on central government debt $d$. Off steady state, the conditions also depend on central government spending $c$, which are potentially different in the first-best and the Ramsey solution. The invariance result implies that under the Ramsey policy with commitment, fiscal decentralization does not have an effect on steady state central government debt. Intuitively, because the Ramsey sequence of policies are chosen at time zero, the choice of time- $t$ central government debt does not have an effect on the future policy choices. ${ }^{38}$ Hence, Equation (30), which summarizes the marginal effects of the choice $d^{\prime}$, is a standard inter-temporal smoothing condition.

${ }^{37}$ Equation (30) simplifies to $v_{c}=\beta v_{c}^{\prime}\left[\frac{1}{S\left(d^{\prime}\right)}-\frac{d^{\prime} S_{d}\left(d^{\prime}\right)}{S\left(d^{\prime}\right)^{2}}\right]$.

38 This is why the right hand-side of Equation (30) is zero, whereas in Equation (14) of the Markov equilibrium the right hand-side contains policy derivative with respect to $d^{\prime}$. 


\section{DERIVATIONS}

\section{D.1 Markov optimality conditions and GEEs}

This section derives the Markov optimality conditions (Equations 12-14) and GEEs (Equations 15 and 16). Denote the local government's Euler equation by $\eta\left(b, b^{\prime}, d^{\prime}, \tau\right)=0$ with Lagrange multiplier $\lambda$. Take derivative of the central government's problem,

$$
\begin{aligned}
\{\tau\} & (1-\theta) u_{g} G_{\tau}+\theta v_{c} C_{\tau}=\lambda \eta_{\tau} \\
\left\{b^{\prime}\right\} & (1-\theta) u_{g} G_{b^{\prime}}+\beta V_{b}^{\prime}=\lambda \eta_{b^{\prime}} \\
\left\{d^{\prime}\right\} & \theta v_{c} C_{d^{\prime}}+\beta V_{d}^{\prime}=\lambda \eta_{d^{\prime}}
\end{aligned}
$$

Envelop conditions are

$$
\begin{aligned}
V_{b} & =(1-\theta) u_{g}\left[G_{b}+G_{\tau} \phi_{b}+G_{b^{\prime}} h_{b}\right]+\theta v_{c}\left[C_{b}+C_{\tau} \phi_{b}+C_{d^{\prime}} p_{b}\right]+\beta\left[V_{b}^{\prime} h_{b}+V_{d}^{\prime} p_{b}\right] \\
V_{d} & =(1-\theta) u_{g}\left[G_{\tau} \phi_{d}+G_{b^{\prime}} h_{d}\right]+\theta v_{c}\left[C_{d}+C_{\tau} \phi_{d}+C_{d^{\prime}} p_{d}\right]+\beta\left[V_{b}^{\prime} h_{d}+V_{d}^{\prime} p_{d}\right]
\end{aligned}
$$

substitute FOCs into Envelop conditions,

$$
\begin{aligned}
V_{b} & =(1-\theta) u_{g} G_{b}+\theta v_{c} C_{b}+\lambda \eta_{\tau} \phi_{b}+\lambda \eta_{b^{\prime}} h_{b}+\lambda \eta_{d^{\prime}} p_{b} \\
V_{d} & =\theta v_{c} C_{d}+\lambda \eta_{\tau} \phi_{d}+\lambda \eta_{b^{\prime}} h_{d}+\lambda \eta_{d^{\prime}} p_{d}
\end{aligned}
$$

Differentiate $\eta$ with respect to $b$ and $d$,

$$
\begin{array}{r}
\eta_{b}+\eta_{\tau} \phi_{b}+\eta_{b^{\prime}} h_{b}+\eta_{d^{\prime}} p_{b}=0 \\
\eta_{\tau} \phi_{d}+\eta_{b^{\prime}} h_{d}+\eta_{d^{\prime}} p_{d}=0
\end{array}
$$

substitute into $V_{b}$ and $V_{d}$,

$$
\begin{aligned}
V_{b} & =(1-\theta) u_{g} G_{b}+\theta v_{c} C_{b}-\lambda \eta_{b} \\
V_{d} & =\theta v_{c} C_{d}
\end{aligned}
$$

substitute into last two FOCs,

$$
\begin{aligned}
(1-\theta) u_{g} G_{b^{\prime}}+\beta\left[(1-\theta) u_{g}^{\prime} G_{b}^{\prime}+\theta v_{c}^{\prime} C_{b}^{\prime}\right] & =\lambda \eta_{b^{\prime}}+\beta \lambda^{\prime} \eta_{b}^{\prime} \\
\theta v_{c} C_{d^{\prime}}+\beta \theta v_{c}^{\prime} C_{d}^{\prime} & =\lambda \eta_{d^{\prime}}
\end{aligned}
$$

Expressing the auxiliary functions in Equations (31), (32) and (33), we get Equations (12), (13) and (14) respectively in Section 3.4.

From Equation (31),

$$
\lambda=\frac{1}{\eta_{\tau}}\left[(1-\theta) u_{g} G_{\tau}+\theta v_{c} C_{\tau}\right]
$$


Substitute the expression for $\lambda$ into Equations (32) and (33), we get the two GEEs,

$$
\begin{aligned}
-u_{g} G_{b^{\prime}}+\frac{\eta_{b^{\prime}}}{\eta_{\tau}}\left[u_{g} G_{\tau}+\frac{\theta}{1-\theta} v_{c} C_{\tau}\right] & =\beta\left[u_{g}^{\prime} G_{b}^{\prime}+\frac{\theta}{1-\theta} v_{c}^{\prime} C_{b}^{\prime}\right]-\beta \frac{\eta_{b}^{\prime}}{\eta_{\tau}^{\prime}}\left[u_{g}^{\prime} G_{\tau}^{\prime}+\frac{\theta}{1-\theta} v_{c}^{\prime} C_{\tau}^{\prime}\right] \\
-\frac{\theta}{1-\theta} v_{c} C_{d^{\prime}}+\frac{\eta_{d^{\prime}}}{\eta_{\tau}}\left[u_{g} G_{\tau}+\frac{\theta}{1-\theta} v_{c} C_{\tau}\right] & =\beta \frac{\theta}{1-\theta} v_{c}^{\prime} C_{d}^{\prime}
\end{aligned}
$$

Rewriting and we get the Equations (15) and (16) in Section 3.4.

Auxiliary functions are

$$
\begin{aligned}
G_{b} & =-1+\tau \\
G_{\tau} & =b \\
G_{b^{\prime}} & =\frac{1}{R\left(b^{\prime}\right)}-\frac{b^{\prime} R_{b}\left(b^{\prime}\right)}{R\left(b^{\prime}\right)^{2}} \\
C_{b} & =-\tau \\
C_{\tau} & =-b \\
C_{d} & =-1 \\
C_{d^{\prime}} & =\frac{1}{S\left(d^{\prime}\right)}-\frac{d^{\prime} S_{d}\left(d^{\prime}\right)}{S\left(d^{\prime}\right)^{2}} \\
\eta_{b} & =u_{g g} G_{b} \\
\eta_{\tau} & =u_{g g} G_{\tau} \\
\eta_{b^{\prime}} & =u_{g g} G_{b^{\prime}}-\beta R_{b}\left(b^{\prime}\right)\left(1-\phi^{\prime}\right) u_{g}^{\prime}+\beta R\left(b^{\prime}\right) \phi_{b}^{\prime} u_{g}^{\prime}-\beta R\left(b^{\prime}\right)\left(1-\phi^{\prime}\right) u_{g g}^{\prime}\left[G_{b}^{\prime}+G_{\tau}^{\prime} \phi_{b}^{\prime}+G_{b^{\prime}}^{\prime} h_{b}^{\prime}\right] \\
\eta_{d^{\prime}} & =\beta R\left(b^{\prime}\right) \phi_{d}^{\prime} u_{g}^{\prime}-\beta R\left(b^{\prime}\right)\left(1-\phi^{\prime}\right) u_{g g}^{\prime}\left[G_{\tau}^{\prime} \phi_{d}^{\prime}+G_{b^{\prime}}^{\prime} h_{d}^{\prime}\right]
\end{aligned}
$$




\section{D.2 Ramsey optimality conditions}

This section gives the original form of the Ramsey optimality conditions (Equations 28-30) and expressions for the auxiliary functions. Denote the local government's Euler equation at time $t$ by $\tilde{\eta}\left(b_{t}, b_{t+1}, \tau_{t}, b_{t+2}, \tau_{t+1}\right)=0$ with Lagrange multiplier $\beta^{t} \gamma_{t}$. Take derivative for all $t>0$

$$
\begin{aligned}
\left\{\tau_{t}\right\} & \beta^{t}(1-\theta) u_{g, t} G_{\tau, t}+\beta^{t} \theta v_{c, t} C_{\tau, t}=\beta^{t} \gamma_{t} \tilde{\eta}_{\tau, t}+\beta^{t-1} \gamma_{t-1} \tilde{\eta}_{\tau^{\prime}, t-1} \\
\left\{b_{t+1}\right\} & \beta^{t}(1-\theta) u_{g, t} G_{b^{\prime}, t}+\beta^{t+1}\left[(1-\theta) u_{g, t+1} G_{b, t+1}+\theta v_{c, t+1} C_{b, t+1}\right]=\beta^{t} \gamma_{t} \tilde{\eta}_{b^{\prime}, t}+\beta^{t+1} \gamma_{t+1} \tilde{\eta}_{b, t+1}+\beta^{t-1} \gamma_{t-1} \tilde{\eta}_{b^{\prime \prime}, t-1} \\
\left\{d_{t+1}\right\} & \beta^{t} \theta v_{c, t} C_{d^{\prime}, t}+\beta^{t+1} \theta v_{c, t+1} C_{d, t+1}=0
\end{aligned}
$$

Expressing the auxiliary functions and writing the above conditions recursively, we get Equations (28)-(30) in Online Appendix C. Further, combining the first two conditions and writing in recursive form:

$$
\begin{aligned}
0= & \underbrace{\left(u_{g} G_{\tau}+\frac{\theta}{1-\theta} v_{c} C_{\tau}-\frac{1}{1-\theta} \gamma^{-} \tilde{\eta}_{\tau^{\prime}}^{-} / \beta\right)}_{\text {within-period shift in spending }}+\overbrace{\left(-\frac{\tilde{\eta}_{\tau}}{\tilde{\eta}_{b^{\prime}}}\right)}^{d b^{\prime} / d \tau(-)} \underbrace{\left[u_{g} G_{b^{\prime}}+\beta\left(u_{g}^{\prime} G_{b}^{\prime}+\frac{\theta}{1-\theta} v_{c}^{\prime} C_{b}^{\prime}\right)-\frac{1}{1-\theta} \gamma^{-} \tilde{\eta}_{b^{\prime \prime}}^{-} / \beta\right]}_{\text {inter-temporal shift in spending via } b^{\prime}} \\
& +\beta \overbrace{\left(-\frac{\tilde{\eta}_{\tau}}{\tilde{\eta}_{b^{\prime}}}\right)\left(-\frac{\tilde{\eta}_{b}^{\prime}}{\tilde{\eta}_{\tau}^{\prime}}\right)}^{\left(\tau^{\prime} / d \tau, b^{\prime \prime} \text { constant }(-)\right.} \underbrace{\left(u_{g}^{\prime} G_{\tau}^{\prime}+\frac{\theta}{1-\theta} v_{c}^{\prime} C_{\tau}^{\prime}-\frac{1}{1-\theta} \gamma \eta_{\tau^{\prime}} / \beta\right)}_{\text {future within-period shift in spending }}
\end{aligned}
$$

This condition is comparable to the first GEE of the Markov equilibrium (Equation 15) with the additional lagged multipliers $\gamma^{-}$(in red) capturing commitment to policies promised the previous period.

The auxiliary functions are

$$
\begin{aligned}
G_{b, t} & =-1+\tau_{t} \\
G_{\tau, t} & =b_{t} \\
G_{b^{\prime}, t} & =\frac{1}{R\left(b_{t+1}\right)}-\frac{b_{t+1} R_{b}\left(b_{t+1}\right)}{R\left(b_{t+1}\right)^{2}} \\
C_{b, t} & =-\tau_{t} \\
C_{\tau, t} & =-b_{t} \\
C_{d, t} & =-1 \\
C_{d^{\prime}, t} & =\frac{1}{S\left(d_{t+1}\right)}-\frac{d_{t+1} S_{d}\left(d_{t+1}\right)}{S\left(d_{t+1}\right)^{2}} \\
\eta_{b, t} & =u_{g g, t} G_{b, t} \\
\eta_{b^{\prime}, t} & =u_{g g, t} G_{b^{\prime}, t}-\beta R_{b}\left(b_{t+1}\right)\left(1-\tau_{t+1}\right) u_{g, t+1}-\beta R\left(b_{t+1}\right)\left(1-\tau_{t+1}\right) u_{g g, t+1} G_{b, t+1} \\
\eta_{b^{\prime \prime}, t} & =-\beta R\left(b_{t+1}\right)\left(1-\tau_{t+1}\right) u_{g g, t+1} G_{b^{\prime}, t+1} \\
\eta_{\tau, t} & =u_{g g, t} G_{\tau, t} \\
\eta_{\tau^{\prime}, t} & =\beta R\left(b_{t+1}\right) u_{g, t+1}-\beta R\left(b_{t+1}\right)\left(1-\tau_{t+1}\right) u_{g g, t+1} G_{\tau, t+1}
\end{aligned}
$$




\section{E Proof of Proposition 2}

Equation (12) can be rewritten as

$$
(1-\theta) u_{g}-\theta v_{c}=\lambda u_{g g}
$$

It is easy to see that proving the Lagrange multiplier $\lambda>0$ is sufficient to prove Proposition 2 .

The rest of the proof will be organized as follows: we first construct an alternate central government's problem and we show that the Lagrange multiplier of this alternate problem is positive; we then show that the allocation and multiplier of this alternate problem also solve the original central government's problem around steady state.

The alternate central government's problem. The alternate central government's problem is similar with the original central government's problem defined in Section 3.4, except that the implementability condition is an inequality.

$$
\max _{\tau, b^{\prime}, d^{\prime}} \quad(1-\theta) u\left(G\left(b, b^{\prime}, \tau\right)\right)+\theta v\left(C\left(b, d, d^{\prime}, \tau\right)\right)+\beta V\left(b^{\prime}, d^{\prime}\right)
$$

subject to inequality

$$
u_{g}\left(G\left(b, b^{\prime}, \tau\right)\right) \leq \beta R\left(b^{\prime}\right)\left(1-\phi\left(b^{\prime}, d^{\prime}\right)\right) u_{g}\left(G\left(b^{\prime}, h\left(b^{\prime}, d^{\prime}\right), \phi\left(b^{\prime}, d^{\prime}\right)\right)\right)
$$

and the central government's value function satisfies the functional equation

$$
V(b, d)=(1-\theta) u(G(b, h(b, d), \phi(b, d)))+\theta v(C(b, d, p(b, d), \phi(b, d)))+\beta V(h(b, d), p(b, d))
$$

Denote the Lagrange multiplier to (36) as $\lambda^{p}$, the optimality conditions are

$$
\begin{array}{ll}
\{\tau\} \quad & (1-\theta) u_{g}-\theta v_{c}=\lambda^{p} u_{g g} \\
\left\{b^{\prime}\right\} & (1-\theta) u_{g} G_{b^{\prime}}+\beta\left[(1-\theta) u_{g}^{\prime} G_{b}^{\prime}+\theta v_{c}^{\prime} C_{b}^{\prime}\right] \\
& =\lambda^{p}\left[u_{g g} G_{b^{\prime}}-\beta\left(1-\tau^{\prime} M_{b}^{\prime}\right) R_{b}^{\prime} u_{g}^{\prime}-\beta R^{\prime}\left(1-\tau^{\prime} M_{b}^{\prime}\right) u_{g g}^{\prime} G_{b}^{\prime}\right] \\
& +\lambda^{p} \Omega_{b^{\prime}}+\beta \lambda^{p^{\prime}} u_{g g}^{\prime} G_{b}^{\prime} \\
\left\{d^{\prime}\right\} \quad & \theta v_{c} C_{d^{\prime}}+\beta \theta v_{c}^{\prime} C_{d}^{\prime}=\lambda^{p} \Omega_{d^{\prime}} \\
& \lambda^{p} \geq 0 \quad \text { and } \quad \lambda^{p}\left[\beta R^{\prime}\left(1-\tau^{\prime}\right) u_{g}^{\prime}-u_{g}\right]=0
\end{array}
$$

where $\lambda^{p} \geq 0$ is from the Kuhn-Tucker Theorem, given the constraint (36) is an inequality. Note that the only difference between (37)-(39) and (12)-(14) is that $\lambda$ is replaced with $\lambda^{p}$ (and $\lambda^{p} \geq 0$ ).

We next show that the optimality conditions (37)-(40) imply that the inequality constraint (36) is binding around the steady state so that the alternate and original problems are equivalent at least around the steady state.

We show it by contradiction. Suppose (36) is not binding so that

$$
\beta R^{\prime}\left(1-\tau^{\prime}\right) u_{g}^{\prime}>u_{g}
$$


Then from (40), $\lambda^{p}=0$. Plug it into (37)-(39), we have

$$
\begin{aligned}
& (1-\theta) u_{g}-\theta v_{c}=0 \\
& u_{g}-\frac{R_{b}^{\prime} b^{\prime}}{R^{\prime}} u_{g}-\beta R^{\prime} u_{g}^{\prime}=0 \\
& v_{c}\left(\frac{1}{S^{\prime}}-\frac{d^{\prime} S_{d}^{\prime}}{S^{\prime 2}}\right)-v_{c}^{\prime}=0
\end{aligned}
$$

Note that (41) contradicts (43) around steady state as long as $b^{\prime}$ and $\tau^{\prime}$ are nonnegative around steady state. From (43), the nonnegativity of $b^{\prime}$ around steady state can be warranted as long as $\beta R(0)<1$ and $R_{b} \geq 0$. As long as $f$ is small enough relative to $(1-\theta) e,(42)$ implies that in steady state the central government wants to subsidize local governments, i.e. $\tau>0$ around steady state. Thus, the contradiction between (41) and (43) implies the constraint (36) has to be binding around steady state.

Therefore, let $\lambda=\lambda^{p}$, the solutions to the alternate central government's problem solve the original central government's problem. Because we have shown $\lambda^{p} \geq 0$, we have $\lambda \geq 0$.

It remains to show that $\lambda^{p} \neq 0$ so that $\lambda^{p}=\lambda>0$. We again show it by contradiction: when $\lambda^{p}=0,(42)$ - (44) still hold. Equation (41) becomes equality:

$$
\beta R^{\prime}\left(1-\tau^{\prime}\right) u_{g}^{\prime}=u_{g}
$$

$\tau>0$ or $R_{b} \geq 0$ around steady state will imply that (45) contradicts with (43). Hence $\lambda=\lambda^{p}>0$. 


\section{F Implement Social Planner's Problem Using Debt Limit}

This section complements Section 3.5 by showing how to use a debt limit on local government borrowing to implement the social planner's allocation.

Local government's problem is

$$
\begin{aligned}
W(b)= & \max _{g, b^{\prime}} u(g)+\beta W\left(b^{\prime}\right) \\
\text { s.t. } & g \leq f+\frac{b^{\prime}}{R\left(b^{\prime}\right)}-b+\tau b \\
& b^{\prime} \leq \text { DebtLimit }
\end{aligned}
$$

The first order condition and the Envelop condition are

$$
\begin{array}{ll}
\left\{b^{\prime}\right\} & u_{g} \frac{1}{R\left(b^{\prime}\right)}+\beta W_{b}^{\prime}-\gamma=0 \\
\{b\} & W_{b}=-u_{g}(1-\tau)
\end{array}
$$

and the complementary slackness condition is

$$
\gamma\left(b^{\prime}-\text { DebtLimit }\right)=0, \quad \gamma \geq 0
$$

where $\gamma$ is the Lagrange multiplier on the debt constraint. Combining the first order condition and the Envelop condition gives

$$
u_{g} \frac{1}{R\left(b^{\prime}\right)}=\beta u_{g}^{\prime}\left(1-\tau^{\prime}\right)+\gamma
$$

Construct

$$
\gamma=\frac{u_{g}\left(g^{*}\right) b^{*^{\prime}} R_{b}\left(b^{*^{\prime}}\right)}{R\left(b^{*^{\prime}}\right)^{2}}+\beta u_{g}\left(g^{*^{\prime}}\right) \tau^{R^{\prime}}
$$

where

$$
\tau^{R}=\frac{g^{*}+b^{*}-b^{*^{\prime}} / R\left(b^{*^{\prime}}\right)-f}{b^{*}}
$$

and * denotes allocations in the social planner's problem. Then it is easy to verify that the social planner's optimality conditions (5)-(7). In the 1996 baseline calibration, steady state $\tau^{R}=0.0468$ and $\gamma=0.0453$.

Now we need the minimum DebtLimit that corresponds to $\gamma$ : complementary slackness condition implies

$$
b^{\prime}<\text { DebtLimit } \Rightarrow \gamma=0
$$

The equations give $\gamma>0$, so we need $b^{\prime}=$ DebtLimit for the complementary slackness condition to hold. In other words, set DebtLimit equal to $b^{*}$. 


\section{G Special Case: $\epsilon=0$}

This section considers the theoretical implications of $\epsilon=0$ to complement the analysis in the baseline model where we assume $\epsilon>0$.

With $\epsilon>0$, central-local transfers are progressive, i.e. regions with lower net worth receive more transfers, and the transfer wedge is positive. When $\epsilon=0$, the transfers are evenly distributed and independent of local fiscal conditions, and the transfer wedge is zero, which means there is no moral hazard associated with local government borrowing. However, the Markov and the Ramsey allocations are still different from the Pareto optimal allocation when local government debt interest rate is $R(B)$, i.e. depends on aggregate local debt. This is because with many infinitesimally small local governments, each of them does not internalize the interest rate externality of a unit of additional debt, whereas the central government internalizes this externality. As a result, the social planner optimally chooses a lower aggregate local government debt than the level in a decentralized equilibrium, and hence the Markov and the Ramsey allocations are not Pareto optimal. Without this externality, however, both the Markov and the Ramsey equilibrium allocations are Pareto optimal. Formally,

Proposition 6. When the central government does not internalize the pecuniary cost of local government borrowing $\left(R_{b}(b)=0\right)$, or when local government also internalizes the pecuniary cost $(R(b)$ instead of $R(B))$, then under a transfer policy that is independent of local conditions (lump-sum), i.e. $\epsilon=0$, both the Markov equilibrium and the Ramsey equilibrium are Pareto optimal.

Let $\lambda=0$, it can be easily verified that (12), (13) and (14) are redundant once the allocation satisfies the first order conditions of the Pareto optimal problem (5), (6) and (7). In the benchmark case where local interest depends on aggregate local debt, when $R_{b}(b)=0$, the Euler equation in the Markov (and Ramsey) equilibrium is the same as (6). Hence the Pareto optimal allocation is also the Markov equilibrium allocation. The equivalence between the Pareto optimal allocation and the Ramsey allocation can be similarly proved. 


\section{H Contemporaneous Interdependence of Local and Central Debt}

This section illustrates the contemporaneous (within-period) interdependence between local and central debt. This relationship complements the discussion of dynamic interdependence in Section 4.3.

This contemporaneous interdependence captures how local government forms expectation about future transfer rate $\tau^{\prime}$ based on future central debt position $d^{\prime}$ and then alters its own debt choices $b^{\prime}$ accordingly. More specifically, at time $t$ when a local government observes that the central government chooses high debt for time $t+1$, it expects a low transfer rate at time $t+1$, which raises the cost of carrying high debt and lowers local consumption at time $t+1$, thus giving the local government incentive to choose a low debt level. ${ }^{39}$

Figure 14: Comparative static of contemporaneous relation between local and central debt

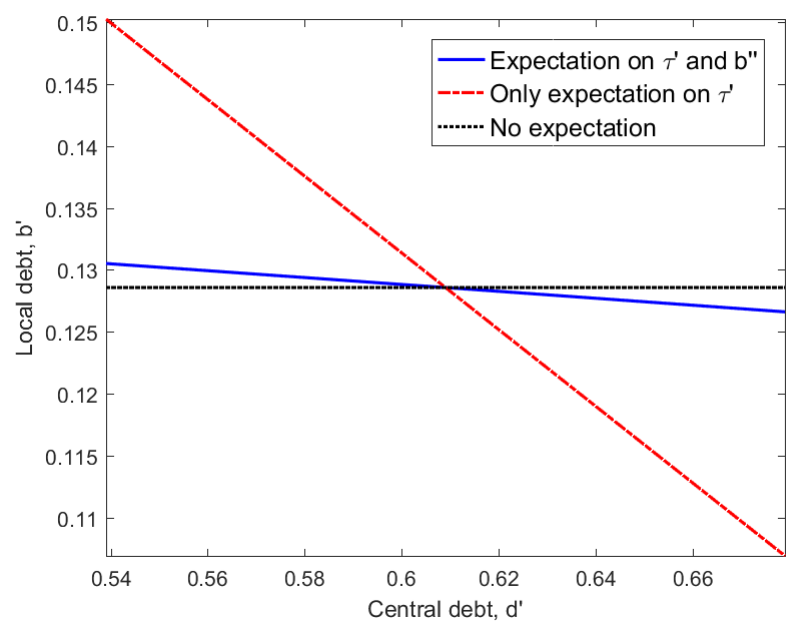

Note: All parameters are at calibrated 1996 values. Comparative statics computed from holding states at steady state levels. Solid blue line allows local government to form expectations on both transfer and future debt. Dashed red line only allows for expectation on transfer. Dotted black line shuts down both expectation channels.

We use a comparative static analysis on the local government's optimality condition (copied below) to illustrate this contemporaneous interdependence.

$$
\begin{aligned}
u_{g}\left(G\left(b_{s s}, b^{\prime}, \tau_{s s}\right)\right)= & \beta R\left(b^{\prime}\right)\left(1-\phi\left(b^{\prime}, d^{\prime}\right) M_{b}\left(b^{\prime}\right)\right) u_{g}\left(G\left(b^{\prime}, h\left(b^{\prime}, d^{\prime}\right), \phi\left(b^{\prime}, d^{\prime}\right)\right)\right) \\
\text { where } \quad & \tau^{\prime}=\phi\left(b^{\prime}, d^{\prime}\right) \text { and } b^{\prime \prime}=h\left(b^{\prime}, d^{\prime}\right) .
\end{aligned}
$$

Figure 14 plots the results from the comparative static analysis. We hold current-period debt $b$ and transfer rate $\tau$ at steady state levels, and look at the relationship between today's choice of central $\left(d^{\prime}\right)$ and local government debt $\left(b^{\prime}\right)$. The downward-sloping solid blue line indicates that same-period central and local debts have a negative relationship, which is consistent with the mechanism outlined before.

A change in $d^{\prime}$ affects $b^{\prime}$ through expectations of both future transfer rate $\left(\tau^{\prime}=\phi\left(b^{\prime}, d^{\prime}\right)\right)$ and future local government debt $\left(b^{\prime \prime}=h\left(b^{\prime}, d^{\prime}\right)\right)$. We next isolate the effect through expected future transfer by setting the

39 We define the Markov equilibrium as the central government choosing both local and central debt, subject to local government's implementability constraint. Alternatively and equivalently, it can be formulated as the central government choosing central debt and transfer rate, given which local government makes local debt choice. This latter formulation is more consistent with the discussion here. 
expected local debt to the steady state value. This gives us the dashed red line, which is again downward sloping, indicating a higher $d^{\prime}$ through the expectation on $\tau^{\prime}$ leads to lower $b^{\prime}{ }^{40}$ Finally, shutting down both expectation channels gives us the flat dotted black line.

40 The steeper slope of the dashed red line shows the channel we shut down - the expectation of future local government debt - drives a positive relationship between $b^{\prime}$ and $d^{\prime}$. Intuitively, a higher central government debt $d^{\prime}$ leads to the expectation of higher future local debt $b^{\prime \prime}=h\left(b^{\prime}, d^{\prime}\right)$, which in turn raises future local spending $g^{\prime}$. To smooth spending, local government increases $b^{\prime}$. 


\section{A Two-Period Model}

We use a two-period model to illustrate the overborrowing mechanism. In particular, we show that (1) given positive local fiscal gaps, the central government has incentive to make transfers, and distortionary transfers encourage local governments to inefficiently (compared to Pareto optimal) overborrow; (2) equilibrium local government debt will be smaller if there is an increase in local governments' own revenue or a decrease in their spending responsibilities. Further, we show that despite overborrowing incentive and distortionary transfers, the central government in the two-period model achieves efficient within-period allocation of resources between local and central governments.

We highlight two main differences from the baseline model in Section 3. First, infinite horizon in the baseline model means the central government's consideration of future policies affects its transfers choice, and as a result it cannot achieve perfect resource sharing between local and central governments. We quantitatively evaluate the importance of dynamics in Section 4.6.

Second, the full model relaxes the assumption of balanced central government budget by allowing for central government debt. This is important because in the data central government debt takes up the majority of general government debt, and in most countries central government debt is also more volatile. ${ }^{41}$ In our baseline model, when both levels of fiscal authorities can accumulate debt, high local debt gives the central government more incentive to make transfers ex post to ensure the local government has enough resources to meet spending needs, and higher transfer in turn increases central government's need to borrow.

\section{I.1 Model environment}

There is one central government and a measure one of small and identical local governments in this economy. There are two periods: period 0 and period 1. Total government tax revenue is exogenous: zero in period 0 and $e$ in period 1. Among the total tax revenue $e$ in period 1, $f$ is local government tax revenue and $e-f$ is central government tax revenue. Local governments make spendings in both periods, and the central government only has spending in period 1.

Preferences. The representative local government's utility function is

$$
u\left(g_{0}\right)+u\left(g_{1}\right)
$$

where $g_{t}$ denotes local government consumption in period $t$. Note that the local government is benevolent and cares about central spendings as well, but it does not have control over central spendings so they drop out of the local government's utility function.

The central government only has spending in period 1, but it cares about spending at both the central and local government levels. Its utility function is ${ }^{42}$

$$
(1-\theta)\left[u\left(g_{0}\right)+u\left(g_{1}\right)\right]+\theta v\left(c_{1}\right)
$$

where $c_{1}$ denotes central government consumption. The utility function captures that the central government is benevolent and the residents value both central and local government spending. The utility weight $\theta \in(0,1)$ can be thought as the relative share of public services that the central government is responsible for (for

\footnotetext{
41 For example, Spain's central government debt is four times larger and ten times more volatile than its local government debt over 1995-2007. Table 12 reports the statistics for OECD countries.

42 Utility from period-0 local spending $g_{0}$ is weighted by $1-\theta$, same as the weight on $g_{1}$ in period 1 . Alternatively, utility from $g_{0}$ can have a weight of 1 . In this latter case, the absolute values of allocations will be different, but the key results still go through.
} 
example, national defense).

Government debt and transfers. For simplicity, we assume only local governments can issue debt: the representative local government borrows $b$ in period 0 and repays in period 1 . Gross interest rates are fixed at $R=1$. In period 1, the central government subsidizes local government borrowing via transfers $T=\tau b$ where $\tau$ is the transfer rate. Here we assume total transfers depend on individual local government debt. The mechanism we discuss here works as long as not all transfers are lump sum.

Timing. In period 0 , the representative local government borrows $b$ and spends $g_{0}=b$. In period 1 , the central government decides transfer rate $\tau$ and spends endowment net of transfers $c_{1}=e-f-\tau b$. The local government receives endowment $f$ and transfers $\tau b$, repays $b$, and spends $g_{1}=f+\tau b-b$.

\section{I.2 Pareto optimal allocation}

Before we move on to the equilibrium, let us derive the Pareto optimal allocation by solving the social planner's problem:

$$
\max _{g_{0}, g_{1}, c_{1}, b}(1-\theta)\left[u\left(g_{0}\right)+u\left(g_{1}\right)\right]+\theta v\left(c_{1}\right)
$$

subject to the feasibility constraints,

$$
\begin{aligned}
g_{0} & =b \\
g_{1}+c_{1} & =e-b
\end{aligned}
$$

Assumption 1. $u(\cdot)$ and $v(\cdot)$ are $\log$ utilities.

Under Assumption 1, it can be easily derived that in the Pareto optimal allocation, the local government debt, local government consumption, and central government consumption are

$$
\left\{b^{p}, g_{0}^{p}, g_{1}^{p}, c_{1}^{p}\right\}=\left\{\frac{(1-\theta) e}{2-\theta}, \frac{(1-\theta) e}{2-\theta}, \frac{(1-\theta) e}{2-\theta}, \frac{\theta e}{2-\theta}\right\}
$$

\section{I.3 Equilibrium}

We solve for the equilibrium allocation of the two-period model backward. In period 1, the representative local government simply spends $g_{1}=f+\tau b-b$, taken as given the transfer rate $\tau$ chosen by the central government.

Central government's problem in period 1. The central government solves

$$
\max _{c_{1}, g_{1}, \tau} \theta v\left(c_{1}\right)+(1-\theta) u\left(g_{1}\right)
$$

subject to budget constraints,

$$
\begin{aligned}
& c_{1}=e-f-\tau b \\
& g_{1}=f+\tau b-b
\end{aligned}
$$

The optimal response function is

$$
\tau^{*}=\Gamma(b ; \theta, f)=\frac{(1-\theta) e-f}{b}+\theta
$$

Local government's problem in period 0. The local government in period 0 takes anticipated central govern- 
ment's transfer rate $\tau$ as given. It chooses borrowing $b$ to be repaid in period- 1 to maximize utilities from spending in both periods:

$$
\max _{b} u\left(g_{0}\right)+u\left(g_{1}\right)
$$

subject to budget constraints in both periods

$$
\begin{aligned}
g_{0} & =b \\
g_{1}+b & =f+\tau b
\end{aligned}
$$

The optimal choice of $b$ is then characterized by the inter-temporal condition,

$$
u^{\prime}(b)=(1-\tau) u^{\prime}(f+\tau b-b)
$$

Because the distortionary transfers create a wedge in the local government's inter-temporal condition, higher (positive) transfer rate lowers the effective cost of borrowing.

Given Assumption 1, the optimal local government's choice of debt $b$ given expected period-1 transfer rate $\tau$ is

$$
b^{*}=H(\tau ; \theta, f)=\frac{f}{2(1-\tau)}
$$

Equilibrium. The equilibrium $\left(b^{*}, \tau^{*}\right)$ is characterized by the solution to Equations (49) and (50):

$$
\begin{aligned}
b^{*} & =e-\frac{f}{2(1-\theta)} \\
\tau^{*} & =1-\frac{(1-\theta) f}{2(1-\theta) e-f}
\end{aligned}
$$

Assumption 2. Local government's share of revenue falls short of its share of spending responsibility, i.e. $f / e<2(1-\theta) /(2-\theta)$.

This assumption says there is a positive local fiscal gap, and given this assumption the equilibrium central government transfer is positive: $\tau^{*}>0$. From (51), we have

Proposition 7. Given Assumptions 1-2, the equilibrium local government borrowing $b^{*}$ satisfies that (1) $b^{*}>b^{p}$; (2) $b^{*}$ decreases in local government endowment, i.e. $d b^{*} / d f<0$; and $(3) b^{*}$ increases in preference share for local spending, i.e. $d b^{*} / d \theta<0$.

The first part of the proposition demonstrates that in the equilibrium, local governments "overborrow" relative to the Pareto optimal allocation. This is because their perceived marginal borrowing cost after transfer, $1-\tau$, is smaller than the marginal borrowing cost from the social planner's point of view (which is one).

The second and third parts of the proposition demonstrates the effects of fiscal decentralization on local government's borrowing. A revenue decentralization (increase in $f$ ) reduces equilibrium local government debt because it reduces transfer rates $(\partial \tau / \partial f<0$ in Equation (49)), and lower transfer rate in turn reduces local borrowing. In contrast, a spending decentralization (increase in $1-\theta$ ) increases equilibrium local debt. This is because a greater preference towards local spending gives the central government more incentive to make transfers $(\partial \tau / \partial(1-\theta)>0$ in Equation 49), and a higher (expected) transfer rate increases local debt by lowering effective borrowing cost. 
Proposition 8. Given Assumption 1, the equilibrium central-local spending ratio in period 1 is the same as in the Pareto optimal allocation, i.e. $c_{1}^{*} / g_{1}^{*}=c_{1}^{p} / g_{1}^{p}=\theta /(1-\theta)$.

Despite the over-borrowing problem in the decentralized equilibrium, the central government still manages to achieve the Pareto optimal spending ratio in the end period (period 1). The fact that end-period debt is zero by construction is key to this result: the central government does not need to consider how period-1 transfer policy affects future borrowing. As such, transfer is used to achieve the perfect resource sharing as in the Pareto optimal allocation. This is in general not true in an infinite horizon model, where the additional consideration of future states and policies prevents the central government from using transfer to achieve perfect resource sharing. 


\section{J A Third Alternative Local Government Interest Rate Schedule}

This section considers the case where neither local nor central governments internalize any pecuniary costs of borrowing. ${ }^{43}$ The analysis here complements the analysis (a) in the benchmark, where only central government internalizes the cost and the asymmetry between central (and social planner) vs. local creates additional overborrowing; and (b) in robustness check Section 6.2, where both central and local governments internalize the cost and so the only overborrowing incentive arises from central government transfer. The goal here is to demonstrate that the key results are robustness to alternative assumptions about how local government interest rate is determined.

The quantitative results, summarized in Table 10, are similar to the benchmark results of Section 4.5. Fiscal decentralization explains $44 \%$ and $23 \%$ of general government debt changes during the 1988-1996 and 1996-2006 periods, respectively. The last column of Table 10 reports the debt levels of the social planner's allocation (Pareto optimal) in 1996 under this alternative assumption. Comparing between the Pareto optimal and Markov equilibrium shows that when the central government does not internalize interest rate externality of debt, there is still overborrowing. Furthermore, in this case the local government also over-spends: the central/local spending ratio is 1.78 in the Markov equilibrium compared with 1.95 in the Pareto optimal allocation.

Table 10: Counterfactual Experiments Under Alternative Interest Rate Assumption: central government does not internalize interest rate effects

\begin{tabular}{|c|c|c|c|c|c|c|}
\hline \multirow[t]{2}{*}{ Parameter } & \multicolumn{3}{|c|}{ Calibrated Values } & & & \\
\hline & 1988 & 1996 & 2006 & & & \\
\hline $\bar{B}$ & 0.001 & 0.034 & 0.007 & & & \\
\hline $\bar{D}$ & 0.254 & 0.5 & 0.198 & & & \\
\hline$\theta$ & 0.814 & 0.661 & 0.554 & & & \\
\hline$\epsilon$ & 0.00364 & 0.00285 & 0.0044 & & & \\
\hline \multirow{2}{*}{ Moment } & \multicolumn{3}{|c|}{ Calibrated Model } & \multicolumn{2}{|c|}{ Counterfactuals } & Social planner \\
\hline & 1988 & 1996 & 2006 & $1988-1996$ & $1996-2006$ & 1996 \\
\hline Local government debt & 0.0619 & 0.1297 & 0.1215 & 0.1343 & 0.1009 & 0.0339 \\
\hline Central government debt & 0.3394 & 0.6109 & 0.3306 & 0.4154 & 0.5736 & 0.5 \\
\hline General government debt & 0.4013 & 0.7406 & 0.4521 & $0.5497(44 \%)$ & $0.6745(\mathbf{2 3 \%})$ & 0.5339 \\
\hline
\end{tabular}

Note: General government debt is the sum of local and central government debt. Setting $R_{b}=S_{d}=0$ in all central government optimality conditions and recalibrating each year. Counterfactual uses revenue $(e$ and $f)$ and spending responsibility $(\theta)$ from end year and all other parameters kept at beginning year. Numbers in parentheses calculate the percent change in general government debt between two years that is explained by counterfactual.

\footnotetext{
${ }^{43}$ Mathematically, we do this by setting the terms $R_{b}$ and $S_{d}$ in all the central government's optimality conditions to zero.
} 


\section{K Additional Tables}

This section includes tables not included in the main text. Table 11 complements Table 4 of Section 4.5 to present additional moments from the counterfactual experiment.

Table 11: Baseline Counterfactual Experiments: Full Table

\begin{tabular}{lccc}
\hline \hline \multirow{2}{*}{ Moment } & \multicolumn{3}{c}{ 1988-1996 } \\
\cline { 2 - 4 } & Model 1988 & Model 1996 & Counterfactual 1996 \\
\hline Local government debt & 0.0623 & 0.1286 & 0.1254 \\
Central government debt & 0.3600 & 0.6090 & 0.4230 \\
General government debt & 0.4222 & 0.7376 & 0.5484 \\
\hline Central-local spending ratio & 3.8311 & 1.7856 & 1.6637 \\
Local government spending & 0.0605 & 0.1205 & 0.1283 \\
Central government spending & 0.2316 & 0.2151 & 0.2135 \\
\hline Vertical fiscal imbalance & 32.4488 & 50.9924 & 53.8488 \\
Central-local transfer & 0.0207 & 0.0648 & 0.0727 \\
\hline \hline & & & $1996-2006$ \\
\cline { 2 - 4 } & Model 1996 & Model 2006 & Counterfactual 2006 \\
\hline Local government debt & 0.1286 & 0.1242 & 0.1058 \\
Central government debt & 0.6090 & 0.3404 & 0.5796 \\
General government debt & 0.7376 & 0.4646 & 0.6854 \\
\hline Central-local spending ratio & 1.7856 & 1.1664 & 0.1612 \\
Local government spending & 0.1205 & 0.1731 & 0.2072 \\
Central government spending & 0.2151 & 0.2019 & 39.3036 \\
\hline Vertical fiscal imbalance & 50.9924 & 43.7552 & 0.0655 \\
Central-local transfer & 0.0648 & 0.0787 & Con
\end{tabular}

Note: General government debt is the sum of local and central government debt. Counterfactual uses revenue $(e$ and $f$ ) and spending responsibility $(\theta)$ from end year and all other parameters kept at the beginning year. 
Table 12 reports statistics of central government and local government debts in OECD countries from 1995 to 2007. Data come from the OECD Fiscal Decentralization Database.

Table 12: Cross-Country Central Government and Local Government Debts, 1995-2007

\begin{tabular}{|c|c|c|c|c|c|}
\hline \multirow[t]{2}{*}{ Country } & \multicolumn{2}{|c|}{$\frac{\text { Central Government Debt }}{\text { GDP }}$} & \multicolumn{2}{|c|}{$\frac{\text { Local Government Debt }}{\text { GDP }}$} & \multirow{2}{*}{$\begin{array}{c}\text { Local Government Debt } \\
\text { Total Government Debt } \\
\text { Mean }\end{array}$} \\
\hline & Mean & Standard Deviation & Mean & Standard Deviation & \\
\hline Australia & 0.1940 & 4.73 & 0.0851 & 4.28 & 0.30 \\
\hline Austria & 0.6558 & 4.23 & 0.0800 & 1.46 & 0.11 \\
\hline Belgium & 1.0970 & 14.82 & 0.1712 & 2.63 & 0.13 \\
\hline Canada & 0.4754 & 12.08 & 0.4894 & 4.06 & 0.51 \\
\hline Czech Republic & 0.2246 & 6.25 & 0.0351 & 6.36 & 0.14 \\
\hline Denmark & 0.5224 & 15.25 & 0.0996 & 14.66 & 0.16 \\
\hline Estonia & 0.0631 & 1.91 & 0.0333 & 1.59 & 0.35 \\
\hline Finland & 0.5631 & 15.70 & 0.0772 & 15.84 & 0.12 \\
\hline France & 0.6925 & 4.43 & 0.0955 & 3.75 & 0.12 \\
\hline Germany & 0.3913 & 2.39 & 0.2377 & 2.35 & 0.38 \\
\hline Greece & 1.1525 & 9.73 & 0.0088 & 9.81 & 0.01 \\
\hline Hungary & 0.6732 & 7.90 & 0.0255 & 5.00 & 0.04 \\
\hline Iceland & 0.2804 & 5.15 & 0.0809 & 15.84 & 0.22 \\
\hline Ireland & 0.3658 & 10.30 & 0.0222 & 10.31 & 0.06 \\
\hline Israel & 0.8871 & 6.49 & 0.0373 & 8.05 & 0.04 \\
\hline Italy & 1.1503 & 8.87 & 0.0849 & 9.13 & 0.07 \\
\hline Japan & 1.1781 & 28.89 & 0.3311 & 26.86 & 0.22 \\
\hline Luxembourg & 0.1266 & 1.04 & 0.0250 & 2.67 & 0.17 \\
\hline Mexico & 0.3987 & 2.07 & 0.0575 & 0.78 & 0.13 \\
\hline Netherlands & 0.5499 & 8.57 & 0.1422 & 7.54 & 0.21 \\
\hline Norway & 0.2944 & 10.21 & 0.1106 & 10.86 & 0.27 \\
\hline Poland & 0.5096 & 1.54 & 0.0383 & 1.38 & 0.07 \\
\hline Portugal & 0.6810 & 6.03 & 0.0315 & 6.88 & 0.04 \\
\hline Slovak Republic & 0.4017 & 10.03 & 0.0438 & 9.35 & 0.10 \\
\hline Slovenia & 0.3670 & 1.22 & 0.0150 & 2.48 & 0.04 \\
\hline Spain & 0.5295 & 10.14 & 0.1217 & 0.40 & 0.19 \\
\hline Sweden & 0.6256 & 16.26 & 0.0868 & 16.44 & 0.12 \\
\hline Switzerland & 0.2813 & 1.71 & 0.2770 & 2.12 & 0.50 \\
\hline United Kingdom & 0.4491 & 2.92 & 0.0582 & 4.49 & 0.11 \\
\hline United States & 0.4632 & 5.25 & 0.1827 & 4.81 & 0.28 \\
\hline Mean & 0.5414 & 7.87 & 0.1062 & 7.07 & 0.17 \\
\hline
\end{tabular}




\section{Additional Plots}

This section contains additional plots not included in the main text.

Figure 15 complements Section 6.1 and shows the effects of revenue and spending decentralization on Markov equilibrium steady state using an alternative (higher) value of local government debt interest elasticity $\left(\psi_{b}=0.05\right)$. The effects are similar to Figure 9, demonstrating the robustness of the baseline choice $\psi_{b}=\psi_{d}=$ 0.03. All parameter values except for $f$ or $\theta$ are held at calibrated 1996 values.

Figure 15: Effects of fiscal decentralization on Markov equilibrium steady state using higher $\psi_{b}$ Effect of a change in local revenue $f$ on Markov equilibrium steady state
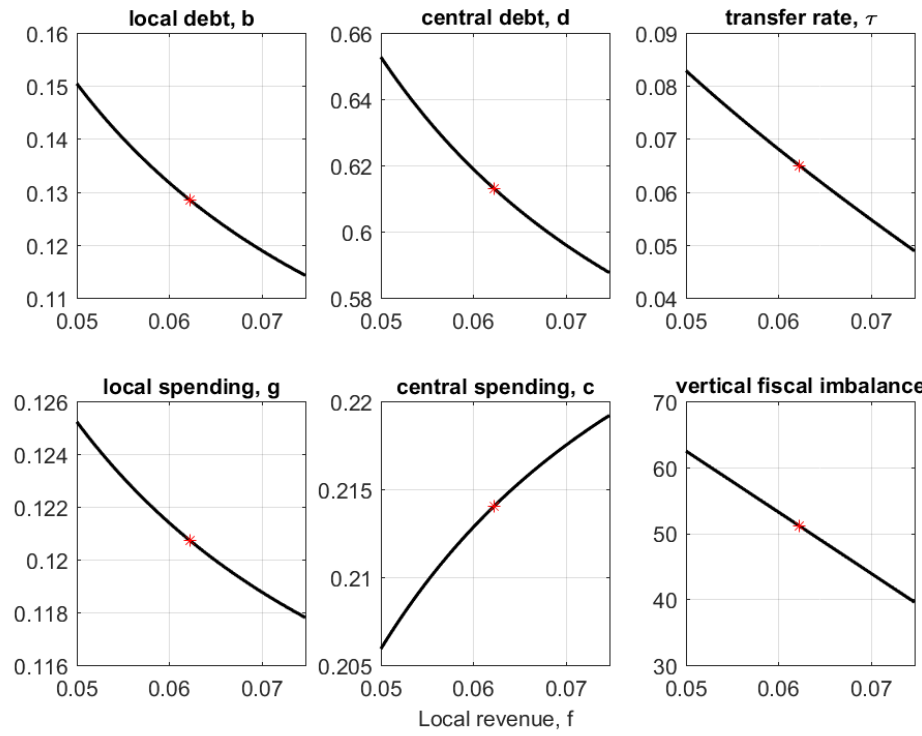

Effect of a change in spending responsibility $\theta$ on Markov equilibrium steady state
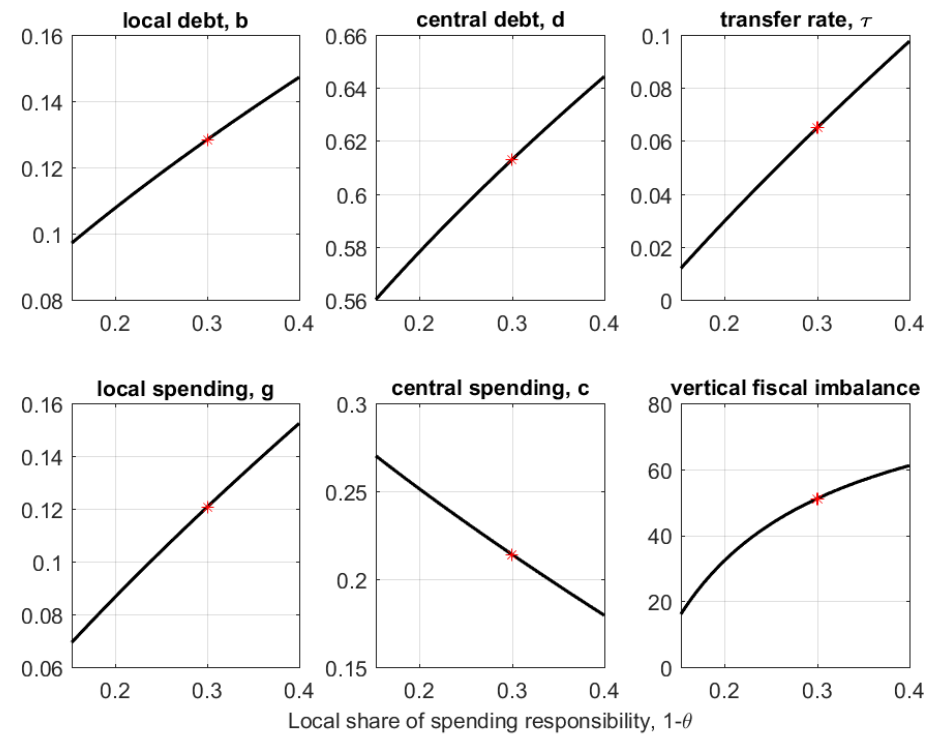
Figure 16 complements Section 6.2 and shows the effects of revenue and spending decentralization on Markov equilibrium steady state when the local government interest rate schedule depends on each region's debt (and not aggregate local debt), i.e. $R(b)$ instead of $R(B)$. The effects are similar to Figure 9, demonstrating the robustness of the baseline results. All parameter values except for $f$ or $\theta$ are held at calibrated 1996 values.

Figure 16: Effects of fiscal decentralization on Markov equilibrium steady state when local government interest rate schedule depends on each region's debt

Effect of a change in local revenue $f$ on Markov equilibrium steady state
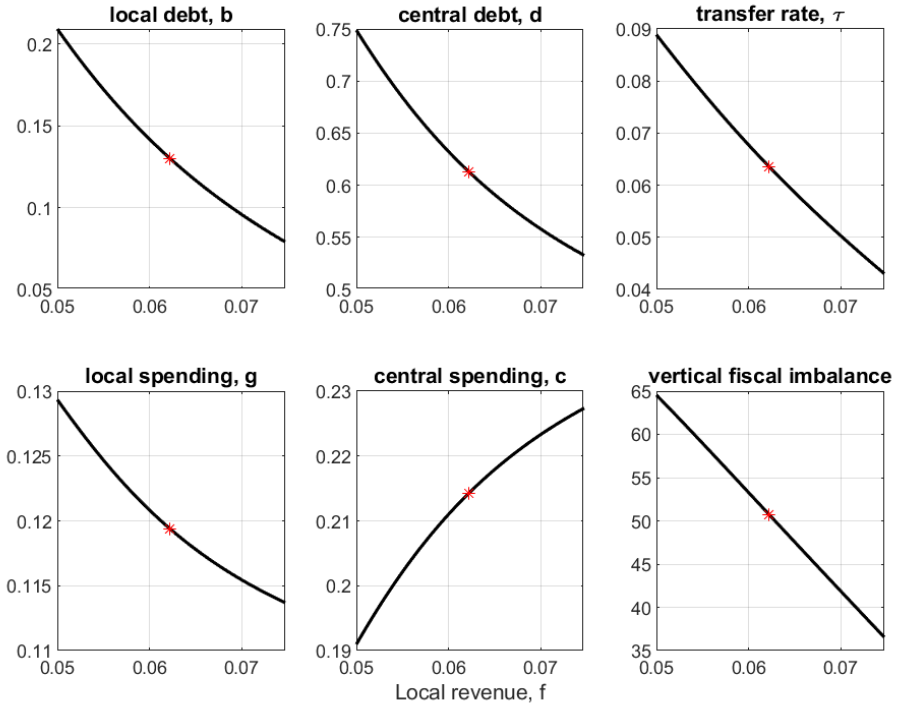

Effect of a change in spending responsibility $\theta$ on Markov equilibrium steady state
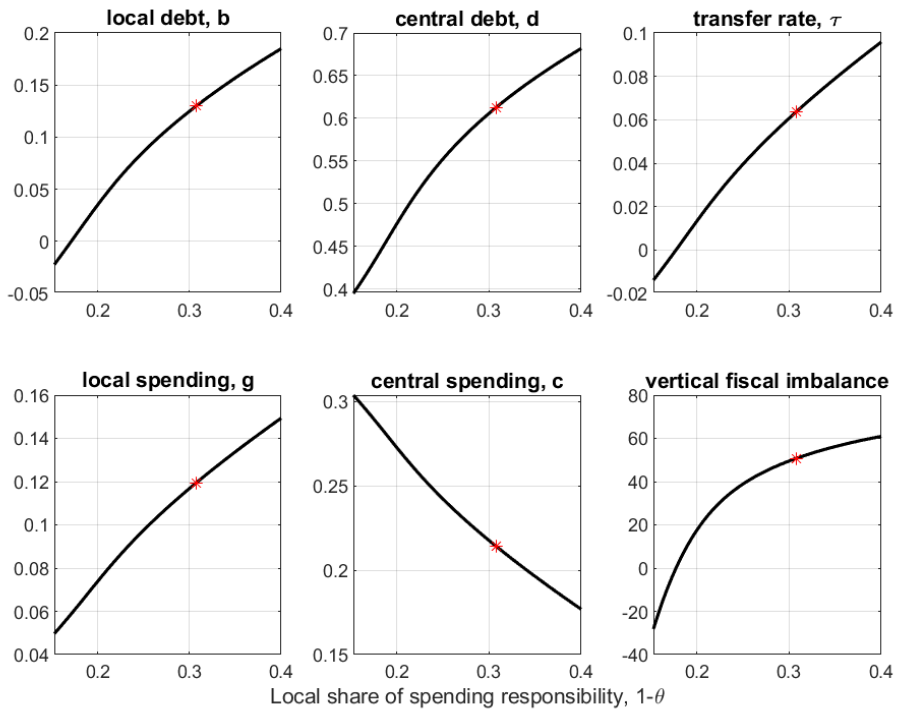


\section{Computational Appendix}

This section outlines the procedures we use to compute Markov-perfect equilibrium steady state and the policy functions used in the quantitative section (Section 4). Given the transfer function $\tau \cdot M(b)$ where $M(b)=(1-\epsilon)+\epsilon b / f$ and $M_{b}(b)=\epsilon / f$, the Markov equilibrium is characterized by the following local government's Euler equation and central government's GEEs

$$
\begin{aligned}
u_{g} & =\beta R\left(b^{\prime}\right)\left(1-\tau^{\prime} M_{b}\left(b^{\prime}\right)\right) u_{g}^{\prime} \\
-u_{g} G_{b^{\prime}}+\frac{\eta_{b^{\prime}}}{\eta_{\tau}}\left[u_{g} G_{\tau}+\frac{\theta}{1-\theta} v_{c} C_{\tau}\right] & =\beta\left[u_{g}^{\prime} G_{b}^{\prime}+\frac{\theta}{1-\theta} v_{c}^{\prime} C_{b}^{\prime}\right]-\beta \frac{\eta_{b}^{\prime}}{\eta_{\tau}^{\prime}}\left[u_{g}^{\prime} G_{\tau}^{\prime}+\frac{\theta}{1-\theta} v_{c}^{\prime} C_{\tau}^{\prime}\right] \\
-\frac{\theta}{1-\theta} v_{c} C_{d^{\prime}}+\frac{\eta_{d^{\prime}}}{\eta_{\tau}}\left[u_{g} G_{\tau}+\frac{\theta}{1-\theta} v_{c} C_{\tau}\right] & =\beta \frac{\theta}{1-\theta} v_{c}^{\prime} C_{d}^{\prime}
\end{aligned}
$$

where the auxiliary functions are defined as

$$
\begin{aligned}
G & =f+\frac{b^{\prime}}{R\left(b^{\prime}\right)}-(1-\tau) b \\
C & =e-f-\tau b+\frac{d^{\prime}}{S\left(d^{\prime}\right)}-d \\
G_{b} & =-1+\tau M_{b}\left(b^{\prime}\right) \\
G_{\tau} & =M\left(b^{\prime}\right) \\
G_{b^{\prime}} & =\frac{1}{R\left(b^{\prime}\right)}-\frac{b^{\prime} R_{b}\left(b^{\prime}\right)}{R\left(b^{\prime}\right)^{2}} \\
C_{b} & =-\tau M_{b}\left(b^{\prime}\right) \\
C_{\tau} & =-M\left(b^{\prime}\right) \\
C_{d} & =-1 \\
C_{d^{\prime}} & =\frac{1}{S\left(d^{\prime}\right)}-\frac{d^{\prime} S_{d}\left(d^{\prime}\right)}{S\left(d^{\prime}\right)^{2}} \\
\eta_{b} & =u_{g g} G_{b} \\
\eta_{\tau} & =u_{g g} G_{\tau} \\
\eta_{b^{\prime}} & =u_{g g} G_{b^{\prime}}-\beta R_{b}\left(b^{\prime}\right)\left(1-\phi^{\prime} M_{b}\left(b^{\prime}\right)\right) u_{g}^{\prime}+\beta R\left(b^{\prime}\right) \phi_{b}^{\prime} M_{b}\left(b^{\prime}\right) u_{g}^{\prime}-\beta R\left(b^{\prime}\right)\left(1-\phi^{\prime} M_{b}\left(b^{\prime}\right)\right) u_{g g}^{\prime}\left[G_{b}^{\prime}+G_{\tau}^{\prime} \phi_{b}^{\prime}+G_{b^{\prime}}^{\prime} h_{b}^{\prime}\right] \\
\eta_{d^{\prime}} & =\beta R\left(b^{\prime}\right) \phi_{d}^{\prime} M_{b}\left(b^{\prime}\right) u_{g}^{\prime}-\beta R\left(b^{\prime}\right)\left(1-\phi^{\prime} M_{b}\left(b^{\prime}\right)\right) u_{g g}^{\prime}\left[G_{\tau}^{\prime} \phi_{d}^{\prime}+G_{b^{\prime}}^{\prime} h_{d}^{\prime}\right]
\end{aligned}
$$

Our general method is to solve for the policy functions $b^{\prime}=h(b, d), d^{\prime}=p(b, d)$ and $\tau=\phi(b, d)$ given states $(b, d)$ and using policy function iteration. We focus on continuously differentiable policy functions.

\section{M.1 Computing equilibrium steady state $^{44}$}

Problems of multiplicity often arise in dynamic games settings such as with our Markov equilibrium. We select a unique differentiable equilibrium using continuity in the transfer function parameter $\epsilon{ }^{45}$

(1) First, solve an analytical solution for the case when $\epsilon=\epsilon_{0}=0$, i.e. all transfer is lump sum, which

\footnotetext{
44 We thank Anastasios Karantounias for helpful discussions on computational methods.

45 Judd (2004) provides more details on this method. We follow similar procedure as his. Here we outline the solution method for when (a) both central and local governments do not internalize pecuniary cost, i.e. $R_{b}=0$, or (b) both central and local internalize pecuniary cost, i.e. $R(b)$ instead of $R(B)$. In these two cases, equilibrium with $\epsilon=0$ is the Pareto optimal case and has analytical solution. The more general case is similar but involves finding the value of $\epsilon$ that equates the equilibrium to Pareto optimal.
} 
corresponds to the Pareto optimal case:

$$
\begin{aligned}
b_{0} & =\bar{B} \\
d_{0} & =\bar{D} \\
c_{0} & =(\theta /(1-\theta))^{1 / \sigma} /\left(1+(\theta /(1-\theta))^{1 / \sigma}\right)\left(e+(\beta-1)\left(b_{0}+d_{0}\right)\right) \\
g_{0} & =1 /\left(1+(\theta /(1-\theta))^{1 / \sigma}\right)\left(e+(\beta-1)\left(b_{0}+d_{0}\right)\right) \\
\tau_{0} & =g_{0}+b_{0}-b_{0} / R\left(b_{0}\right)-f
\end{aligned}
$$

(2) Next, iterate on $\epsilon$. For the $t^{\text {th }}$ iteration: $\epsilon_{t}=\epsilon_{t-1}+\Delta \epsilon, t=1,2, \ldots$, solve for a system of nine equations: Local government's Euler equation, central government's GEEs, their respective derivatives with respect to $b$ and $d$

$$
\begin{aligned}
& 0=\operatorname{Euler}\left(b, b^{\prime}, \tau, b^{\prime \prime}, \tau^{\prime}\right) \\
& 0=\operatorname{GEE} 1\left(b, d, b^{\prime}, d^{\prime}, \tau, b^{\prime \prime}, d^{\prime \prime}, \tau^{\prime}, h^{b}, \phi^{b}\right) \\
& 0=\operatorname{GEE2}\left(b, d, b^{\prime}, d^{\prime}, \tau, b^{\prime \prime}, d^{\prime \prime}, \tau^{\prime}, h^{d}, \phi^{d}\right) \\
& 0=d \operatorname{Euler}\left(b, b^{\prime}, \tau, b^{\prime \prime}, \tau^{\prime}\right) / d b \\
& 0=d \operatorname{Euler}\left(b, b^{\prime}, \tau, b^{\prime \prime}, \tau^{\prime}\right) / d d \\
& 0=d \operatorname{GEE} 1\left(b, d, b^{\prime}, d^{\prime}, \tau, b^{\prime \prime}, d^{\prime \prime}, \tau^{\prime}, h^{b}, \phi^{b}\right) / d b \\
& 0=d \operatorname{GEE} 1\left(b, d, b^{\prime}, d^{\prime}, \tau, b^{\prime \prime}, d^{\prime \prime}, \tau^{\prime}, h^{b}, \phi^{b}\right) / d d \\
& 0=d \operatorname{GEE} 2\left(b, d, b^{\prime}, d^{\prime}, \tau, b^{\prime \prime}, d^{\prime \prime}, \tau^{\prime}, h^{d}, \phi^{d}\right) / d b \\
& 0=d \operatorname{GEE} 2\left(b, d, b^{\prime}, d^{\prime}, \tau, b^{\prime \prime}, d^{\prime \prime}, \tau^{\prime}, h^{d}, \phi^{d}\right) / d d
\end{aligned}
$$

where superscript denote policy function derivatives, e.g. $\phi^{b}$ is the derivative of policy function $\tau$ with respect to $b$. We set step size $\Delta \epsilon=0.00001$. We compute functional derivatives as follows, for example

$$
\begin{aligned}
\frac{d \operatorname{Euler}\left(b, b^{\prime}, \tau, b^{\prime \prime}, \tau^{\prime}\right)}{d b}= & \frac{\partial \operatorname{Euler}\left(b, b^{\prime}, \tau, b^{\prime \prime}, \tau^{\prime}\right)}{\partial b}+\frac{\partial \operatorname{Euler}\left(b, b^{\prime}, \tau, b^{\prime \prime}, \tau^{\prime}\right)}{\partial b^{\prime}} h^{b}+\frac{\partial \operatorname{Euler}\left(b, b^{\prime}, \tau, b^{\prime \prime}, \tau^{\prime}\right)}{\partial \tau} \phi^{b} \\
& +\frac{\partial \operatorname{Euler}\left(b, b^{\prime}, \tau, b^{\prime \prime}, \tau^{\prime}\right)}{\partial b^{\prime \prime}}\left(h^{b} h^{b}+p^{b} h^{d}\right)+\frac{\partial \operatorname{Euler}\left(b, b^{\prime}, \tau, b^{\prime \prime}, \tau^{\prime}\right)}{\partial \tau^{\prime}}\left(h^{b} \phi^{b}+p^{b} \phi^{d}\right)
\end{aligned}
$$

and we set second derivatives to zero. In steady state, $b=b^{\prime}=b^{\prime \prime}, d=d^{\prime}=d^{\prime \prime}$ and $\tau=\tau^{\prime}$. Use solutions from the previous iteration as the initial guess to exploit continuity.

The solution consists of steady state policies and their first-order derivatives with respect to $b$ and $d$ :

$$
\left(b_{t}, d_{t}, \tau_{t}, h_{t}^{b}, p_{t}^{b}, \phi_{t}^{b}, h_{t}^{d}, p_{t}^{d}, \tau_{t}^{d}\right)
$$

(3) Iterate until $\epsilon=\bar{\epsilon}$ where $\bar{\epsilon}$ is the calibrated value in Section 4.

\section{M.2 Computing policy functions on a grid (b,d)}

We define policy functions $h(b, d), p(b, d)$ and $\phi(b, d)$ as Taylor expansions around equilibrium steady state solved before. We then use these functions to iterate (53)-(55) over a grid $(b, d)$. For future values $b^{\prime \prime}=$ $h(h(b, d), p(b, d))$ we use symbolic toolbox to compute derivatives. We increase the order of Taylor expansions until changes in Euler errors are small. 